\title{
Probabilistic Seismic Hazard Characterization and Design Parameters for the Sites of the Nuclear Power Plants of Ukraine
}

\author{
J.B. Savy, W. Foxall \\ January 1, 2000
}

U.S. Department of Energy

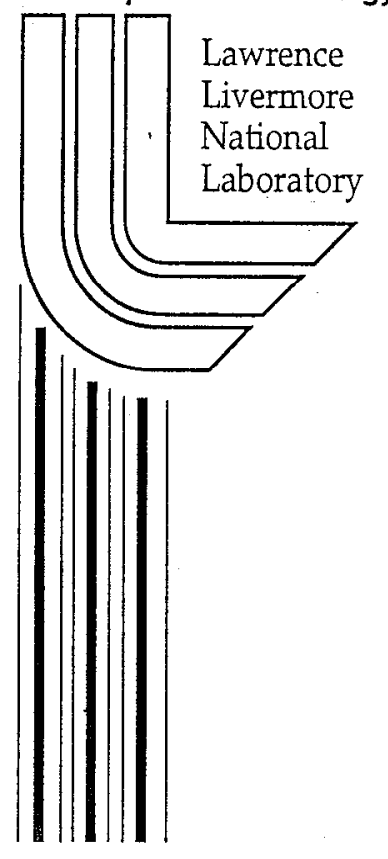




\section{DISCLAIMER}

This document was prepared as an account of work sponsored by an agency of the United States Government. Neither the United States Government nor the University of California nor any of their employees, makes any warranty, express or implied, or assumes any legal liability or responsibility for the accuracy, completeness, or usefulness of any information, apparatus, product, or process disclosed, or represents that its use would not infringe privately owned rights. Reference herein to any specific commercial product, process, or service by trade name, trademark, manufacturer, or otherwise, does not necessarily constitute or imply its endorsement, recommendation, or favoring by the United States Government or the University of California. The views and opinions of authors expressed herein do not necessarily state or reflect those of the United States Government or the Universily of California, and shall not be used for advertising or product endorsement purposes.

Work performed under the auspices of the U. S. Department of Energy by the University of California Lawrence Livermore National Laboratory under Contract W-7405-Eng-48.

This report has been reproduced

directly from the best available copy.

Available to DOE and DOE contractors from the

Office of Scientific and Technical Information

P.O. Box 62, Oak Ridge, TN 37831

Prices available from (423) 576-8401

http://apollo.osti.gov/bridge/

Available to the public from the

National Technical Information Service

U.S. Department of Commerce

5285 Port Royal Rd.

Springfield, VA 22161

http://www.ntis.gov/

OR

Lawrence Livermore National Laboratory

Technical Information Department's Digital Library

http://www.llnl.gov/tid/Library.html 


\section{Probabilistic Seismic Hazard Characterization and Design Parameters for the Sites of the Nuclear Power Plants of Ukraine}

Manuscript date: January 21, 2000

Prepared by

J. B. Savy

W. Foxall

Lawrence Livermore National Laboratory

7000 East Avenue

Livermore, CA 94550

Prepared for

Argonne National Laboratory 


\begin{abstract}
The U.S. Department of Energy (US DOE), under the auspices of the International Nuclear Safety Program (INSP) is supporting in-depth safety assessments (ISA) of nuclear power plants in Eastern Europe and the former Soviet Union for the purpose of evaluating the safety and upgrades necessary to the stock of nuclear power plants in Ukraine.

For this purpose the Hazards Mitigation Center at Lawrence Livermore National Laboratory (LLNL) has been asked to assess the seismic hazard and design parameters at the sites of the nuclear power plants in Ukraine. The probabilistic seismic hazard (PSH) estimates were updated using the latest available data and knowledge from LLNL, the U.S. Geological Survey, and other relevant recent studies from several consulting companies. Special attention was given to account for the local seismicity, the deep focused earthquakes of the Vrancea zone, in Romania, the region around Crimea and for the system of potentially active faults associated with the Pripyat Dniepro Donnetts rift. Aleatory (random) uncertainty was estimated from the available data and the epistemic (knowledge) uncertainty was estimated by considering the existing models in the literature and the interpretations of a small group of experts elicited during a workshop conducted in Kiev, Ukraine, on February 2-4, 1999.
\end{abstract}

A draft report, dated April 30, 1999, was produced and peer-reviewed by DOE and an outside expert on PSHA and Eastern Europe seismicity. This final document incorporates the updates generated by the review. 


\section{TABLE OF CONTENTS}

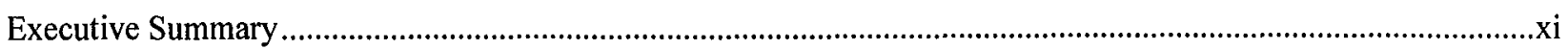

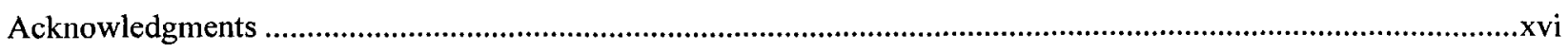

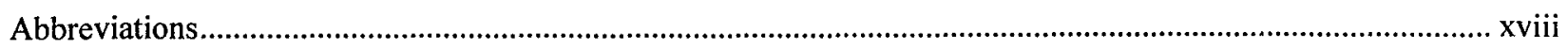

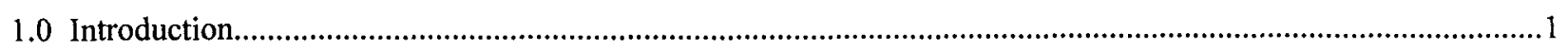

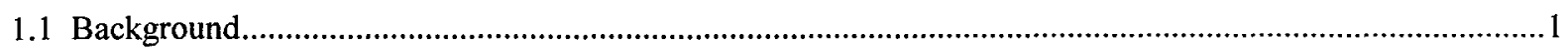

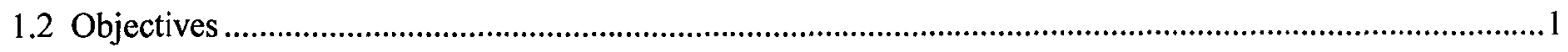

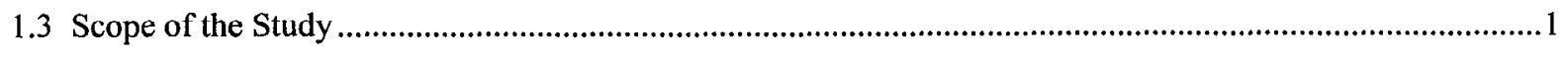

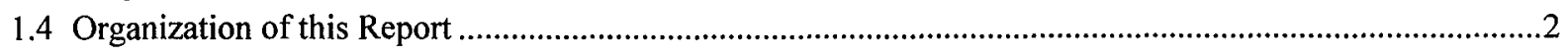

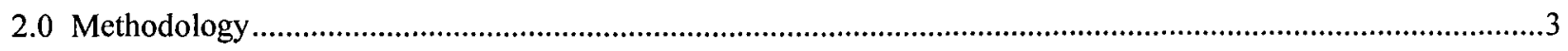

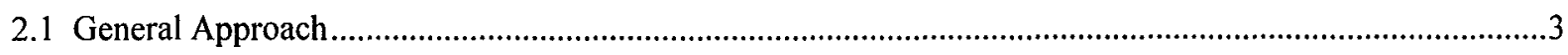

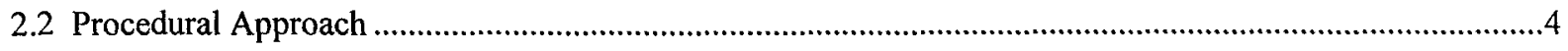

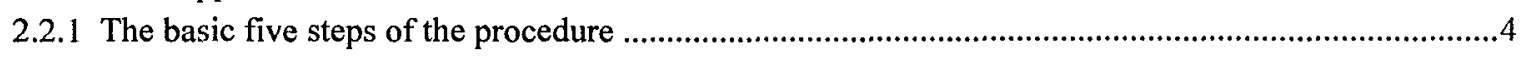

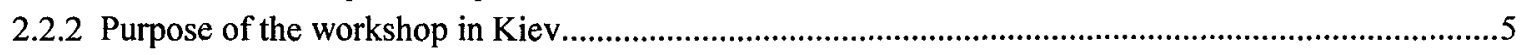

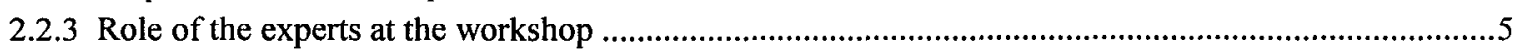

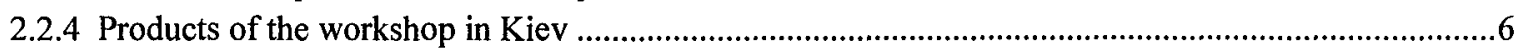

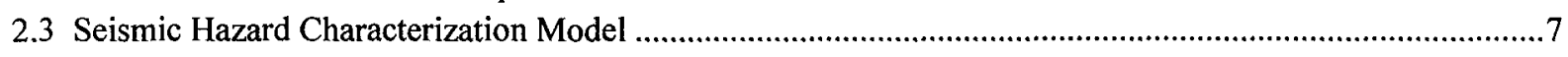

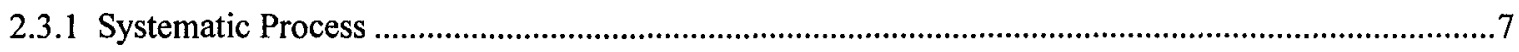

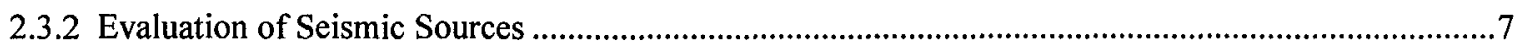

2.3.3 Evaluation of Earthquake Recurrence and Maximum Magnitude ........................................................ 8

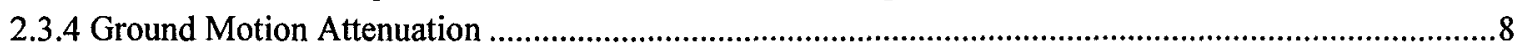

2.3.5 Mathematical Model to Calculate Seismic Hazard.........................................................................

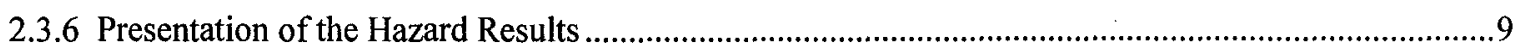

3.0 Assessment of the Seismic Hazard at the sites of the Ukraine nuclear power Plants ......................................11

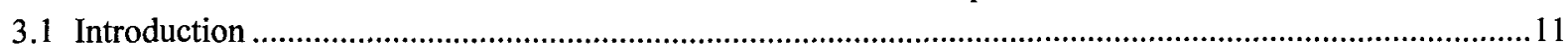

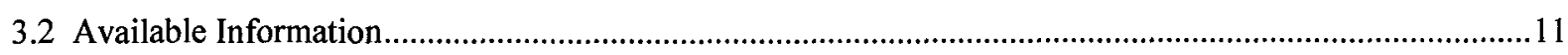

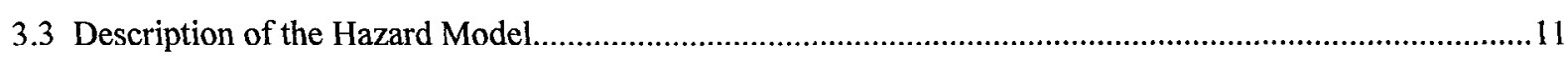

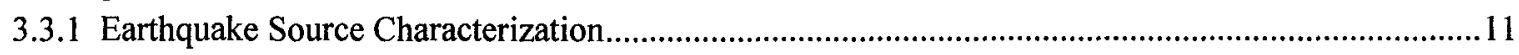

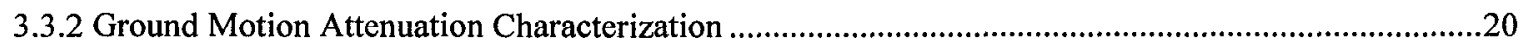

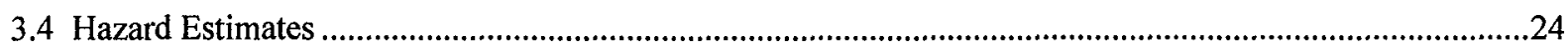

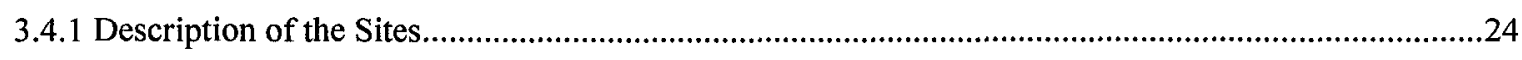

3.4.2 Total Hazard at the Sites of the Ukraine Nuclear Power Plants: Nominal Case .................................2.

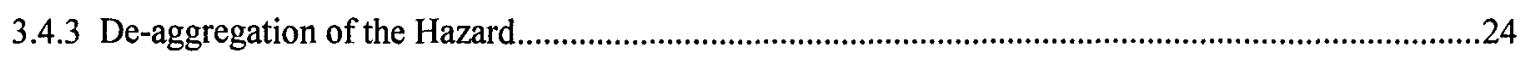

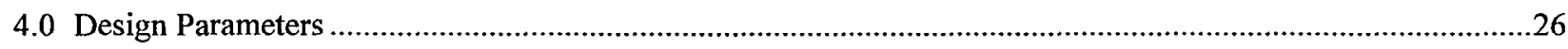

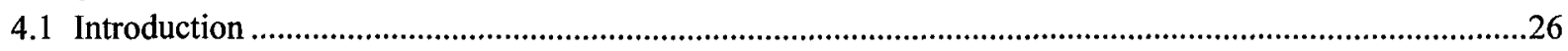

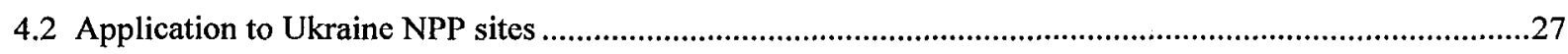

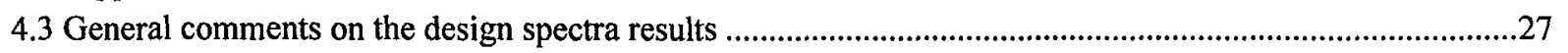

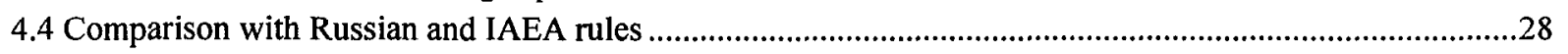

4.4.1 Russian rules for design of nuclear power plants at the time of design of the Ukraine NPPs ....................28

4.4.2 IAEA rules for establishing seismic design parameters......................................................................29

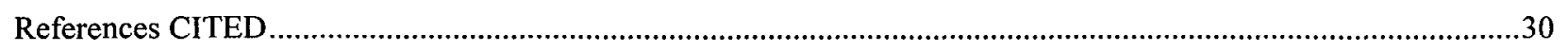




\section{LIST OF TABLES}

Table 3.3.1.1: Preliminary characterization of the source zones ........................................................................34

Table 3.3.1.3.1: Seismicity rates modeling of the seismic source zones used in the Ukraine PSHA study..........35

Table 3.3.2.1: Weights Assigned to Each of the Seven Attenuation Models Selected for Ukraine.......................36

Table 3.3.2.2: Equations of the median estimates for the Seven Attenuation Models selected for Ukraine, for

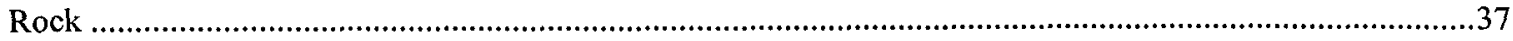

Table 3.3.2.3: Characterization of the Aleatory Uncertainty in the Ground Motion Predictions .........................38

Table 3.3.2.4: Stratigraphy and material properties of the Chernobyl site (from ISMES, 1997) .........................38

Table 3.4.2.1 Summary of the Review Level earthquake PGA, D-bar and M-bar for the five sites in Ukraine and

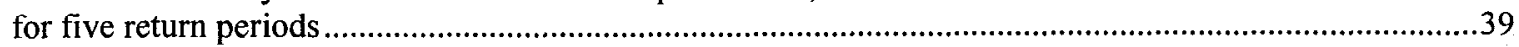




\section{LIST OF FIGURES}

Figure 2.3.1: Basic Steps of the Methodology of assessing Vibratory Ground Motion Probabilistic Hazard......40

Figure 3.3.1.1: Schematic Tectonic Map of the Ukraine Region.......................................................................... 41

Figure 3.3.1.2: Seismic Source Zones and NGDC/NEIS Commonwealth of Independent States Catalog

Scismicity , 150 BC-1989. The Nuclear Power Plant Sites Are Shown in Red.............................................42

Figure 3.3.1.3: ISC Instrumental Earthquake Locations, 1964-March, 1993..................................................43

Figure 3.3.1.4: Tectonic Map of the Carpathian System. ...........................................................................44

Figure 3.3.1.3.1: Observed cumulative annual number of earthquakes in Zone 1, the Carpathian seismic zone.

Estimate of the range of rates of events greater than magnitude 3.5 and $6.0, f(3.5)$ and $f(6.0)$ respectively.

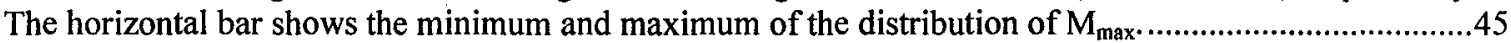

Figure 3.3.1.3.2: Observed cumulative annual number of earthquakes in Zone 2a, Western East European

Craton. Estimate of the range of rates of events greater than magnitude 3.5 and $4.5, f(3.5)$ and $f(4.5)$

respectively. The horizontal bar shows the minimum and maximum of the distribution of $\mathrm{M}_{\max } \ldots \ldots \ldots \ldots \ldots . . . . . .46$

Figure 3.3.1.3.3: Observed cumulative annual number of earthquakes in Zone 2b, the East Carpathian Extension seismic zone. Estimate of the range of rates of events greater than magnitude 3.5 and $4.5, f(3.5)$ and $f(4.5)$

respectively. The horizontal bar shows the minimum and maximum of the distribution of $\mathrm{M}_{\text {max }}$.................47

Figure 3.3.1.3.4: Observed cumulative annual number of earthquakes in Zone 3, the Zakarpatye seismic zone. Estimate of the range of rates of events greater than magnitude 3.5 and 5.0, $f(3.5)$ and $f(5.0)$ respectively.

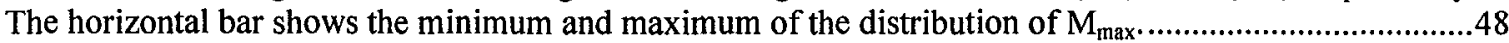

Figure 3.3.1.3.5: Observed cumulative annual number of earthquakes in Zone 13, the Vrancea (Shallow Events) seismic zone. Estimate of the range of rates of events greater than magnitude 3.5 and $5.0, f(3.5)$ and $f(5.0)$ respectively. The horizontal bar shows the minimum and maximum of the distribution of $\mathrm{M}_{\max } \ldots \ldots \ldots \ldots \ldots . . . . .49$

Figure 3.3.1.3.6: Estimates of the seismicity rates from the literature for Zone 4, the Vrancea (Deep Events) seismic zone. $F(5.0)$ and $f(6.5)$ are the estimates of the ranges of annual rates used in this analysis. The horizontal bar shows the range of $\mathrm{M}_{\mathrm{m}}$

Figure 3.3.1.3.7: Observed cumulative annual number of earthquakes in Zone 5, the Dobrogea seismic zone. Estimate of the range of rates of events greater than magnitude 3.5 and $6.0, f(3.5)$ and $f(6.0)$ respectively. The horizontal bar shows the minimum and maximum of the distribution of $\mathrm{M}_{\max } \ldots . . . . . . . . . . . . . . . . . . . . . . . . . . . . .51$

Figure 3.3.1.3.8: Observed cumulative annual number of earthquakes in Zone 6, the West Crimea seismic zone. Estimate of the range of rates of events greater than magnitude 3.5 and 5.5, $f(3.5)$ and $f(5.5)$ respectively.

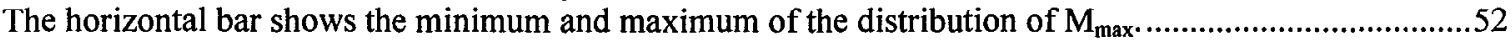

Figure 3.3.1.3.9: Observed cumulative annual number of earthquakes in Zone 7, the Crimea Kerch Caucasus seismic zone. Estimate of the range of rates of events greater than magnitude 3.5 and $5.5, f(3.5)$ and $f(5.5)$ respectively. The horizontal bar shows the minimum and maximum of the distribution of $\mathrm{M}_{\max } \ldots \ldots \ldots \ldots \ldots . . . .53$

Figure 3.3.1.3.10: Observed cumulative annual number of earthquakes in Zone 8, the Deformed Black Sea Plate seismic zone. Estimate of the range of rates of events greater than magnitude 3.5 and $5.5, f(3.5)$ and $f(5.5)$ respectively. The horizontal bar shows the minimum and maximum of the distribution of $\mathrm{M}_{\max } \ldots \ldots \ldots \ldots \ldots . . . . .54$

Figure 3.3.1.3.11: Observed cumulative annual number of earthquakes in Zone 9, the Yalta seismic zone. Estimate of the range of rates of events greater than magnitude 3.5 and $6.5, f(3.5)$ and $f(6.5)$ respectively. The horizontal bar shows the minimum and maximum of the distribution of $\mathrm{M}_{\max }$

Figure 3.3.1.3.12: Observed cumulative annual number of earthquakes in Zone 14, the Pripyat Dniepro Donnets Rift, rare events, seismic zone. Estimate of the range of rates of events greater than magnitude 3.5 and 7.5 , $f(3.5)$ and $f(7.5)$ respectively. The horizontal bar shows the minimum and maximum of the distribution of

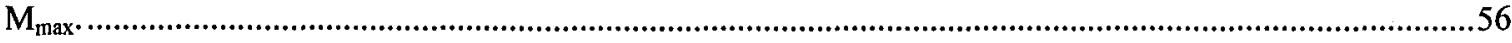

Figure 3.3.1.3.13: Observed cumulative annual number of earthquakes in Zone1 1, the East European Craton seismic zone. Estimate of the range of rates of events greater than magnitude 3.5 and $6.5, f(4.5)$ and $f(4.5)$ respectively. The horizontal bar shows the minimum and maximum of the distribution of $\mathrm{M}_{\max }$

Figure 3.3.1.3.14: Observed cumulative annual number of earthquakes in Zone 12, the Background Black Sea seismic zone. Estimate of the range of rates of events greater than magnitude 3.5 and $4.5, f(3.5)$ and $f(4.5)$ respectively. The horizontal bar shows the minimum and maximum of the distribution of $\mathrm{M}_{\max } \cdots \ldots \ldots \ldots \ldots . . . . .58$ 
Figure 3.3.2.1: Plot of the Ground Motion Attenuation Models selected for the Stable Region, for Rock Conditions and M4

Figure 3.3.2.2: Plot of the Ground Motion Attenuation Models selected for the Stable Region, for Rock Conditions and M5.

Figure 3.3.2.3: Plot of the Ground Motion Attenuation Models selected for the Stable Region, for Rock Conditions and M6

Figure 3.3.2.4: Plot of the Ground Motion Attenuation Models selected for the Stable Region, for Rock Conditions and $\mathrm{M} 7$

Figure 3.3.2.5: Plot of the Ground Motion Attenuation Models selected for the Vrancea Deep Events, for Rock Conditions and $\mathrm{M} 4$

Figure 3.3.2.6: Plot of the Ground Motion Attenuation Models selected for the Vrancea Deep Events, for Rock Conditions and M5.

Figure 3.3.2.7: Plot of the Ground Motion Attenuation Models selected for the Vrancea Deep Events, for Rock Conditions and M6.

Figure 3.3.2.8: Plot of the Ground Motion Attenuation Models selected for the Vrancea Deep Events, for Rock Conditions and M7.

Figure 3.3.2.9: Plot of the Ground Motion Attenuation Models selected for the Vrancea Shallow Events, for Rock Conditions and M4

Figure 3.3.2.10: Plot of the Ground Motion Attenuation Models selected for the Vrancea Shallow Events, for Rock Conditions and M5.

Figure 3.3.2.11: Plot of the Ground Motion Attenuation Models selected for the Vrancea Shallow Events, for Rock Conditions and M6.

Figure 3.3.2.12: Plot of the Ground Motion Attenuation Models selected for the Vrancea Shallow Events, for Rock Conditions and M7.

Figure 3.4.1: General Geology of Ukraine showing the location of the five nuclear plant sites whose coordinates are given below:

Figure 3.4.2.1 PSHA Results for a rock site at CHERNOBYL, at foundation level, in terms of the $15^{\text {th }}, 50^{\text {th }}$, $85^{\text {th }}$ and arithmetic mean of the annual probability of exceedance of Peak Ground Acceleration. ...............72

Figure 3.4.2.2 PSHA Results for a rock site at KHMELNYSTSKYY, at foundation level, in terms of the $15^{\text {th }}$, $50^{\text {th }}, 85^{\text {th }}$ and arithmetic mean of the annual probability of exceedance of Peak Ground Acceleration. ........73

Figure 3.4.2.3 PSHA Results for a rock site at RIVNE, at foundation level, in terms of the 15th, 50th, 85thand arithmetic mean of the annual probability of exceedance of Peak Ground Acceleration.

Figure 3.4.2.4 PSHA Results for a rock site at SOUTH-UKRAINE, at foundation level, in terms of the 15th, 50th, 85thand arithmetic mean of the annual probability of exceedance of Peak Ground Acceleration. ......75

Figure 3.4.2.5 PSHA Results for a rock site at ZAPORIZHZYA, at foundation level, in terms of the 15th, 50th, 85 thand arithmetic mean of the annual probability of exceedance of Peak Ground Acceleration. ..............76

Figure 3.4.2.6: Summary of the PSHA results for the Ukraine sites, for rock conditions at the foundation level in terms of the arithmetic mean annual probability of exceedance of the PGA..........................................77

Figure 3.4.2.7: Summary of the Review Level PGA (cm/s2) for five sites in Ukraine and for 100-yr, 500-yr, 1000-yr, 10,000-yr and 100,000-yr Return Periods.

Figure 3.4.2.8: Summary of the Review Level Magnitude values (M-bar) for five sites in Ukraine and for 100yr, 500-yr, 1000-yr, 10,000-yr and 100,000-yr Return Periods.

Figure 3.4.2.9: Summary of the Review Level D-bar values for five sites in Ukraine and for 100-yr, 500-yr, 1000 -yr, 10,000-yr and 100,000-yr Return Periods.

Figure 3.4.3.1: Distance-Magnitude bins contributions to the mean 100-yr return period total hazard at Chernobyl, for rock conditions.

Figure 3.4.3.2: Distance-Magnitude bins contributions to the mean 1000-yr return period total hazard at Chernobyl, for rock conditions

Figure 3.4.3.3: Distance-Magnitude bins contributions to the mean 10,000-yr return period total hazard at Chernobyl, for rock conditions.

Figure 3.4.3.4: Distance-Magnitude bins contributions to the mean 100-yr return period total hazard at Khmelnytskyy, for rock conditions. 
Figure 3.4.3.5: Distance-Magnitude bins contributions to the mean 1000-yr return period total hazard at Khmelnytskyy, for rock conditions.

Figure 3.4.3.6: Distance-Magnitude bins contributions to the mean 10,000-yr return period total hazard at Khmelnytskyy, for rock conditions.

Figure 3.4.3.7: Distance-Magnitude bins contributions to the mean 100-yr return period total hazard at Rivne, for rock conditions.

Figure 3.4.3.8: Distance-Magnitude bins contributions to the mean 1000-yr return period total hazard at Rivne, for rock conditions

Figure 3.4.3.9: Distance-Magnitude bins contributions to the mean 10,000-yr return period total hazard at Rivne, for rock conditions.

Figure 3.4.3.10: Distance-Magnitude bins contributions to the mean 100-yr return period total hazard at SouthUkraine, for rock conditions.

Figure 3.4.3.11: Distance-Magnitude bins contributions to the mean 1000-yr return period total hazard at South-Ukraine, for rock conditions.

Figure 3.4.3.12: Distance-Magnitude bins contributions to the mean 10,000-yr return period total hazard at South-Ukraine, for rock conditions.

Figure 3.4.3.13: Distance-Magnitude bins contributions to the mean 100-yr return period total hazard at Zaporizhzya, for rock conditions.

Figure 3.4.3.14: Distance-Magnitude bins contributions to the mean 1000-yr return period total hazard at Zaporizhzya, for rock conditions.

Figure 3.4.3.15: Distance-Magnitude bins contributions to the mean 10,000-yr return period total hazard at Zaporizhzya, for rock conditions.

Figure 3.4.3.16: Magnitude bins contributions to the total mean hazard at Chernobyl, for rock site conditions for 100-yr, 500-yr, 1000-yr, 10,000-yr and 100,000-yr return periods.

Figure 3.4.3.17: Magnitude bins contributions to the total mean hazard at Khmelnytskyy, for rock site conditions for 100-yr, 500-yr, 1000-yr, 10,000-yr and 100,000-yr return periods.

Figure 3.4.3.18: Magnitude bins contributions to the total mean hazard at Rivne, for rock site conditions for 100-yr, 500-yr, 1000-yr, 10,000-yr and 100,000-yr return periods.

Figure 3.4.3.19: Magnitude bins contributions to the total mean hazard at South-Ukraine, for rock site conditions for 100-yr, 500-yr, 1000-yr, 10,000-yr and 100,000-yr return periods.

Figure 3.4.3.20: Magnitude bins contributions to the total mean hazard at Zaporizhzya, for rock site conditions for 100-yr, 500-yr, 1000-yr, 10,000-yr and 100,000-yr return periods.

Figure 3.4.3.21: Distance bins contributions to the total mean hazard at Chernobyl, for rock site conditions for $100-\mathrm{yr}, 500-\mathrm{yr}, 1000$-yr, 10,000-yr and 100,000-yr return periods.

Figure 3.4.3.22: Distance bins contributions to the total mean hazard at Khmelnytskyy, for rock site conditions for 100-yr, 500-yr, 1000-yr, 10,000-yr and 100,000-yr return periods.

Figure 3.4.3.23: Distance bins contributions to the total mean hazard at Rivne, for rock site conditions for 100yr, 500-yr, 1000-yr, 10,000-yr and 100,000-yr return periods.

Figure 3.4.3.24: Distance bins contributions to the total mean hazard at South-Ukraine, for rock site conditions for 100-yr, 500-yr, 1000-yr, 10,000-yr and 100,000-yr return periods.

Figure 3.4.3.25: Distance bins contributions to the total mean hazard at Zaporizhzya, for rock site conditions for 100-yr, 500-yr, 1000-yr, 10,000-yr and 100,000-yr return periods.

Figure 4.1.1: Comparison of the 5\% Damped Response Spectral Shapes for the Generic Craton Soil Conditions at the Ukraine NPP Sites.

Figure 4.2.1: 100 year Return Period , 5\% Damped Design Response Spectra for the Five Ukraine NPP Sites.107

Figure 4.2.2: 1000 year Return Period, 5\% Damped Design Response Spectra for the Five Ukraine NPP Sites.108

Figure 4.2.3: 10,000 year Return Period , 5\% Damped Design Response Spectra for the Five Ukraine NPP Sites.109

Figure 4.4.1.1: Range of Observed Peak Ground Acceleration Values versus Modified Mercalli Intensity

(MMI), from Trifunac and Brady,(1975). 
X 


\section{EXECUTIVE SUMMARY}

The Hazards Mitigation Center at Lawrence Livermore National Laboratory (LLNL) calculated the seismic hazard and design parameters at the sites of the nuclear power plants in Ukraine. The probabilistic seismic hazard (PSH) estimates were first updated using the latest available data and knowledge from LLNL, the U.S. Geological Survey, and other relevant recent studies from several consulting companies. Special attention was given to account for the local seismicity, the deep focused earthquakes of the Vrancea zone, in Romania, the region around Crimea and for the system of potentially active faults associated with the Pripyat Dniepro Donnets rift. Aleatory (random) uncertainty was estimated from the available data and the epistemic (knowledge) uncertainty was estimated by considering the existing models in the literature and the interpretations of a small group of experts elicited during a workshop conducted in Kiev, Ukraine, on February 2-4, 1999.

The design parameters were calculated following NRC regulations 1.165 and DOE standards (DOE-STD1022 to 1024). It was found that the local and regional predicted seismicity dominate the hazard for the low return periods and that the contribution shifts gradually to the dominance of the large events distant sources such as the Vrancea or Crimea zones for the large return periods. Based on the comparisons of the hazard in terms of Peak Ground Acceleration (PGA) and excluding consideration of seismic capacity of the plants and potential consequences, the site of the South Ukrainc appears to be subjected to the highest seismic threat, Khmelnytskyy comes next, then Rivne and Zaporizhzya and finally Chernobyl.

When data were insufficient to estimate the uncertainties, results obtained in performing similar studies in the eastern United States and abroad were used. The calculations were performed for the PGA at the foundation level for rock site conditions for the five sites in Ukraine: Chernobyl, Khmelnytskyy, Rivne, South Ukrainc and Zaporizhzya. Site specific data were used when available to establish the 5\% damped design response spectra. For sites without information on the specificity of their soil conditions, the $5 \%$ damped response spectrum was established according to the NUREG-0098 rules. The NRC rules give a conservative response spectral shape that is anchored to the design PGA. For Zaporizhzya and Khmelnytskyy, lack of sufficient information lead to using the NUREG-0098 Rock site spectral shape. We were able to establish that Rivne and South-Ukraine have soil condition closer to the generic soil of the NUREG-0098. Using these assumptions for the site conditions led to a re-ordering of the sites exposure when performing the ranking based on the design response spectra.

The results shown in the figures 1 and 2 , and table 1 (taken from Figures 3.4.2.6, 4.2.3 and Table 3.4.2.1 in the report) are for the mean hazard in terms of annual probability of exceedance of the PGA (Figure 1 and in Table 1) and for the 10000-year return period 5\% damped design response spectra (Figure 2) for the five sites. 


\begin{tabular}{|c|c|c|c|c|c|}
\hline \multirow{2}{*}{$\begin{array}{c}\text { Return } \\
\text { Period }\end{array}$} & \multicolumn{5}{|c|}{ Peak Ground Acceleration Level (cm/s/s) } \\
\cline { 2 - 6 } & CHERNOBYL & KHMELNYSTSKYY & RIVNE & SOUTH UKRAINE & ZAPORIZHYA \\
\hline $100 \mathrm{yr}$ & 40.8 & 45.0 & 41.4 & 54.5 & 42.8 \\
\hline $500 \mathrm{yr}$ & 72.4 & 77.9 & 69.3 & 89.9 & 74.0 \\
\hline $1000 \mathrm{yr}$ & 87.8 & 93.1 & 83.3 & 107.0 & 88.7 \\
\hline $10000 \mathrm{yr}$ & 159.9 & 171.8 & 144.9 & 196.0 & 156.5 \\
\hline $100000 \mathrm{yr}$ & 273.0 & 292.8 & 245.1 & 323.4 & 261.6 \\
\hline
\end{tabular}

\begin{tabular}{|c|c|c|c|c|c|}
\hline \multirow{2}{*}{$\begin{array}{l}\text { Return } \\
\text { Period }\end{array}$} & \multicolumn{5}{|c|}{ Magnitude of the Review Level Earthquake M-bar } \\
\cline { 2 - 6 } & CHERNOBYL & KHMELNYSTSKYY & RIVNE & SOUTH UKRAINE & ZAPORIZHYA \\
\hline $100 \mathrm{yr}$ & 5.80 & 6.00 & 6.00 & 6.20 & 5.90 \\
\hline $500 \mathrm{yr}$ & 6.00 & 6.20 & 6.20 & 6.50 & 6.10 \\
\hline $1000 \mathrm{yr}$ & 6.10 & 6.30 & 6.30 & 6.70 & 6.20 \\
\hline $10000 \mathrm{yr}$ & 6.40 & 6.60 & 6.60 & 7.00 & 6.50 \\
\hline $100000 \mathrm{yr}$ & 6.60 & 6.80 & 6.80 & 7.20 & 6.70 \\
\hline
\end{tabular}

\begin{tabular}{|c|c|c|c|c|c|}
\hline \multirow{2}{*}{$\begin{array}{l}\text { Return } \\
\text { Period }\end{array}$} & \multicolumn{5}{|c|}{ Distance of the Review Level Earthquake D-bar (km) } \\
\cline { 2 - 6 } & CHERNOBYL & KHMELNYSTSKYY & RIVNE & SOUTH UKRAINE & ZAPORIZHYA \\
\hline $100 \mathrm{yr}$ & 88 & 223 & 95 & 346 & 92 \\
\hline $500 \mathrm{yr}$ & 106 & 270 & 124 & 361 & 118 \\
$1000 \mathrm{yr}$ & 115 & 289 & 138 & 366 & 130 \\
\hline $10000 \mathrm{yr}$ & 141 & 334 & 180 & 372 & 169 \\
\hline $100000 \mathrm{yr}$ & 166 & 367 & 215 & 370 & 204 \\
\hline
\end{tabular}

Table 1 Summary of the Review Level earthquake PGA, D-bar and M-bar for the five sites in Ukraine and for five return periods 


\section{Mean Hazard estimates for the 5 Ukraine sites for PGA (Bedrock)}

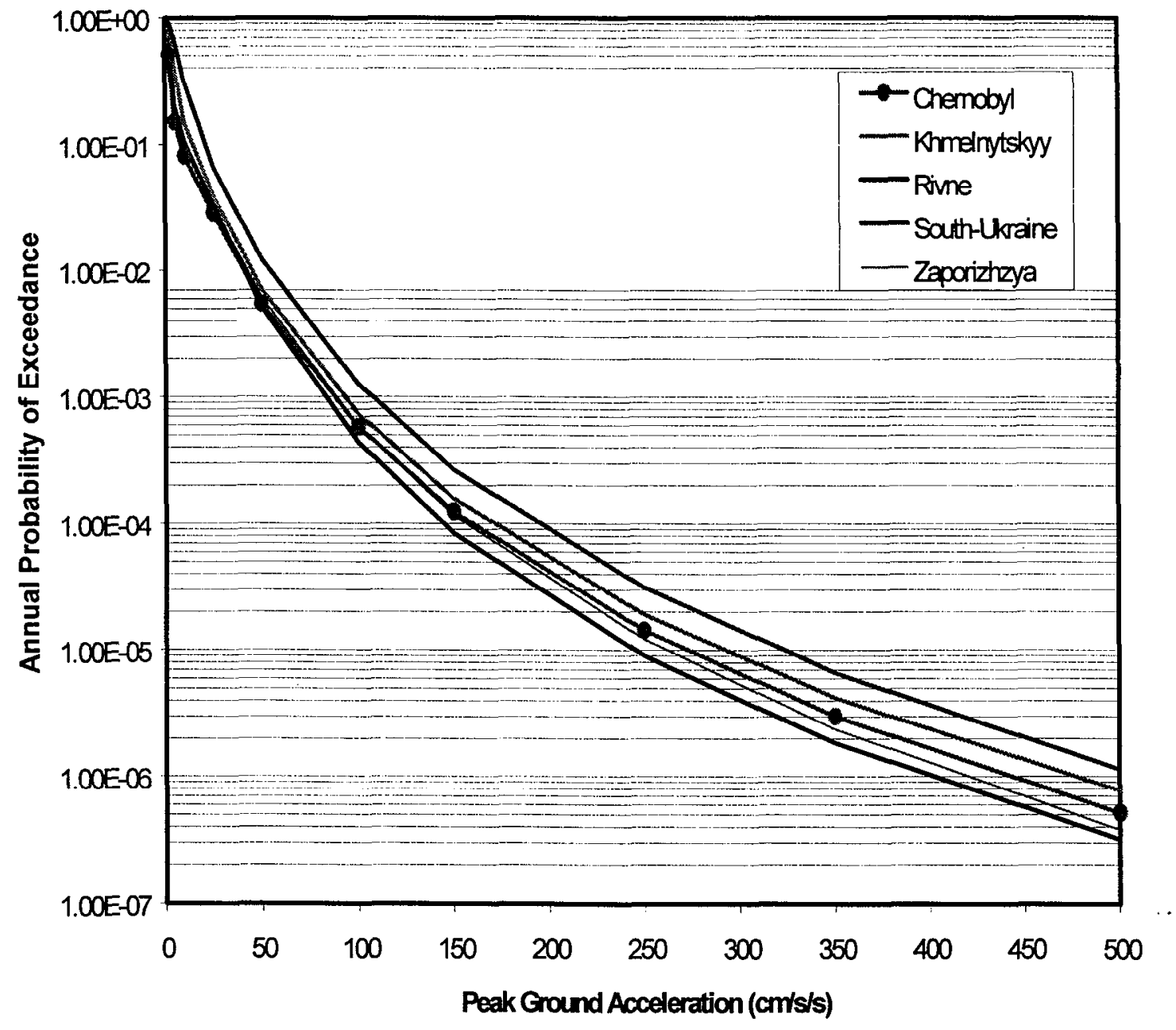

Figure 1: Summary of the PSHA PGA results for the Ukraine sites, for rock conditions at foundation level in terms of the the arithmetic mean. 


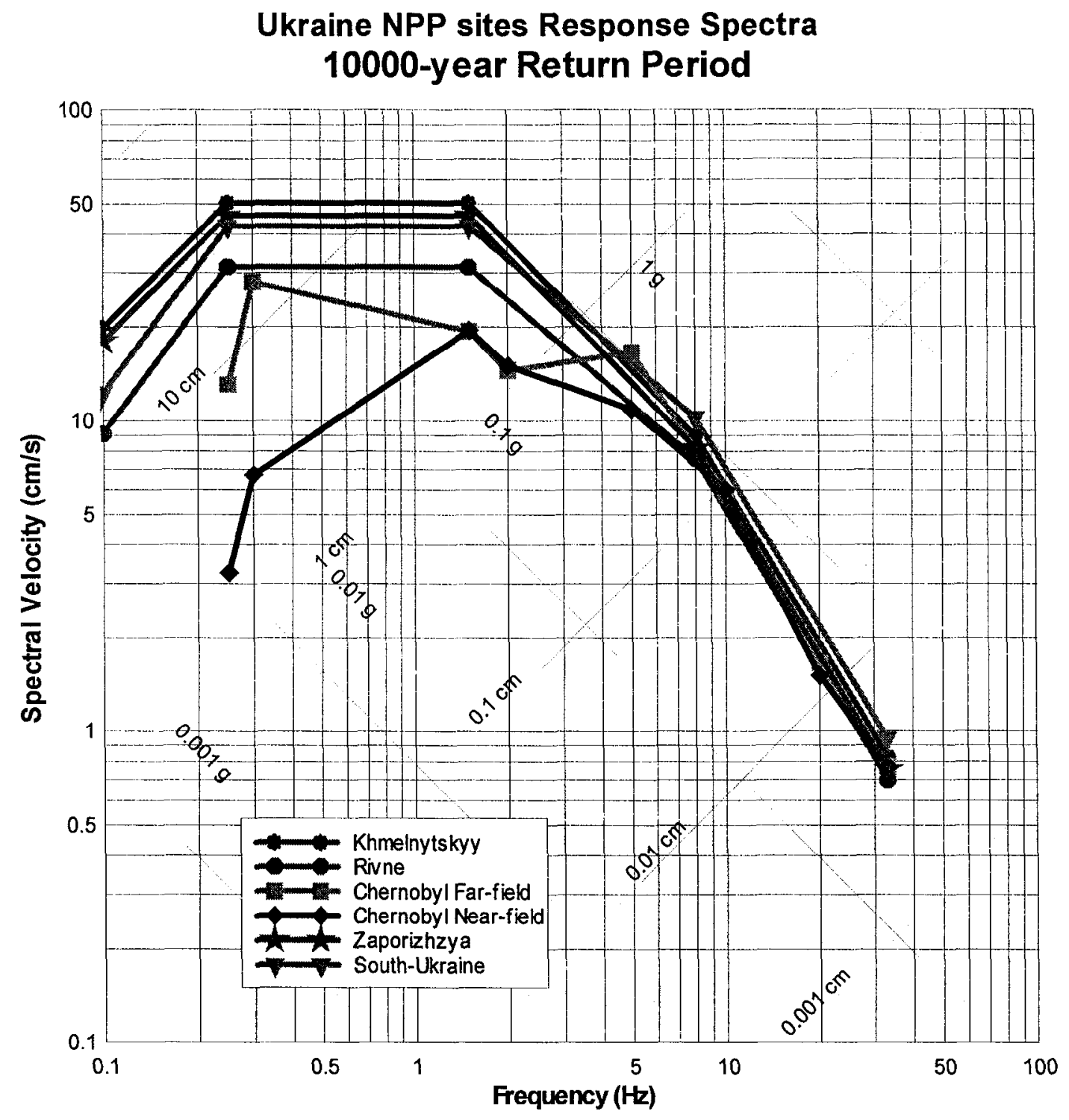

Figure 2: 1,000-year Return Period,5\% Damping Design Response Spectra for the Five Ukraine NPP sites. 


\section{ACKNOWLEDGMENTS}

The authors wish to acknowledge the support of numerous experts around the country, in Ukraine and other countries who provided interpretations and offered judgments on seismicity and ground motion modeling which were factored into this study. Their contributions have been referenced as personal communications.

We also thank the DOE/Argonne project manager, Dr. Christian Kot for his support and for his help in securing the facilities for the workshop in Kiev and for his help in acquiring some data on the sites.

We thank Mr. Norbert Jousten and the European Commission, in Bruxelles, Belgium, for allowing us to use the results of studies performed under their auspices by ISMES for the Crimea and the Chernobyl regions.

And finally we thank Dr. Aybars Gurpinar, of IAEA, and several anonymous DOE and Argonne persons for their review of the draft document. Their comments were important in the finalization of the seismicity rates of the seismic zones which are reflected in the final results shown in this report. 


\section{ABBREVIATIONS}

$\begin{array}{ll}\text { BP } & \text { before present } \\ \text { CE } & \text { Controling earthquake } \\ \text { CEUS } & \text { central and eastern United States } \\ \text { CNA } & \text { central North America } \\ \text { DBE } & \text { design basis earthquake } \\ \text { DOE } & \text { U.S. Department of Energy } \\ \text { DRS } & \text { dynamic response spectrum } \\ \text { ENA } & \text { eastern North America } \\ \text { HMC } & \text { Hazard Mitigation Center at LLNL } \\ \text { IAEA } & \text { International Atomic Energy Agency } \\ \text { LLNL } & \text { Lawrence Livermore National Laboratory } \\ \text { NRC } & \text { Nuclear Regulatory Commission } \\ \text { PGA } & \text { peak ground acceleration } \\ \text { PSH } & \text { probabilistic seismic hazard } \\ \text { PSHA } & \text { probabilistic seismic hazard analysis } \\ \text { SSHAC } & \text { Senior Seismic Hazard Analysis Committee } \\ \text { TFI } & \text { Technical Facilitator Integrator } \\ \text { UHS } & \text { uniform hazard spectra } \\ \text { WUS } & \text { western United States } \\ \end{array}$




\section{PROBABILISTIC SEISMIC HAZARD CHARACTERIZATION AND DESIGN PARAMETERS FOR THE SITES OF THE NUCLEAR POWER PLANTS OF UKRAINE}

\subsection{INTRODUCTION}

\subsection{Background}

The U.S. Department of Energy (US DOE), under the auspices of the International Nuclear Safety Program (INSP) is supporting in-depth safety assessments (ISA) of nuclear power plants in Eastern Europe and the former Soviet Union. As part of this program, assessment of seismic-related safety of operating VVER nuclear power plants (NPP) has been in progress in various countries that have these types of reactors. The assessments have been prompted either by regulatory requirements or evidence of higher seismic hazard than was used at the time the plants were designed. Unlike in the Eastern European countries, which have received much assistance in the area from the European Community, little work relative to seismic hazards has been carried out in Ukraine to date. This study pertains to determining the seismic hazard in Ukraine and comes under the purview of the ISA of the South Ukraine NPP. It is intended that the seismic assessments be carried out in the framework of the overall ISA supported by the DOE-INSP.

The Hazard Mitigation Center (HMC) at Lawrence Livermore National Laboratory (LLNL) has been asked by Argonne National Laboratory (ANL) to update the seismic design response parameters for the Ukraine power plant sites.

The purpose of the study is to generate an independent assessement of the seismic hazard. It has to be using the latest, most appropriate sets of data available and it has to fulfill the criteria of a state-of-the -art Probabilistic Seismic Hazard Analysis (PSHA) defined as standards in the United States and documented in the SHHAC, 1997, the Nuclear Regulatory Commission Guide DG 1.165, 1998 and applied in many studies ( see example Savy et al., 1999, DOE/CRWMSOC, 1998, Savy and Foxall, 1998). One of the important aspect of this methodology is to integrate the full spectrum of knowledge from the scientific community and to assess the uncertainty in the hazard estimates due to the lack of total knowledge of the seismotectonic process.

The standard methodology, briefly decribed in chapter 2 , is governed by a set of rigourous criteria and concepts that define the process of performing the study. It can be applied with various level of efforts.

\subsection{Objectives}

The objective is to follow the recommandations of the SHHAC, the DOE-STD-1023-95 standard, and to use site specific information to the extent possible. For this purpose the seismic zonation applies specifically to each site but the local site conditions have only been included when data were available. The goal of the study is therefore to generate the best probbabilistic estimate of the seismic hazard at the sites, using all the available data in the United States and those that can be obtained in the open literature and by interacting with Ukrainian and European local experts. This report describes the methodology and provides the seismic design parameters in the form of tables and figures for the structural engineers.

\subsection{Scope of the Study}

The overall purpose of this study was to provide recommendations on the seismic design parameters for the Ukraine nulear power plant sites to be used in a simplified Probabilistic Risk Analysis (PRA) for 
comparing the relative risk associated with each plant under the seismic threat. For each of the five sites the following information was generated:

- Ground motion estimates for six values of the annual probability of exceedance; $10^{-2}, 2 \times 10^{-3}, 10^{-3}$, $5 \times 10^{-4}, 10^{-4}$ and $10^{-5}$, for peak ground acceleration (PGA) and for response spectral values

- Deagregation of the total hazard results for several return periods.

- The magnitude and location of the Controlling Earthquakes (CE) and the resulting spectral shape.

- The final design parameters and their comparison with international practices, including the recommendations of the International Atomic Energy Agency (IAEA) and the Russian practices.

This study makes use of the latest technology in the area of PSHA, and uses all available information on the geology, seismology, tectonics, and geological engineering from previous LLNL and European studies for eastern Europe. It relies also on the experience and ground motion data collected for the eastern U.S. and other studies, including previous site-specific studies and regional studies such as USGS96.

Given the very low seismicity of the region of interest, it was felt that a large distant region of enhanced seismic activity, could have a dominant effect on the total hazard for any of the Ukraine sites. Based on experience in other similar studies, it is well understood that for levels of hazards in the range of a few hundred years to a few thousand years, distant seismogenic sources such as the Vrancea zone in could contribute orders of magnitudes greater hazard than any of the other potential seismic sources. For that reason, we included in the analysis all identifiable seismic sources within $700 \mathrm{~km}$ of any of the sites.

This study uses all relevant site-specific information available for the PSHA. Since a great deal of work has taken place at Chernobyl, some information is available on the stratigraphy which is assumed to be representative of generic sites on the European Craton. Although that information was not sufficient to make a detailed site-specific characterizationfor all sites, it allowed us to narrow the selection of spectral shapes..

\subsection{Organization of this Report}

This report includes four sections and a collection of tables and figures.

Section 1 gives background information and describes the study.

Section 2 describes the methodology for assessing seismic hazards.

Section 3 describes the seismic hazard assessment forn the Ukraine nuclear power plant sites.

Section 4 discusses the application of DOE-STD-1023-95 and the steps involved in development of the design criteria.

Table and figure caption numbers correspond to the section in which they are discussed. For example, Figure 3.4-1 is discussed in Section 3.4 of the report. 


\subsection{METHODOLOGY}

\subsection{General Approach}

A methodology to assess seismic hazards and uncertainty at Ukraine plant sites must provide technically sound results that meet the regulatory requirements, are amenable to regulatory review, and make appropriate use of site characterization data. To help meet these goals, the methodology incorporates attributes described below:

1) Experience Based. The methodology takes advantage of the experience gained from recent assessments of seismic hazards. Over the past decade, probabilistic methods have evolved into the generally preferred state-of-the-art for assessing vibratory ground motion at critical facilities. By incorporating recurrence information and input variability, these methods provide a more complete evaluation of hazard for risk-based design, long-term performance assessment, and regulatory review than do deterministic methods. Recent applications of probabilistic methodologies, associated lessons learned, and ongoing evaluations and integration of seismic hazard methodologies (e.g., the Senior Seismic Hazard Analysis Committee (SSHAC) study, jointly sponsored by the DOE, the NRC, and EPRI) provide the basis for the methodology described in this report.

2) Data-Driven. Development of inputs to the seismic hazard methodology and the associated input variability is based on site-specific data. The methodology is capable of incorporating all relevant available site-specific data, including information on earthquake recurrence. The methodology also allows seismic hazard assessments to be easily updated, as new data become available.

3) Proper Uncertainty Treatment. The methodology provides an unbiased assessment of seismic hazards by incorporating and properly treating various types of input variability. These types of variability include uncertainty in data interpretations and randomness in the earthquake process. In comparison with typical deterministic methods, treating uncertainty in a probabilistic framework results in a more complete characterization of seismic hazards. The uncertainty is directly incorporated into the calculation of hazard, rather than qualitatively contributing to selection of a deterministic value. This facilitates regulatory decision-making and risk-based design. The methodology accommodates alternative relationships describing physical processes (e.g., earthquake occurrence); alternative values of parameters associated with those relationships (e.g., amount of fault dip, slip rates, and maximum magnitudes); and alternative interpretations based on site characterization data.

4) Flexible. The methodology accommodates a range of credible scientific interpretations, approaches, and data. Further, the methodology allows rational consideration of unlikely or highly uncertain scenarios. For example, the methodology accommodates the notion of seismic sources occurring in regions where faults are presently unmapped or unknown. This flexibility results from the probabilistic framework in which alternative input interpretations are explicitly incorporated.

5) Facilitate Sensitivity Analysis. The methodology is structured such that sensitivity analyses are facilitated. Such analyses identify important contributors to the hazard result and the relative importance of various data and interpretations. Similarly, they are used to highlight relationships or parameters for which differences in interpretation or data do not strongly influence the hazard at the site. Hence, the methodology aids in setting priorities for additional data collection and analysis efforts, so that the most important technical issues are addressed and reductions in uncertainty have the greatest impact.

To fulfill the above requirements, the present state-of-the-art approach (as described in the SSHAC report [NUREG/CR-6372]) uses the concept of the Technical Facilitator Integrator to rationally integrate the 
information from a group of experts. For limited-effort studies such as the one presented in this report, the requirements are fulfilled in a simplified approach. The trade-off between a full-fledged analysis of the type described in SSHAC and the one used here is not in the quality or credibility of the results, but rather in the total amount of uncertainty in the estimated hazard.

In this study, the LLNL analysis team's main challenge was to gain sufficient knowledge of existing interpretations of the data by the scientific community - and to use its experience from previous studiesto realistically represent the uncertainty that exists in the scientific community.

The LLNL team first collected all the information available from the LLNL and open literature and data banks, the geology and tectonics of the region, and on existing hazard models (see Section 3 ). This information was used to formulate a set of seismic source maps and seismic source recurrences. Since for most sites a site-specific response spectrum shape is not available, a median standardized spectral shape may be used as long as the shape is consistent with or conservative for the site conditions. A procedure similar to that for obtaining the spectra shapes defined in NUREG/CR-0098 for standardized spectra was applied to the Ukrainian plant sites, in accordance with the country regulatory requirements which permit such an approach. Where local geology is available, such as for the South Ukraine site albeit in insufficient quantity, it was used. In the absence of such country-specific spectra, those given in NUREG/CR-0098 are used.

\subsection{Procedural Approach}

\subsubsection{The basic five steps of the procedure}

The main thrust of this study is in the characterization of all the uncertaintics in the process, the data and the physical models.

To achieve this, we use multiple experts to identify "all" the possible viable alternatives of the seismic zonation and ground motion models, and we develop a "composite picture".

The procedure includes five steps that are summarized as follows:

- First, we collect all the relevant geophysical, tectonics, geology and geotechnical information available. This includes reports on previous studies, technical papers in scientific journals and standard information from public and government databases.

- The second step consist for the analysis team (Lawrence Livermore National Laboratory) in formulating as many preliminary seismic zonation models as the data warrant.

- The third step consists in a working meeting in Kiev.

- The fourth step consists in finalizing the hazard models and performs the calculations.

- The fifth step of this procedure consists in having a peer review of the study.

Finally we evaluate the relative hazard at the sites of the nuclear power plants in Ukraine. 


\subsubsection{Purpose of the workshop in Kiev}

The purpose of the working meeting in Kiev was to interact with Ukraine scientists and engineers with knowledge of the regional seismicity and tectonics and the goal was to develop interactively a set of seismic zonations for the hazard calculation model. To achieve these goals, the workshop, the of which the agenda is given in Apendix 1, was organized along the following items of presentation and discussion:

1. Introduce and discuss the PSHA methodology use for this study.

2. Review and evaluate the existing data colected by the LLNL team.

3. Discuss the existence and the validity of other relevant data available to the participants.

4. Ask the invited scientists/engineers to present their interpretations of the data in the form of possible alternate seismic zonation models for the PSHA.

5. The LLNL team presents its preliminary models of seismic zonation as a starting point for the interactive updating of those models.

6. Discussion, evaluation of the alternate seismic zonation models.

7. Construction of a "logic tree" summarizing all the alternatives and interactively develop a set of weights for each branch of the logic tree.

8. Discuss the seismicity rates and the upper magnitude cutoffs in the different seismic sources considered for the seismic zonation maps. Discuss methods to derive the seismicity rates.

9. Perform a similar but simpler approach for the determination of the ground motion attenuation equations to be used in the PSHA.

\subsubsection{Role of the experts at the workshop}

Because an extensive review of the existing data was the first task performed prior to the workshop, it was not expected that new outlier interpretations unknown to the LLNL team would be unearthed at the workshop. However, it is very important to confirm it and it is also very important, as given in the SHHAC reommendations (SHHAC, 1997), to check with the local experts that no important scientific fact has been misinterpreped or overlooked. 
The role of the experts at the workshop was therefore fourfold: (a) to identify new data, (b) provide an evaluation of the data available, (c) play the role of proponents in providing their views on the interpretation of the data and (d) provide feedback to the LLNL team in the evaluation of the various interpretations and models.

The participants were thouroughly briefed on the purpose of the workshop and were asked to prepare themselves for the workshop with the following requests:

They were asked to bring all relevant data that could be examined by the entire panel in order to develop alternate seismic zonation models or ground motion attenuation models. This included physical data, exiting models or personal interpretations.

They wcre asked to participate actively in the discussions and provide personal technical opinions. They were told that different experts have sometimes very different opinions, including some not espoused by the community at large. However nonstandard these opinions are, they were told that they were welcome for discussion. This is an important part of identifying the knowledge uncertainty.

They were asked to be ready to respond to the questions in the elicitation of alternate models and/or the weights on existing models (for seismic sources and/or ground motion models). An expert may bc specialized in the identification of seismic sources only, or ground motion attenuation only, or both.

The participants were also asked to be ready to discuss seismicity rates in the different regions of Ukraine, or at least to discuss methods to obtain them.

\subsubsection{Products of the workshop in Kiev}

One of the initial goals of the workshop was to generate a final set of models for use in the PSHA. That meant to agree on the following set of items:

1. A set of seismic source alternatives for the performance of a

PSHA in Ukraine,

2. A set of weights on the alternatives,

Whatever additional data to be used by LLNL to update the source

models if necessary,

The necessary data on the seismicity rates and/or a consensus on the method to obtain them.

6. A set of viable ground motion models or ground motion estimates.

These general goals for the results of the workshop were reached. It was not possible however to collect or even identify sufficient site specific geotechnical or geological information for performing reliable soil dynamics analyses in order to determine the shape of the site specific response spectra. 


\subsection{Seismic Hazard Characterization Model}

\subsubsection{Systematic Process}

Five steps are involved in deriving the distribution of seismic hazard.

Step 1: Evaluation of Seismic Sources.

Determine the spatial distribution of seismic sources. In the region around the site, identify faults and volumetric zones that will be the sources of future seismic activity. Characterize the uncertainty in the spatial description of each source.

Step 2: Evaluation of Earthquake Recurrence and Maximum Magnitude.

For each seismic source, describe the rate of occurrence and relative size (e.g., magnitude, moment) distribution of future seismicity. In addition, evaluate the maximum magnitude for each source. Characterize the uncertainty in recurrence relations and in maximum magnitude.

Step 3: Ground Motion Attenuation.

For the site region, evaluate or determine relations that express how the amplitude of ground motion parameters varies with earthquake magnitude and source-to-site distance. Characterize the uncertainty in these ground motion/attenuation relations.

Step 4: Mathematical Model to Calculate Seismic Hazard.

Integrate over each combination of inputs determined in steps 1 through 3 to calculate a seismic hazard and plot a curve expressing the annual probability that a given value of ground motion will be exceeded. Carry out the integration for all combinations of inputs to incorporate the variability of input evaluation.

Step 5: Presentation of the Hazard Results.

Express the results of step 4 as a distribution of seismic hazard curves that can be represented by a mean curve and curves representing particular percentiles of the distribution.

Each of these steps is discussed below and shown schematically in Figure 2.3-1.

\subsubsection{Evaluation of Seismic Sources}

A seismic source represents a portion of the earth's crust with a potential to generate future earthquakes. Within a seismic source, the probability of earthquake occurrence and the size of the maximum magnitude are generally considered to be invariant. Seismic sources include faults with a potential to affect the nuclear plant sites. Seismic sources also depict volumetric zones in which future earthquakes may occur, but for which specific faults are not identified.

In identifying and characterizing seismic sources, the scale of features to be considered and the level of investigation varies with distance from the site. Because ground motion attenuates with distance as the distance to the site increases, earthquake size must increase to produce significant ground motion at the site. The size of earthquake that a feature can generate is rclated to its physical dimensions. Thus, as onc gets farther from the site, larger faults are required for a significant ground motion potential to exist at the site.

Each seismic source is evaluated to provide its: 
- spatial description, including variability in that description (two-dimensional zone of diffused seismicity or three-dimensional faults)

- probability of activity

- dependency on other seismic sources.

Alternate interpretations of the spatial description of a seismic source permitted by the available data are weighted according to their ability to explain the data. The spatial description of a seismic source includes an evaluation of the depth of earthquakes associated with the source.

For each source, a probability of activity is assessed, which expresses the probability that the source is seismogenic and is based on the evidence of its activity during the Quaternary period. Such assessments are based on available data, and take into account alternative tectonic interpretations, including the orientation of the stress field. Dependencies among seismic sources are also evaluated. For example, a seismic source interpretation based on a particular tectonic model may be inconsistent with a seismic source interpretation based on another tectonic model. Such sources would have a mutually exclusive dependency.

\subsubsection{Evaluation of Earthquake Recurrence and Maximum Magnitude}

An earthquake recurrence relationship, a maximum magnitude, and the variability in these parameters characterize each seismic source. For recurrence, the relationship expresses the expected number of earthquakes per year of magnitudes greater than some minimum magnitude, $\mathrm{m}_{0}$. This distribution is developed from observed seismicity and geologic data. Since the level of seismicity in the region is low and the historical record is short, compared with the large return periods considered, geologic data such as paleoseismic recurrence intervals and slip rates are expected to provide the primary basis for recurrence characterization of the fault sources. For volumetric source zones, the historical and instrumental seismicity records form the primary data for characterization of recurrence. Additional calculations and experience are used to provide uncertainty on these estimates. Alternative interpretations consistent with the data were evaluated to describe the uncertainty in recurrence relations.

A maximum magnitude is assessed for each seismic source. Variability is assessed on the basis of consistency shown by the different regression calculations, the relative quality of the different data types, and alternative interpretations of the data.

\subsubsection{Ground Motion Attenuation}

A ground motion attenuation function is a probability density function whose parameters are functions of the earthquakes and site characteristics. The standard version is a function of the magnitude of the earthquake and its distance from the site of interest. The probability of exceeding a certain value of the ground motion caused by an earthquake of magnitude $M$ and located at a distance $R$ from the site is calculated by means of the ground motion attenuation function.

\subsubsection{Mathematical Model to Calculate Seismic Hazard}

As developed by Cornell (1968), the probabilistic hazard methodology aims to calculate the annual probabilities that various levels of ground motion (e.g., peak horizontal ground acceleration) will be exceeded at a site. Procedures to accomplish this assessment are described by Cornell and form the basis for recent state-of-the-practice methodologies applied to nuclear power plants and to DOE facilities.

The probabilistic hazard curve represents the integration, over all earthquake sources and magnitudes, of the probability of future earthquake occurrence and, given an earthquake occurrence, its effect at a site of interest. In general, the temporal occurrence of earthquakes can be represented as a Poisson process and 
its distribution in magnitude can be represented by an exponential distribution. Thus, the probability that, at a given site, a ground motion parameter, $Z$, will exceed a specified value, $z$, during a specified time period, $T$, is given by the expression:

$$
P(Z>z)=1.0-e^{-v(z) T} \leq v(z) \cdot T
$$

Where $v(z)$ is the average frequency during time period $T$ when the level of ground motion parameter $Z$ exceeds $z$ at the site resulting from earthquakes from all sources in the region. The inequality at the right of Equation 1 is valid regardless of the appropriate probabilistic relationship for earthquake occurrence, and $v(z) \cdot T$ provides an accurate estimate of the hazard for probabilities of 0.1 or less provided $v(z)$ is the appropriate value for the time period of interest.

The frequency of exceedance, $v(z)$, incorporates the variability (randomness and uncertainty) in the time, size, and location of future earthquakes and variability in the level of ground motions they produce at the site. It is computed by the expression:

$$
v(z)=\sum_{n=1}^{N} a_{n}\left(m^{\circ}\right) \int_{m=m^{\circ}}^{m^{n}} \int_{=0}^{\infty} f_{n}(m) f_{n}(r \mid m) P(Z>z \mid m, r) d r d m
$$

where

$a_{n}\left(m^{\circ}\right)$ is the frequency of earthquakes on seismic source $n$ above a minimum magnitude of engineering significance, $m^{\circ}$;

$m^{u}$ is the maximum magnitude possible in source $n$. In the rest of this document it is also called $M_{\max }$. $f_{n}(m)$ is the probability density function of event size on source $n$ between $\mathrm{m}^{\circ}$ and a maximum earthquake size for the source, $\mathrm{M}_{\max }$;

$f_{n}(r \mid m)$ is the probability density function for distance to earthquake rupture on source $n$, which may be conditional on the earthquake size; and

$P(Z>z \mid m, r)$ is the probability that, given a magnitude $m$ earthquake at a distance $r$ from the site, the ground motion exceeds a value $z$.

In practice, the double integral in Equation 2 is replaced by a double summation with the density function $f_{n}(m)$ and $f_{n}(r \mid m)$ replaced by discrete representations of their corresponding cumulative functions. As shown in Figure 2.2-1 (Step 4), the result is a hazard curve expressing the annual probability that various levels of the ground motion parameter will be exceeded.

\subsubsection{Presentation of the Hazard Results}

The basic calculation described above results in a seismic hazard estimate for a single characterization of seismic sources, associated recurrence and maximum magnitude evaluations, and a single ground motion/attenuation relation. Thus, the result of this calculation is a single hazard curve (Figure 2.3.1 Step 4) that represents the randomness inherent in the natural phenomena of earthquake generation and seismic wave propagation. There is also uncertainty in the characterizations of seismic sources and ground motion/attenuation. This uncertainty arises from incomplete knowledge of earthquake processes, limited data, and permissible alternative interpretations of the available data. The methodology explicitly incorporates these uncertainties into the analyses to quantify the uncertainty in the final hazard results.

The Monte Carlo approach to uncertainty propagation, used in this study, makes use of multiple subjective probability distributions for the various parameters of the hazard-input evaluations. The 
computation samples from these distributions, using Monte Carlo simulation techniques, are used to derive mean and percentile hazard curves. When using this approach, uncertainty in seismic source zonation is represented by weighted alternative maps; uncertainty in recurrence is characterized by subjective probability distributions on the recurrence parameters; and uncertainty in ground motion evaluations is characterized by a set of alternative ground motion relationships and their associated weights. 


\subsection{ASSESSMENT OF THE SEISMIC HAZARD AT THE SITES OF THE UKRAINE NUCLEAR POWER PLANTS}

\subsection{Introduction}

The seismic hazard assessment at the sites of the NPPs in Ukraine followed the methodology described in Chapter 2. The first element of the study was to review the body of work published in scientific journals and other engineering publications on the subject of the seismicity of the region of interest which included at least all areas within $800 \mathrm{~km}$ to $1000 \mathrm{~km}$ from any of the NPP sites.

The next step was to formulate some preliminary seismic source zonation models from our understanding of the tectonics of the region and then, to conduct a workshop in Kiev, on February 2-5, 1999 (also described in Chapter 2), to discuss the alternative models with local geologists and seismologists. The workshop was aimed at evaluating all the possible alternative models put forth by the LLNL team and by the participants. The "strawman" set of models presented at the workshop was updated to take into account the new information obtained during the workshop. Instead of a complete detailed summary of the workshop the following sections of this report give the final products and present the elements, which were discussed at the workshop. A general agenda of the workshop is given in Appendix 1.

\subsection{Available Information}

The information used for this study consisted of the published literature available in the USA and some in the Russian and Ukrainian scientific journals. The scientific articles consulted and evaluated are listed in the Appendix 2.

We also obtained copies of recent studies, one for the Chernobyl site and commissioned by the European Community (Tacis, 1997) and another for the design of a nuclear power plant in Crimea (ISMES, 1991).

\subsection{Description of the Hazard Model}

\subsubsection{Earthquake Source Characterization}

\subsubsection{General Tectonic setting and development of the seismic sources models}

Fig. 3.3.1.1 is a schematic tectonic map of the Ukraine region. Fig. 3.3.1.2 shows the seismicity of the region (see Section 3.3.1.2) and the numbered earthquake source zones used in the PSHA. The source zones are named in Table 3.3.1.1, which also lists the shortest distance from each zone to the nearest NPP site, the largest historical earthquake recorded in the zone, and the best estimate, lower bound and upper bound maximum magnitudes estimated for the PSHA. The source zones correspond in general to the major tectonic structural features shown in Fig. 3.3.1.1, and can be divided into two classes; more or less tectonically active zones along the northern Black Sea-Crimea - Caucasus belt and the Carpathian mountains, and zones within the interior of the East European Craton (EEC), which is a "stable continental region" (SCR) as defined by Johnston et al. (1994). Definition of zone boundaries within the Carpathians, the western part of the EEC, and in the Black Sea-Crimea-Caucasus region is based largely upon the distribution of historical seismicity. Definition of the Vrancea zone (Zone 4) is also based upon 
numerous published seismo-tectonic and structural analyses. Evaluation of the viability of the PripyatDniepro-Donnets Rift as a source of significant earthquakes distinct from the rest of the EEC is based upon available interpretations of geological and geophysical data and comparison with analogous structures worldwide.

Preliminary ("strawman") versions of Figure 3.3.1.2 and Table 3.3.1.1 formed the basis for the expert elicitation and discussion of alternative interpretations at the Kiev workshop on Feb. 3 and 4, 1999. The geometry of source zones within in the Black Sea-Crimea-Caucasus region are based on the detailed zonation carried out for the Crimea NPP (ISMES, 1990). The Carpathian zone (Zone 1) is based on the zonation for the Chernobyl NPP (Tacis, 1997), with additions and modifications based on our initial review of the available data. There was general consensus at the workshop that the preliminary zonation adequately represents the potential seismic sources within the region, so that the final zone geometry shown in Fig. 3.3.1.2 are essentially unchanged from the preliminary map. Not all of the workshop participants agreed, however, that all of the zones are needed to capture all potential sources, based on the available data.

The EEC background zone is the host zone for all of the NPP sites. All of the sites are located more than $200 \mathrm{~km}$ from all but one (Carpathian) of the active tectonic source zones, which, with the exception of Vrancea and Yalta, have maximum observed historical earthquakes less than M6.5. Therefore, with the exception of the Carpathians, Vrancea and possibly Yalta, substantial changes to these zones do not have a significant effect on the hazard at any of the Ukraine NPP sites. Consequently, the main focus of the workshop was directed towards characterizing the Carpathian, Vrancea and EEC zones, as described below. Characterization of the remaining zones is described only briefly.

\subsubsection{Earthquake catalog}

The earthquake epicenters plotted on Fig. 3.3.1.2 include all the events having magnitudes of 3 or greater in the earthquake catalog for the Commonwealth of Independent States (CIS) (former Soviet Union) distributed by the Earthquake Information Service (NEIC) of the U.S. Geological Survey (USGS) (J. Dewey, personal communication) for the period 1129-1989 plus five events listed in the NOAA National Geophysical Data Center (NGDC)/NEIC CIS catalog (NGDC/NEIS, 1996) for the period 150 BC-1107. The NEIC and NGDC/NEIS catalogs contain both pre-instrumental and instrumentally recorded earthquakes for the years 1122-1989 and 150 BC-1978, respectively. Both catalogs are based on the original data compilation by Kondorskaya and Shebalin (1982), and are supplemented by data from USSR station reports and published literature for 1978 onwards (a bibliography of data sources is given in NGDC/NEIS, 1996). Fig. 3.1.1.3 shows instrumental locations for all earthquakes within the Ukraine region in the International Seismological Centre (ISC) catalog for 1964-1993, including events without assigned magnitudes (crosses). (The magnitude scale on Fig. 3.1.1.3 corresponds to mb routinely reported in the ISC catalog.)

\subsubsection{Estimation of the maximum magnitude possible in a seismic zone (Mmax)}

In the absence of any real physical knowledge of the particular geological features which will be the cause for the occurrence of future earthquakes, the assignment of a probability distribution of $M_{\max }$ followed the general technique which consists in determining the magnitude of the largest event ever observed in the seismic zone and adding an arbitrary 0.5 to that magnitude. Since one would be more 
likely to have observed the real maximum in a very long period of observation than in a short period, we modulated the choice of bounds on the distribution depending on the length of time since the largest event. For example the largest event in Zone 7 (Crimea-Kerch-Caucasus) occurred 2000 years ago. This event was estimated to be a M5.8. We assumed that magnitude to be the value of the maximum, but allowed for some uncertainty (bounds 5.8 to 6.0 ).

\subsubsection{Seismic source zones}

\section{Zones 1 and 2a: Carpathians}

The Carpathian mountains (Fig. 3.1.1.4) are part of the northern branch of the Alpine Mediterranean fold/thrust system, which has a very complicated tectonic history. The Eastern Carpathians, which are of most relevance to the PSHA, evolved during two phases of tectonic convergence (Royden and Burchfeil, 1989). The first event, from the Cretaceous to the early Tertiary, deformed internal units in the Carpathians, and the second, from late Oligocene to Miocene, deformed the external flysch units. Subduction of oceanic lithosphere under continental fragments to the west continued until about the early to mid Miocene, when completion of the subduction of oceanic lithosphere caused the onset of continentcontinent collision between the Eurasian plate to the east and the continental fragments to the west, with widespread compressional deformation of the European foreland. The arrival of thickened continental crust in the late Miocene caused overthrusting and folding to the east of accreted sediments on to the foredeep deposits, and eventually collision ceased about 9Ma (e.g. Wenzel et al., 1998). Minor crustal deformation continues to the present, however, as evidenced by the low rate of occurrence of small and moderate crustal earthquakes, and continued low-level Pliocene-Quaternary faulting and folding (e.g. Linzer, 1996). Tacis (1997) suggests that present-day compression of the Eastern Carpathians may be driven by continuing extension and subsidence of the intra-Carpathian Pannonian Basin to the west, which, like the smaller Transylvanian Basin, formed as a back-arc basin.

The source zones within the Eastern and Southern Carpathians (Zones 1, 2b, and 3) shown in Fig. 3.3.1.2 encompass the mountain belt to crustal depths and the Miocene foredeep. For completeness, we have extended the zone defined by Tacis (1997) (Zone 1) to the west (Zone 2b). Zone 1 excludes the very active Vrancea zone of moderate to large intermediate depth $(>70 \mathrm{~km})$ earthquakes at the intersection of the Eastern and Southern Carpathians, which constitutes a separate source zone (Zone 4) and is described below. The Zakarpatye region (Fig. 3.1.1.2) is also defined as a separate zone (Zone 3).

The diffuse seismicity within the East Carpathian crustal zones appears to be associated with low-level deformation accommodated by minor reactivation of pre-existing faults (e.g. Linzer, 1996). Kharitonov et al. (1996) speculated that small earthquakes felt in the Zakarpatye region may be concentrated near mapped faults; crustal deformation has also been tentatively associated with faults in Bukovina (the area immediately north of the Romanian border in the vicinity of Chernotvsky, Fig. 3.1.1.2) (Somov, 1998). I Iowever, the scismicity and other available data do not suggest the existence of regional-scale faults that should be treated as significant discrete sources of hazard to the Ukraine NPPs. The maximum magnitude reported from Zones 1 and $2 b$ is 5.3 (1875, Kharitonov et al., 1996), so that the best estimate maximum magnitude of 6.5 is conservative.

\section{Zone 3: Zakarpatye}

Zakarpatye is possibly distinct in that the seismicity rate within this zone appears to be appreciably higher than in the rest of the Eastern Carpathians (Fig. 3.3.1.2). M. Lazarenko suggested at the Kiev workshop that this might be partly due to the relatively dense seismic network in this region during recent years. However, most of the epicenters shown on Fig. 3.3.1.2 are not instrumental but are based on felt 
reports, many of which are described by Kharitonov et al. (1996), and a concentration of small, instrumentally located events is not evident in Fig. 3.1.1.3. The best estimate Mmax for this zone is 6.0, based on the largest reported historical event in 1778, estimated at M5.4 (Kharitonov et al., 1996). The largest instrumental magnitude for this zone is M4.3.

\section{Zone 4: Vrancea}

The tight cluster of intermediate depth $(>70 \mathrm{~km})$ earthquakes in the Vrancea zone continues to be the subject of intensive investigation. Four events having Mw greater than 6.9 have occurred during the last 50 years, and there have been three earthquakes this century greater than Mw7.2 (Wenzel et al., 1998). Assuming that the record of large earthquakes for the last 600 years is complete, the average recurrence interval for Mw6.8 and greater is about 20 years, and for Mw7.2 and greater about 35 years, in agreement with the estimates for this century (Wenzel, 1998). The largest earthquake recorded instrumentally was Mw7.7 in 1940 (Onescu and Bonjer, 1997), and the largest historical event reported was the Mw7.8 earthquake in 1802 (Onescu and Bonjer, 1997, based on Purcaru, 1979).

The instrumentally recorded intermediate-depth earthquakes at Vrancea are tightly constrained to a volume only $70-80 \mathrm{~km}$ in length, 30-40 km wide and between the depths of 70 and $230 \mathrm{~km}$; events larger than Mw6.5 have been confined to the $70-180 \mathrm{~km}$ depth interval. The main issue concerning Vrancea posed at the Kiev workshop was whether the intermediate depth seismicity is restricted to the volume defined by the instrumental seismicity, which then constitutes a well defined source zone, or whether there is a possibility that such events could occur elsewhere along the Carpathian arc to the NE. The results of recent seismic tomography and hypocenter relocation studies (Fan et al. 1998; Wenzel et al., 1998) strongly favor the former. The Vrancea intermediate depth hypocenters define a plane that strikes $\mathrm{NE}$ and dips almost vertically to the NW. All of the earthquakes are coincident with a high-velocity zone imaged in three-dimensional P-wave velocity models that has the same strike and dip as the plane defined by the hypocenters. These are exactly the characteristics that delineate active island arc subduction zones, and strongly supports the interpretation that the earthquakes occur within a Benioff zone that defines a slab of NW-subducting lithosphere, imaged directly as high velocity (cold) material. However, the alongstrike length of the high velocity zone is roughly the same as, or only slightly larger than, that of the seismicity distribution. This supports earlier interpretations that only a small remnant fragment of lithosphere is subducting under Vrancea and that subduction has ceased along the rest of the Carpathian arc, in agreement with the generally interpreted tectonic history of the arc. Therefore, we define the Vrancea source zone within the crustal volume defined by the intermediate depth seismicity, and restrict the seismicity throughout the surrounding Eastern Carpathian zone to crustal depths, as described above.

The origin of the subducting fragment and the mechanics of this terminal phase of subduction remain the subject of debate. The most recent studies suggest that the subducting slab is either a small fragment of oceanic lithosphere that was formerly located between the East European platform and the Moesian continental sub-plate (Fig. 3.1.1.1) (Royden and Burchfiel, 1989; Linzer, 1996); or the last of the oceanic plate that preceded continental lithosphere into the subduction zone (Fan et al., 1998; Wenzel et al, 1998). Fan et al. propose that the oceanic fragment remains attached to the lower part of the Moesian subplate. Wenzel et al. suggest that the deeper part of the oceanic slab was formerly attached to the westward-subducting European plate but now remains attached only to younger NW-subducting oceanic material that is in turn attached to the subducted Moesian sub-plate.

We select the largest reported historical magnitude, Mw7.8, as our best estimate of the maximum magnitude for the Vrancea source zone. An upper bound magnitude can be estimated by assuming that a single event ruptures the entire $110-\mathrm{km}$ down-dip width of the slab, which yields a rupture area of 8,800 $\mathrm{km} 2$. Using the empirical magnitude-rupture area relationship for reverse faults of Wells and Coppersmith 
(1994), this corresponds to a mean magnitude of Mw8.0. However, Onescu and Bonjer (1997) showed that the events since 1940 have ruptured separate depth segments of the zone, and, based on the earthquake record for the last millennium, these authors conclude that even events as large as the 1802 earthquake, which might rupture at most one or two adjacent segments, are likely to be very rare. Therefore, we consider that Mw7.9 is a conservative choice of the upper bound on Mmax.

Dobrogea, northern Black Sea, Crimea, Kerch Peninsular, and NW Caucasus

The Alpide thrust belt (Kimmerides) extending from Dobrogea (Fig. 3.1.1.1) across the mountains of southern Crimea and the Kerch and Taman Peninsulars to the NW Caucasus (fig. 3.1.1.1) defines a tectonic zone of low to moderate present-day activity. Deformation within this belt results from a minor component of slow convergence of Black Sea lithosphere in a generally northerly direction (ISMES, 1990; Saintot et al., 1998). Seismic activity in the region extending from offshore the western Crimea coast along the Kerch and Taman peninsulars is ascribed to deformation caused by underthrusting of the Black Sea lithosphere beneath the Neogene Alpide fold/thrust belt and accretionary wedge in a NW-NNW direction (ISMES, 1990). The direction of underthrusting rotates to NNW-NNE under the NW Caucasus. The complex residual deformation of the NW Black Sea and Dobrogea is presently poorly understood.

Definition of seismic zones in the Crimea-Caucasus region is described in considerable detail in the Crimea NPP seismic hazard report prepared by ISMES (1990). We have adopted the ISMES zone definitions for W. Crimea (Zone 6), deformed Black Sea plate (Zone 8), and Yalta (Zone 9). In view of the large distances of all of these zones from the ncarest NPP sitcs, we have amalgamated the remaining, less active zones defined by ISMES (S. Kerch Peninsular, Anapa, Crimean Mountain, Kerch StraitTaman Peninsular, and fore-Caucasus) into a single Crimea-Kerch-Caucasus zone (Zone 7). The definition of the Dobrogea-N.W. Black Sea zone (Zone 5) was adopted from Tacis (1997). None of these zones make a significant contribution to the hazard at any of the NPP sites, so they are only briefly summarized below.

\section{Zone 5: Dobrogea-NW Black Sea}

The rate of activity within this zone is significantly lower than that further to the west, but a few moderate events have been reported from Dobrogea (Fig3. 3.1.1.2, 3.1.1.3). The maximum observed magnitude for this zone is estimated as 6.4 (1865). We assign a maximum magnitude of 6.5 and a maximum upper bound magnitude of 6.8 .

\section{Zone 6: W. Crimea}

ISMES (1990) identify earthquakes within this zone associated with transpression along right-lateral tear faults in the shallow crust in addition to compressional events at the main detachment surface between the underthrusting Black Sea crust and the Alpide fold/thrust belt. We estimate a maximum magnitude mode of 5.8 with 6.2 upper bound for this zone based on the maximum recorded magnitude (lower bound) of 5.7 (1957).

\section{Zone 7: Crimea-Kerch-Caucasus}


ISMES describe deformation and seismicity within the five original zones that make up this combined zone as ranging from relatively minor shallow activity along the S. Kerch Peninsular to moderate deeper compressive and transpressive activity associated with the main underthrust contact. The largest earthquake reported in the combined zone is estimated as M5.8 (63BC).

\section{Zone 8: Deformed Black Sea Plate}

Deformation seaward of the Crimean fold/thrust system is ascribed in part to normal faulting within the Black Sea crust where it bends downward to underthrust the Alpide system. Moderate seismicity within this zone extends to depths more than $30 \mathrm{~km}$. The maximum magnitude recorded in this zone was 5.8 (1966).

\section{Zone 9: Yalta}

This small zone contains the most intense seismicity and largest earthquakes recorded along the entire Dobrogca-Crimea-Caucasus belt. ISMES propose that relatively intense deformation is concentrated here along the upper edge of the underthrusting Black Sea plate where the plate experiences its maximum bending and where it incorporates the strong, brittle rocks comprising the Mid-Black Sea Ridge(Fig. 3.1.1.1). The maximum event recorded in this zone was the M6.8 1927 earthquake.

\section{East European Craton}

All of the NPP sites are located within the Sarmatian block of the EEC, the ancient core of Europe that was assembled during the Paleoproterozoic. The basement of the Sarmatian block comprises several welded Archean terranes (e.g. Bogdanova and Gorbatschev, 1998). In common with other Craton regions, the very low rate of seismicity and absence of known young deformational structures attest to the longterm stability of the interior of the EEC. This is also indicated by recent finite element modeling (Tacis, 1997), which suggests a very low strain rate within the Ukrainian interior. The largest observed event in the EEC was M4.8 (1954) which is our selection for the lower bound for $\mathrm{M}_{\max }$, and 5.3 for the upper bound.

\section{Zone 10: Pripyat-Dniepro-Donnets Rift}

The Pripyat-Dniepro-Donets Rift (PDDR) is the largest rift structure within the EEC and comprises three sub-basins; the shallow Pripyat trough, the deep Dniepro-Donnets basin, and the partially inverted Donates segment (Stovba et al., 1996; van Wees et al., 1996). The main rifting phase initiated during the Devonian, and the last major extensional episode occurred during the Carboniferous and Permian. The rift system has been the subject of intensive geophysical and geological studies, which include more than 3000 line-miles of deep seismic sounding, oil and gas exploration, and drilling as deep as $6 \mathrm{~km}$. The main rift bounding faults dip at $70^{\circ}-80^{\circ}$. Up to $4 \mathrm{~km}$ of normal displacement occurred on the main faults during the major rifting phases. Tectonic reactivation of the rift faults is often revealed by large-scale salt diapirism. Based upon such evidence, Stovba et al. (1996) suggested that faults were locally reactivated under a compressional stress regime during the late Cretaceous to early Paleogene, although some of the Kiev workshop participants consider it more likely that the compressional deformation seen on seismic 
sections was the result rather than the cause of salt diapirism, which may have initiated with extension at mid-crustal depths.

The PDDR formed a major topic of discussion at the Kiev workshop because of its similarity to other preCenozoic rifts worldwide, which a detailed study by Johnston et al. (1994) shows to be strongly correlated with the occurrence of large earthquakes within stable continental interiors (SCR) (see Fig.4.3 of the Johnston et al. report for the definition of SCR), and hence must be carefully evaluated as potentially significant earthquake sources. Johnston et al. showed that SCR earthquakes are strongly concentrated in pre-Ncogenc extended crust, and are caused predominantly by compressional reactivation of normal faults. Extended crust represents only $28 \%$ of SCR crust worldwide, but contains all SCR earthquakes greater than $\mathrm{M} 7$ and $68 \%$ of those greater than M6; the highest seismicity occurs in extended crust that has experienced additional later extension or later orogeny. The correlation is strongest for Mesozoic-Cenozoic rifts, which contain all historical earthquakes greater than 7 , but it is also significant for Paleozoic rifts, such as the Southern Oklahoma aulacogen (Holocene surface faulting and paloearthquakes of about M7) and the Ottawa rift (Mw6.9 1925 earthquake) (see also Wheeler, 1998).

The Paleozoic PDDR shows evidence for reactivation during the Cretaceous-Paleogene, and so fits the criteria for it to be considered as a potential seismic source. It is favorably oriented for compressional reactivation within the current regional stress field (the stress field is not well determined, however). The seismicity rate within the rift is extremely low (Fig. 3.3.1.2), but this is common to many of the active rifts studied by Johnston et al. Therefore, the PDDR discussion at the workshop focused on possible surface and subsurface evidence for Holocene-Quaternary faulting. There appears to be no definite evidence for active, large-scale Holocene-Quaternary surface faulting within the PDDR, but this is commonly the case for active or potentially reactivated rifts worldwide. Strakhov et al. (1997) reported that regional-scale fault zones in the Chernobyl vicinity may have been active in the Neogene-Quaternary, and appear to be associated with a concentration of microearthquake activity. However, no assessment is given by these authors of whether these fault systems are presently capable of producing significant earthquakes, as opposed to localizing the low-level deformation they describe. The deep subsurface within and surrounding the PDDR has been studied much more intensively than in most rifts (e.g. Wheeler, 1998), and evidence for large Quaternary fault offsets at depth has not been reported. Prominent faults clearly offset pre-Mesozoic horizons in deep seismic sections such as those discussed by Stovba et al.,1996, but do not offset Cenozoic horizons.

Based on the relatively abundant data available, there appears to be no evidence for Holocene-Quaternary reactivation of major PDDR faults, and there is no record of large earthquakes within the interior of the EEC. However, given the very low strain rate indicated by the Tacis (1997) finite element modeling and generally assumed within craton interiors, large earthquakes would be expected to be very rare events, with recurrence intervals on the order of 104 years or longer (see, for example, Savy and Foxall, 1998). Therefore, we admit the possibility of earthquakes as large as Mw7.5 [by analogy with the South Oklahoma aulacogen (Savy and Foxall, 1998)] within the PDDR, but assign them a probability of existence (i.e. confidence level) of only $1 \%$. This combined with the very long recurrence interval of $10^{4}$ years that was assumed for these events mean that they have a negligible effect on the hazard at any of the NPP sites.

In the calculations, this $1 \%$ weighted zone is identified as Zone 14 and the other more likely alternative is Zone 10.

\section{Zone 11: East European Craton}


The stable EEC is the host source zone for all of the NPP sites. According to the CIS catalog, the seismicity rate is somewhat higher towards the SW margin of the craton, adjoining the Eastern Carpathian zone (Fig. 3.3.1.2). Therefore, the western EEC within Ukraine is treated as a separate source zone (Zone 2a). The maximum event reported for Zone 11 within $700 \mathrm{~km}$ of any of the plants is M4.8 (1954). The best estimate Mmax of 5.0 for this zone reflects the very sparse activity within all but the western EEC.

\section{Zone 2a: Western EEC}

The largest event reported in the catalog for the Western EEC zone has an estimated magnitude of 4.8 (1842), based upon which a best estimate Mmax of 5.3 is assigned .

\section{Zone 12: Black Sea background}

All of the seismicity and tectonics information available was used to define the sources of earthquakes in the active zones of the Dobrogea- West Black Sea, West Crimea, Crimea-Kerch-Caucasus, Yalta and Deformed Black Sea Plate (Zones 5, 6,7, 8 and 9). Therefore, these zones constitute the model that explains all the data, but since there is no evidence that earthquakes similar to those in Zone 5 could not occur in the rest of the Black Sea area a background zone was created. The probability distribution of the $\mathrm{M}_{\max }$ is therefore the same as for Zone 5 but the low observed seismicity in zone 12 leads to very low seismicity rates correspondingly.

\section{Zone 13: Vrancea Shallow events}

7one 4 models the area where frequent deep events of magnitude between M5.5 and M7.9 occur. Zone 13 is intended to account for the remaining events of smaller magnitudes that occur in the shallow portion of the crust in that same area. Its $M_{\max }$ probability distribution has a mode (M5.3) lower than the minimum (M5.5) magnitude range for the deep large events, and its upper bound (M6.0) overlaps with it.

\section{Zone 14: Pripyat-Dniepro-Donnets Rift (Large rare events)}

Zone 10 actually models the occurrence of events for the most likely alternative ( $99 \%$ of the weight) which is that this area is not distinguishable from the European Craton. Zone 14 models the second and less likely alternative (1\% of the weight) described above in the discussion on Zone 10.

\subsubsection{Uncertainty in the seismic source zones maps}

Each of the seismic sources described above is one possible representation of an area, or a physical structure of where earthquakes are believed to be likely to occur in the future, based on our understanding of the geology, the tectonics, the observed seismicity and all other relevant information that can be collected. Although the hazard at the Ukraine NPPs is likely to be governed by very few sources, and given the relative lack of features in the general areas around the NPPs, there was a need to express the uncertainty on the geometry of some of the regional seismic sources. The main uncertainty in the seismic sources map appears to be in the determination of whether zones $2 a, 5$ and 10 are distinct from the underlying EEC background or not. Other distant zones such as Vrancea and W. Crimea are so far from 
the NPPs that their shape and small variations in their exact location do not affect the estimate of the hazard at the sites. This point was discussed at the workshop and the experts were asked to estimate the relative weight that they would give to each of the possible pairs of alternatives. Zone $2 \mathrm{a}$ was believed to be three times more likely to be distinct from the background than to be undistinguishable from it. Thus we assigned a weight of $75 \%$ to the model where Zone $2 \mathrm{a}$ is distinct, $25 \%$ to the model where it is an integral part of the background. Similarly, the Dobrogea zone was assigned $80 \%$ for being distinct and $20 \%$ for being part of the background and the PDDR was given $99 \%$ for being distinct and $1 \%$ for being part of the background.

\subsubsection{Seismicity rates in the seismic source zones (SSZ)}

Following the general approach described in the SSHAC report (SSHAC 1997) for this study, the seismicity rates were established in a three-phase operation.

First, we evaluated the available catalogues of earthquakes for the region of interest including the Russian catalogue (SSR), and the NOAA's catalogue in addition to the information directly available at LLNL. We constructed a subset of these catalogues appropriate for this study by ensuring that there were no repetitions, no mining events and that all reported events were in the final subset.

Second, we sorted the events in the catalogue into data files of events contained in each of the seismic source zone described in the previous section and we plotted the logarithms of the cumulative number of events versus the magnitude. For each of the SSZ, we first plotted the data alone for all the magnitudes available in the catalogue. A least square fit was then performed on the data for several values of the minimum magnitude in order to evaluate the degree of incompleteness of the data and to obtain several preliminary estimates of the seismic for estimating the knowledge uncertainty.

Third we used the above input, information collected in the literature, discussions at the workshop and our expcrience from previous studies to determine the parameters of the probability density function of the seismicity rates for each SSZ. The parameters of interest for each SSZ were:

- $f(3.5)$, the number of events greater than magnitude 3.5 occurring per year in the source zone,

- $f\left(m_{1}\right)$, the number of events greater than $m_{1}$ occurring per year in the source zone. Where $m_{1}$ is an arbitrary magnitude value, greater than 3.5 and smaller than the maximum ever possible in the zone $\left(\mathrm{M}_{\max }\right)$.

$-\mathrm{M}_{\max }$, the maximum magnitude possible for the source zone.

For each of the two magnitude values, 3.5 and $\mathrm{m}_{1}$, a triangular distribution of the annual rates of occurrence was determined. The parameters of the triangular distribution functions were, the Mode, a lower bound and an upper bound.

The uncertainty in $\mathrm{M}_{\max }$ was also expressed with a triangular distribution, the parameters of which, mode, lower bound and upper bound, were determined mostly from tectonic considerations, as explained in section 3.3 above.

For the Vrancea deep events several detailed studies are available which enabled us to have a more detailed comparison as shown in Figure 3.3.1.3.6. The estimates presented in Figure 3.3.1.3.6 are taken from studies which include the study by Androne, 1998, and 1996, personal 
communications, a study by Trifu and Shumela, 1996, a study by Radu et al and results of research presented in EOS, 1998.

The results of this three-phase operation are summarized in Table 3.3.1.3.1 and in Figures 3.3.1.3.1 to 3.3.1.3.14.

\subsubsection{Ground Motion Attenuation Characterization}

\subsubsection{Ground Motion Models selection}

In this section, we document the selection of the appropriate ground motion model to be used in the study. We compared several recent models and selected different models depending on whether the seismic energy was initiated in a crustal environment similar to the eastern European craton, the shallow portion of the Vrancea zone (less than $100 \mathrm{~km}$ in depth) or from the deep earthquakes of the Vrancea zone.

We reviewed the models available for the stable region of North America and those for deep sources for which estimates of the uncertainty exist. Very few models available are applicable for Eastern Europe. A number of models have been developed recently for studies around Romania and for the Chernobyl site which take into account the inhomogeneity of the earth crust (ISMES, 1997 and Androne, personal communication, 1998). The Romanian models were developed with specific data relevant to the seismic activity of the Vrancea area and the seismic zones around Romania.

The models selected for this study are described below and compared in Figures 3.3.2.1 through Figures 3.3.2.12.

Case of the earthquakes other than at Vrancea:

In recent years, ground motion relations describing peak ground motion and response spectra for eastern North America (ENA) and central North America (CNA) have been dominated by the use of physical modeling and stochastic models (e.g., Atkinson and Boore 1993; Boore and Atkinson 1987; EPRI 1988; Toro and McGuire 1987; and Toro et al. 1997). Two equally weighted sets of attenuations were used in a recent study of the stable region of Eastern North America by the USGS (USGS , 1996). Stochastic simulation and random vibration theory were used to derive both sets of relations. The first (Toro et al. 1993) was a rock site model based on $m_{b L}$, and the second set was a firm rock site model derived by USGS based on a Brune source model with a stress drop of 150 bars.

The model developed by Atkinson and Boore, 1995, (from here called AB95) did provide an estimate of the epistemic uncertainty by adding a constant variance obtained from previous studies to the aleatory variance. In the Toro, Abrahamson and Schneider 1997 model, titled "Model of Strong Ground Motions from Earthquakes in Central and Eastern America: Best Estimates and Uncertainties" (from here called TAS97), the associated uncertainties are derived by considering the uncertainties in parametric values in the numerical simulations, as well as the uncertainties associated with the ground motion itself. Ad hoc probability distribution functions were assumed for the distribution of the uncertain parameters. In the USGS, 1996 study, the epistemic uncertainty was considered with the use of a range of models selected in an ad hoc fashion and assigned equal weights.

Italian strong motion data were used in a study by Sabetta and Pugliese, 1987, to develop median attenuation curves for a range of soil site conditions in Italy. The data consisted of 190 horizontal components of accelerograms recorded from 17 earthquakes in Italy since 1976 and ranging from 4.6 to 
6.8 magnitudes $\left(\mathrm{M}_{\mathrm{s}}\right.$ for greater than $5.5, \mathrm{M}_{\mathrm{L}}$ otherwise). The prediction equation provides the aleatory uncertainty only as the standard error on the logarithm of the ground motion value.

\section{Case of the earthquakes from Vrancea:}

The Atkinson and Boore model developed for the Cascadia region of the Western United States, for rock sites, (Atkinson and Boore, 1997), uses a stochastic model approach. The model is based on the Brune point source with a stress parameter of 50 bars. The model were compared to ground motion data from Cascadia region but no data from large subduction zones in other regions. The equation derived were deemed adequate for predicting motion from large events in the magnitude $\left(M_{w}\right)$ range and conservative, i.e. overpredictive, for the very large events at distances less than $100 \mathrm{~km}$. Since the Vrancea zone is more than several hundreds of kilometers from any of the five sites in Ukraine, we considered this model as appropriate for this study. The authors provide a detailed analysis of the aleatory uncertainties for their model.

The ISMES model was developed for the Chernobyl study (ISMES, 1997). It relied on a worldwide set of recordings from 91 events having depths in the range of 100 to $150 \mathrm{~km}$, very similar to the Vrancea zone. The region of origin of these events includes Vrancea itself, Taiwan, Papua-New Guinea, Japan and the Cascadia area. A standard multi-linear regression was performed to obtain the median attenuation curve from these data.

The Romanian models were developed recently for the characterization of the seismic hazard at the site of the Romanian nuclear power plant. A special attention has been given to the directivity of the attenuation showing different attenuation rates in the direction NW-SE as NE-SW specifically from the Vrancea earthquakes. It is also the only set of models we found that differentiates betwcen shallow and decp Vrancea events (Androne, personal communication, 1998). These models do not provide detail uncertainty estimates.

The following models were selected

- BA95, Atkinson and Boore, 1995

- $\quad$ SP87, Sabetta and Pugliese, 1987

- TA97, Toro and Abrahamson, 1997

- $\mathrm{AB} 97$, Atkinson and Boore, 1997

- ISMES97, ISMES, Chernobyl Study, 1997

- ROM1, Androne, personal communication, 1998

- ROM3, Androne, personal communication, 1998,

as representative of the most recent models of ground motion prediction for the sites in Ukraine. In the final selection, our purpose was to select models that, for use in the hazard calculation, would incorporate the opinion of the committee of ground motion modelers, including the epistemic uncertainty associated with it, without being biased with over-conservatism or under-estimation of the ground motion.

\subsubsection{Knowledge uncertainty in the ground motion model selection}

Uncertainty in the hazard calculations stems from the random, also called aleatory, uncertainty in the physical process itself and from our lack of total knowledge in this process. The knowledge uncertainty, 
also called epistemic uncertainty, is dealt with by selecting a range of models that the scientific community would agree, include the range of viable models and, following the SSHAC approach (SSHAC, 1997), assigning weights to the models. The task of assigning these weights is delicate and relies on an evaluation of the models, how well they explain the data, how well they have been analyzed, peer reviewed, documented and a certain degree of subjectivity on the part of the analysis team.

In this section we develop the arguments in support of the weighting scheme used in this analysis. The resulting weights are presented in Table 3.3.2.1.

We compared the seven peak ground acceleration prediction models for three magnitudes: $M_{w}=4,5,6$ and 7 , corresponding to $\mathrm{m}_{\mathrm{bLg}} 3.7,5.5,6.3$ and 7 as obtained by the relation:

$$
\mathrm{M}_{\mathrm{w}}=2.715-0.277 \mathrm{M}_{N}+0.127 \mathrm{M}_{N}^{2} \quad \text { (Boore and Atkinson 1987) }
$$

where

$\mathrm{M}_{\mathrm{N}}$ is the magnitude scale developed by Nuttli, and is equal to $\mathrm{m}_{\mathrm{bLg}}$.

AB95, BA97 and TA97 use the $M_{w}$ scale. SP87, ISMES97 ROM1 and ROM3 use local magnitudes for small events and $M_{s}$ for large events.

The models have been grouped into three groups:

- Group 1, Models for events other than Vrancea,

-BA95

-SP87

-TA97

- Group 2, Models for deep Vrancea events,

-AB97

-ISMES97

-ROM1

- Group 3, Models for shallow Vrancea events.

-BA95

-SP87

-TA97

-ROM3

Figures 3.3.2.1 through 3.3.2.12 show the models for the median estimates of the PGA in $\mathrm{cm} / \mathrm{s} / \mathrm{s}$ as a function of the distance for $\mathrm{M}_{\mathrm{w}}=4,6,7$ and $\mathrm{m}_{\mathrm{bLg}}=3.7,5.5,6.3$ and 7, respectively. The first four figures are for the events of Group 1, the next four are for Group 2, and the last four are for Group 3.The figures show a remarkable degree of agreement in groups 1 and 3. For the distances of interest, the BA95 model sits well in the middle of the set, but for the deep Vrancea earthquakes of group 2, it predicts higher accelerations for short distances, and an order of magnitude smaller accelerations for distances in the range of 400 to $700 \mathrm{~km}$, as compared to the other two models at magnitude 4, (see Figure 3.3.2.5). At large magnitudes, ROM1 is approximately an order of magnitude higher than ISMES97 and AB97 is an order of magnitude lower. In our opinion, the level of documentation provided in the literature for the AB97 model lead to a high level of credibility. The ISMES97 model was developed with world data and deserves also a high level of credit and given that ROM1 has been only obtained by private 
communication, without the benefit of a peer review, we decided to assign a lower weight to that model than to the other two.

Overall for all the other magnitude ranges and for both Group 1 and Group 3, the models span a reasonable range of prediction values and lead to a level of knowledge uncertainty consistent with our previous studies in the United States (Savy et al, 1998, Savy and Foxall, 1998.) For Group 2, we feel comfortable that the range of possibilities is adequately covered by the three models selected, with AB97 and ROM1 providing reasonable lower and upper bounds, respectively.

To express our belief, as a proxy of the belief of the entire scientific community, that each of the models was appropriate to Ukraine, the Craton and the Vrancea area, we used a combination of each of the models in each group by assigning a weight to each. The weights expressed the degree to which each of the models represented the available data for the Ukraine Craton (stable region), the Vrancea deep and Vrancea shallow area, and the level of documentation, review and challenge that each had been subjected to. These weights, which express our knowledge uncertainty, are summarized in Table 3.3.3.1 and the equations for each of the models are given in Table 3.3.3.2.

\subsubsection{Aleatory uncertainty in the ground motion predictions}

The aleatory uncertainty is that uncertainty which, if we were using the absolute correct median estimate attenuation model, would express the variability in the prediction for a given magnitude and distance. For a model derived empirically from data collected in observed events, this uncertainty is represented by the residuals from a best-fit calculation.

In this study, we used the estimates of the standard deviation obtained by Atkinson and Boore, 1995 for the Craton models, the estimates obtained by Atkinson and Boore, 1997 for the deep Vrancea events and the estimate obtained by the Romanian study, (Androne, personal communication, 1998), for the shallow Vrancea events. We used the ranges of values considered appropriate in the United States, Central and Eastern U.S., to express the knowledge uncertainty. For the case of the shallow Vrancea events for which the Romanian study shows a much larger standard deviation, we used a slightly larger value anchored on the Romanian mean estimate and with larger range.

The values used for the standard deviation on the common logarithm of the acceleration prediction are summarized in Table 3.3.2.3.

\subsubsection{Spectral attenuations and spectral shapes}

The standard approach in the United States is to select a range of ground motion models representing several frequencies of the response spectrum. Typically 5 to 10 frequencies are considered. The results of the hazard analysis is then a set of Uniform Hazard Response Spectra, one for each return period, in which the site specificity is reflected by applying site correction factors which are calculated from the geotechnical information on the top layers above bedrock at the site. The parameters necessary to characterize the site are: the stratigraphy and mechanical properties of the materials in those top layers, such as the $\mathrm{G}$ modulus, the material damping as well as their variation as a function of strain.

For this study, we were able to obtain data on the local site conditions for Chernobyl, Rivne and SouthUkraine. Some of this data were obtained at the workshop, in Kiev, and some of it is taken from the two studies performed by ISMES.

The most complete description available to us is for Chernobyl for which a detailed stratigraphy and soil material properties are given in a study funded by the European Commission (ISMES, 1997). Table 3.3.2.4 gives a representative average of those soil conditions. 
For the South-Ukraine site, the Status Report, SUSA-200DL11E.XV1 was used. Revision 1 provides some information. The" basement of the reactor building foundation plate is [made of] granite gravel with some [small] insignificant inclusions of hard clays and sands of different grains". The reported G modulus of the granite gravel is $4.010^{7} \mathrm{~N} / \mathrm{m}^{2}$ varying from 3.8 to $5.810^{7} \mathrm{~N} / \mathrm{m}^{2}$. Assuming a generic volumic mass of $2000 \mathrm{~kg} / \mathrm{m}^{3}$ for the gravel gives a shear wave velocity of 120 to $183 \mathrm{~m} / \mathrm{sec}$, therefore equivalent to the top layer found at Chernobyl.

Mr. Sergiy Vyzhva provided the shear wave velocity of the top 30 meters at Rivne at the workshop in the form of a plot of $V_{s}$ as a function of depth. The lowest shear wave velocity near the surface is $200 \mathrm{~m} / \mathrm{sec}$ and monotonously increases to $1150 \mathrm{~m} / \mathrm{sec}$ at $38 \mathrm{~m}$ of depth. This makes this site different from Chernobyl and definitely stiffer, similar to a western U.S. rock.

For the other two sites, we were not able to acquire additional information on the local site conditions. Considering that the five sites are located on the European Craton, a stable geologic structure, the spectral shapes developed for the Chernobyl site were judged appropriate to be used for the other sites for which no specific information is available. Therefore the hazard calculations were performed for the PGA only and the review level earthquake was used to anchor the spectral shapes.

\subsection{Hazard Estimates}

\subsubsection{Description of the Sites}

The general location of the five sites in Ukraine is shown in Figure 3.4.1, with the coordinates used in the study. These coordinates are within a resolution of no more than $10 \mathrm{~km}$, but since the sites are located in areas of low to very low seismicity rates, and the hazard is dominated by distant earthquakes, the resolution of the location coordinates used here is adequate.

\subsubsection{Total Hazard at the Sites of the Ukraine Nuclear Power Plants: Nominal Case}

The analysis was performed using the ground motion models, the zonation maps and seismicity rates described in section 3.3. The results for rock site conditions at the foundation level are presented in figures 3.4.2.1 to 3.4.2.5 for each of the sites. In those Figures four hazard curves are shown which represent the $15^{\text {th }}, 50^{\text {th }}, 85^{\text {th }}$ percentiles of the hazard and the arithmetic mean hazard curve. The horizontal axis is in terms of peak ground acceleration (PGA), in $\mathrm{cm} / \mathrm{sec} / \mathrm{sec}$, and the vertical axis gives the annual probability of exceedance of the PGA. These hazard curves are obtained by considering all the possible events, which can generate the PGA, weighted by their respective rates of occurrence and including the unccrtainties. Figure 3.4.2.6 shows the mean hazard curves for the five sites and the results are tabulated in table 3.4.2.1. These results are also summarized in Figure 3.4.2.7 that show the review level earthquakes PGA $\left(\mathrm{cm} / \mathrm{s}^{2}\right.$ for the five sites and for the five return periods.

\subsubsection{De-aggregation of the Hazard}

The hazard estimates at the five site locations were de-aggregated to determine the relative contributions of magnitudes and distances to the total hazard to enable the calculation of the mean magnitude (M-bar) and mean distance (D-bar). M-bar and D-bar are interpreted, in the NUREG and DOE guidelines, as the parameters of a deterministic earthquake that would generate at the site the same ground motion as the ground motion associated with the hazard level selected. That is, if we select a hazard level of $10^{-4}$, i.e. a 10,000 year return period event, which from the mean hazard curve would lead to some PGA value, say $300 \mathrm{~cm} / \mathrm{s}^{2}$ for example, we calculate the average parameters (M-bar and D-bar) which contributed to this level of hazard. Then we would expect an earthquake of magnitude M-bar located at a distance D-bar from the site to generate a ground motion PGA of approximately $300 \mathrm{~cm} / \mathrm{s}^{2}$. 
This opcration was performed with a discrect sct of magnitude and distance intervals and the contributions were first calculated for each of the bins of distance and magnitude and for five hazard levels, namely for the 100-year, 500-year, 1000-year, 10,000-year and 100,000-year return period events. These results are shown in Figures 3.4.3.1 to 3.4.3.25 in a set of 3-D plots. The horizontal axes represent the distance from the site and the magnitude of the earthquakes and the vertical axis gives the contribution of each of the bins, distance-magnitude, to the total hazard. These figures show that the hazard is controlled by the seismicity in the regions around the sites for the low return periods. As the return period increases, the distant seismicity from large earthquakes takes over. Therefore for the large return periods, the contribution to the hazard is bipolar. (See Figures 3.4.3.3, 3.4.3.6, 3.4.3.9, 3.4.3.12 and 3.4.3.15.) Consequently, the single parameter (M-bar, D-bar) is not a good descriptor of the realistic contributing events and the spectral shapes to be considered in the design spectra will be an envelop of the regional and the distant spectral shapes, as explained in chapter 4.0.

This situation arises from the fact that the Vrancea seismic zone has a rate of occurrence very high as well as having very high upper magnitude cutoff.

\subsubsection{Sensitivity Analysis}

\subsubsection{Effect of the lower magnitude bound of integration}

Integrating from $\mathrm{m}_{\mathrm{bLg}}=5\left(\mathrm{M}_{\mathrm{w}} \sim 4.5\right)$ rather than 3.75 reduces the hazard estimates in the $10^{-2}$ to $10^{-3}$ hazard range. It does not reduce it in the range of interest between $10^{-3}$ and $10^{-6}$. The ground motion is reduced less than $1 \%$ at the $10^{-4}$ hazard level.

\subsubsection{Sensitivity to the weight given to the Pripyat Dniepro Donnets Rift (Large Events) (PDDRL)}

In the nominal calculations, the PDDRL is given a low weight Although low ( $\mathrm{W}=1 \%$ or lower), the weight on this alternative model did not exclude a possible substantial contribution for low to very-low hazard levels (i.e., $10^{-4}$ or lower annual probability of exceedance). We tested this hypothesis by virtually eliminating the PDDRL as a viable model, by dividing its weight by 10 . The results from this comparison do not show any difference in the estimated hazard. Therefore, in this probabilistic analysis, where the dominant contributions at large return periods comes in large part from the high recurrence rates and high magnitudes Vrancea seismic zone, the zones with moderate seismicity rate and/or low magnitude cutoff and/or low probability of existence do not contribute significantly to the hazard. In a deterministic context, this would not necessarily the case. 


\subsection{DESIGN PARAMETERS}

\subsection{Introduction}

The purpose of this study is primarily to establish a set of hazard curves for each Ukraine nuclear power plant sites to be used in a simplified PRA, and to establish a set of design parameters to be used as review level inputs (the Review Level Earthquake RLE or the Controlling Earthquake CE). The standard methods in the U.S. determined by the NRC (NUREG 1.165) and applied by the DOE (DOE STD-1023-95) call for a site-specific analysis which requires extensive knowledge of the soil properties at the site. Since that information was not available to us for all sites, at the time of the analysis, the method was modified for the circumstance. Instead of performing a full spectral hazard analysis, we performed the analysis with the best PGA attenuation models and we used the spectral shapes developed for a generic Craton in the Chernobyl study.

Since we are not calculating uniform hazard spectra (UHS), there is no need to compare them with a local site-specific spectrum at the two frequencies recommended in the standards (average of $1-2.5 \mathrm{~Hz}$ and average of $5-10 \mathrm{~Hz}$ ).

The design spectrum for a particular return period is the appropriate spectral shape (in all cases the spectral shape from a distant event in the Vrancea zone) anchored to the PGA corresponding to the return period. This spectral shape is derived from a distant large earthquake; therefore it emphasizes the low frequencies and contains very little energy at high frequency. Thus, in keeping with the spirit of the standards, an arbitrary deterministic scenario of a small to medium earthquake that could occur in the vicinity of the sites, at a reasonable rate, must be considered to ensure that high frequencies (in the $5-10 \mathrm{~Hz}$ range) are not underestimated. What is a "reasonable rate" is difficult to formalize. We followed common practice in the U.S. in selecting the maximum of earthquake magnitudes ever observed locally and locate it at $15 \mathrm{~km}$ from the site. For Chernobyl we relied on the ISMES study which used the same approach but used a catalogue of events around the site and from similar tectonic regions to determine the shape of the local events spectrum (ISMES, 1997.)

Given the lack of information on the soil site conditions, we also considered using the standard spectral shapes defined by the NRC in the NUREG-0098 document. Figure 4.1.1 shows the four spectral shapes considered for use in this study.

The shapes of the Figure 4.1.1 are normalized to 1g PGA and are as follows:

- $\quad$ Rock $0098=$ NUREG-0098 for generic rock conditions,

- $\quad$ Soil 0098 = NUREG-0098 for generic soil conditions,

- ISMES Far-field = Spectral shape defined in the ISMES 1997 study for Chernobyl for far field events of the deep Vrancea type,

- ISMES Near field = Spectral shape defined in the ISMES study for Chernobyl for near-field events.

Aside from the $5 \mathrm{~Hz}$ spectral value for the ISMES Far-field, which is above the standard 0098 spectra, the spcctra are fully enveloped by them. Consequently, we find it appropriate to use the NUREG 0098 spectral shapes for all sites were no soil data are available. For Chernobyl, it is appropriate to use the shapes developed specifically for that site. The data available for SouthUkraine and for Rivne support the selection of the generic soil and for the other two sites, Khmelnytskyy and Zaporizhzya, for lack of information we use the rock site conditions, which are the most conservative.

Summarizing, the six spectral shapes used in this study are:

- Chernobyl: ISMES 1997 two spectral shapes (Near-field and Far-field), 
- Khmelnytskyy: NUREG 0098 Rock condition,

- Rivne: NUREG 0098 Soil condition,

- South-Ukraine: NUREG 0098 Soil condition,

- Zaporizhzya: NUREG 0098 Rock condition.

\subsection{Application to Ukraine NPP sites}

The design criteria development followed these steps:

Step 1: We performed a PSHA for the sites, producing PGA mean, $15^{\text {th }}, 50^{\text {th }}$ (median) and $85^{\text {th }}$ percentiles hazard curves. The results of this step are shown in Figures 3.4.2.1 to 3.4.2.6.

Step 2: From the hazard analysis, we used the mean hazard curves to determine the level of ground motion (e.g., PGA) corresponding to the $10^{-4}$ hazard corresponding to the applicable hazard level defined in the US regulations for nuclear power plants and nuclear facilities (NUGEG 1.165 and DOE STD 1023-95).

Step 3: We de-aggregated the mean PGA hazard curve to determine the contribution of each selected bin of magnitude and distance.

Step 4: We determined the parameters, M-bar and D-bar, of the controlling earthquakes (also called the Review-level Earthquake) as the weighted average of magnitudes and distances, with the contributions used as weights and using bin-central values in calculations.

Step 5: We performed Step 4 for five return periods. The results of this step 3 are shown in Figures 3.4.3.1 to 3.4.3.25. The results of step 4 are summarized in table 3.4.2.1 which gives the magnitudes and distances for the controlling earthquakes, as well as the PGAs (in cm/sec/sec) for each return period and for each site. The return periods used in the analysis are 100 years, 500 years and 1000 years. They correspond to values used at the time of design of the NPPs in Ukraine, 1000 years and 10,000 years which are used for the design of nuclear facilities in the U.S. and 100,000 years is routinely calculated for checks on the trends.

Step 6: We developed the 5\%-damped design response spectrum for each of the controlling earthquakes of Table 3.4-2.1 for 100-year, 1000-year and 10,000-year return periods. We used the $84^{\text {th }}$ percentile spectral shapes described in section 4.1, shown in Figure 4.1.1, and anchoring them to the PGA corresponding to the desired mean hazard level. For example the NUREG 0098 spectral shape for soil conditions was anchored to a PGA $(33 \mathrm{~Hz})$ value of $196.0 \mathrm{~cm} / \mathrm{sec}^{2}$ for the 10,000 -year return period design spectrum at the South-Ukraine site.

The results for the five sites and for 100-year, 1000-year and 10,000-year return periods are shown in Figures 4.2.1, 4.2.2 and 4.2.3.

Since the Far-field events at Chernobyl generate a response spectrum above that of the Near-field events, we retain only the former.

\subsection{General comments on the design spectra results}

In a first examination of the results based only on the estimates of the hazard for the PGA on rock at the five sites, we found that the South-Ukraine site was the site exposed to the highest hazard. When we introduced the response spectral shapes we were obliged to make assumptions on the site conditions for those sites where no data was available. We adopted the current practice, which is to use the generic spectral shapes established by the NRC for those cases. 
Since the generic rock spectrum is higher than the generic soil and that furthermore theses two are higher than the empirical spectrum determined for the Chernobyl site by an amount greater than the ratio of the PGAs from the hazard curves, the ranking of the sites could be considered different now when examining the design response spectra, as shown in Figures 4.2.1 to 4.2.3.

Collecting data on the soil properties of each of the sites, except Chernobyl for which the information is already available, could help in reducing the design values for the 4 other sites.

\subsection{Comparison with Russian and IAEA rules}

\subsubsection{Russian rules for design of nuclear power plants at the time of design of the Ukraine NPPs}

The design rules for nuclear power plants at the time of design of the Ukraine plants distinguished two types of facilities:

- Facilities not necessary for the safety of the plant,

- Facilities, buildings and structures in which safety related systems are located constitute the category 1 .

Facilities not in category 1 are designed for a standard type of seismic events, the Design Earthquake (DE), which is defined by a "Repetition Time" of 100 years.

Facilities in Category 1 are design for a large rare event called the Maximal Calculated Earthquake (MCE) which is defined by a "Repetition Time" of 10,000 years.

The DE and MCE are defined in terms of Medvedev Sponheuer Karnic (MSK) intensity, which is the scale commonly used in Eastern Europe. For the ranges of intensities considered, the MSK scale is similar to the Modified Mercalli Intensity (MMI) scale used in the USA.

From the information available to us, we can estimate the range of PGA values that the design earthquakes correspond to for the South Ukraine NPP. The DE for South Ukraine was established as MSK V and the MCE as MSK VI. It is well known that there is no direct relationship between Intensities and PGA (Hershberger, 1956), but it is possible to determine a range of possible values from observed strong motion data. Trifunac (Trifunac, 1975) compiled Intensity-PGA relationships from 9 researchers, including Richter (1958), Medvedev and Sponheuer (1969). His correlation is shown in Figure 4.4.1.1 as two curves, which bound the range of observed PGA values. The range is approximately the size of one decade.

For MMI 5 the range of PGA values is from $10 \mathrm{~cm} / \mathrm{sec}^{2}$ to $100 \mathrm{~cm} / \mathrm{sec}^{2}$ and for MMI 6 the range is from $16 \mathrm{~cm} / \mathrm{sec}^{2}$ to $250 \mathrm{~cm} / \mathrm{sec}^{2}$. Our results are $54.5 \mathrm{~cm} / \mathrm{sec}^{2}$ and $196.0 \mathrm{~cm} / \mathrm{sec}^{2}$ for the 100 year and 10,000-year Return Period respectively.

Conversely, Figure 4.4 .1 .1 shows that a $196.0 \mathrm{~cm} / \mathrm{sec}^{2}$ acceleration could have been produced by an earthquake in the range of MMI intensity VI to anything greater than intensity VIII with a central value of about MMI VII.

It is therefore difficult to compare with results of previous studies because of the difference in the approaches, one being deterministic based on intensity data which does not correlate well with observed ground motion, and the other probabilistic based on actual recordings of strong ground motion. It can only be said that the two sets of results are not inconsistent with one another. 


\subsubsection{IAEA rules for establishing seismic design parameters.}

The IAEA rules, reprinted below, are taken from the Safety Guide No.50-SG-S1 which stipulates that two levels of earthquake severity should be considered and their application is clarified in the Safety Guide No.50-SG-S2:

- "SL-2 level corresponds directly to ultimate safety requirements. This level of extreme ground motion shall have a very low probability [note: In some member States, SL-2 corresponds to a level with a probability of $10^{-4}$ per year of being exceeded.] of being exceeded during the lifetime of the plant and represents the maximum level of ground motion to be used foOr design purposes. Its evaluation shall be based on the seismotectonic model and a detailed knowledge of the geology and engineering parameters of the strata beneath the site area.

Regardless of the exposure to seismic hazard, it is recommended that a design basis ground motion corresponding to the safety level SL-2 earthquake be adopted for every nuclear power plant. The recommended minimum level is a peak ground acceleration of $0.1 \mathrm{lg}$ (zero period of design response spectrum).

- The SL-1 level corresponds to a less severe, more likely [In some Member States, SL1 corresponds to a level with probability of $10^{-2}$ per year of being exceeded.] earthquake load condition which has a different safety implication than SL-2."

The IAEA recognizes that the methods used to establish the earthquake levels can be either deterministic or probabilistic. The general approach would therefore be similar to the NRC Appendix A (Deterministic case) or similar to the approach used in our study for the estimation of the seismic hazard (Probabilistic case). 


\section{REFERENCES CITED}

Atkinson, G. M. and D. M. Boore. "Ground Motion Relations for Eastern North America," Bull. Seis. Soc. Am., Vol. 85, no. 1, pp. 17-30, February 1995.

Bernreuter, D. L., A. Boissonnade, and S. Short. "Investigation of Techniques for the Development of Seismic Design Basis Using the Probabilistic Seismic Hazard Analysis," NUREG/CR-6066 (UCRL-ID-128920), October 1997.

Bernreuter, D. L., J. B. Savy, R. W. Mensing and J. C. Chen. "Seismic Hazard Characterization of 69 Nuclear Plant Sites East of the Rocky Mountains," NUREG/CR-5250, Vols. 1-8, 1988.

Bogdanova S.V., and R. Gorbatschev. "EUROBRIDGE-1998: Results and Outlook". Geofizicheskiy Zhurnal, 20, 60-63, 1998.

Boore, D. M. and G. M. Atkinson. "Stochastic Prediction of Ground Motion and Spectral Response Parameters at Hard-Rock Sites in Eastern North America," Bull. Seis. Soc. Am., Vol. 77, pp. 440-467, 1997.

Department of Energy. DOE Standard, "Natural Phenomena Hazards Performance Categorization Guidelines for Structures, Systems, and Components," DOE-STD-1021-96, January 1996.

EPRI. "Engineering Model of Earthquake Ground Motion for Eastern North America," EPRI NP-6074, Electric Power Research Institute, Palo Alto, California, 1988.

EPRI. "Seismic Hazard Methodology for Central and Eastern United States," EPRI NR-4726, Electric Power Research Institute, Palo Alto, California, Vols. 1-10, 1988.

EPRI. "Guidelines of Determining Design Basis Ground Motions," EPRI-TR-1022931193, Electric Power Research Institute, Palo Alto, California, Vol. 1, 1993.

Fan, G., T. Wallace, and D. Zhao. "Tomographic Imaging of Deep Velocity Structure Beneath the Eastern and Southern Carpathians, Romania: Implications for Contincntal Collision". J. Geophys. Res., 103, 2705-2723, 1998.

Frankel, A. et al. "National Seismic-Hazard Maps: Documentation," USGS Open File Report 96532, Denver, Colorado, June 1996.

Hershberger,J. "A comparison of Earthquake Accelerations with Intensity Ratings", Bull, Seism. Soc. Am., Vol.46,pp.317-320, 1956.

International Atomic Energy Agency: "Earthquakes and Associated Topics in Relation to Nuclear Power Plant Siting" Safety Guide No. 50-SG-S1 (Rev.1), Vienna, Austria, 1991. 
Johnston, A.C., K.J. Coppersmith, L.R. Kanter, and C.A. Cornell. "The Earthquakes of Stablc Continental Regions, Volume 1: Assessment of Large Earthquake Potential". Prepared for the Electric Research Power Institute, Palo Alto, California, 1994.

Kharitonov, O., O. Kostyuk, V. Kutas, P. Pronishin, and I. Rudenskaya. "Seismicity of the Ukraine Territory", Institute of Geophysics, Ukraine National Academy of Science, Kiev, (preliminary translation), 1996.

Kondorskaya, N.V., and N.V. Shebalin, Catalog of strong earthquakes in the U.S.S.R. from ancient times through 1977, Report SE-31, World Data Center A for Solid Earth Geophysics, Boulder, Colorado, USA, 608 p., 1982.

Linzer, H-G. "Kinematics of Retreating Subduction along the Carpathian Arc, Romania". Geology, 24, 167-170, 1996.

Lawrence Livermore National Laboratory. "Seismic Hazard Characterization of the DOE New Production Reactor Sites. Vol. 3: Application to the SR Site, South Carolina," report for the Department of Energy by J. Savy, D. Bernreuter, J. C. Chen, B. C. Davis, J. Ueng, and C. Short, NPR92-147JBS, Rev. A Draft, March 31, 1992.

National Geophysical Data Center/National Earthquake Information Service, Seismicity Catalogs, Volume 2: Global and Regional, 2150 B.C.-1996 A.D., CD available from NOAA NGDC, Boulder, Colorado, USA, 1996.

NEHRP. Recommended Provisions for Seismic Regulations for New Buildings and Other Structures, Part 1: Provisions (FEMA 302), National Earthquake Hazards Reduction Program, prepared by the Building Seismic Safety Council, 1997

Onescu, M-C., and K-P Bonjer. "A Note on the Depth Recurrence and Strain Release of Large Vrancea Earthquakes". Tectonophysics, 272, 291-302, 1997.

Purcaru, G. "The Vrancea, Romania, earthquake of March 4, 1977 - a quite successful prediction". Phys. Earth and Planet. Inter., 18, 274-287, 1979.

Royden, L., and B.C. Burchfiel. "Are Systematic Variations in Thrust Belt Style Related to Plate Boundary Processes? (the Western Alps versus the Carpathians)". Tectonics, 8, 51-61, 1989.

Saintot, A., J. Angclier, A. Ilyin, and O. Goushtchenko. "Reconstruction of Paleostress Fields in Crimea and the North West Caucasus, Relationship with Major Structures". In "Peri-Tethys Memoir 3: Stratigraphy and Evolution of Peri-Tethys Platforms, S. Crasquin-Soleau and E. Barrier, Eds., Mem. Mus. Natn. Hist. Nat., Paris, 177, 89-112, 1998.

Savy, J.B., W. Foxall, and D.L. Bernreuter. "Probabilistic Seismic Hazard Characterization and Design Parameters for the Pantex Plant”. UCRL-CR-132282, Lawrence Livermore National Laboratory, California, 1998. 
Savy, J. B., W. Foxall, and N. Abrahamson, and D. Bernreuter. "Guidance for Performing Probabilistic Seismic Hazard Analysis for a Nuclear Plant Site: Example Application to the Southern United States," NUREG/CR-6607, 1999.

Somov, V.I., Recent activity of tectonic disturbances in Bukovina from data of instrumental studies, Geofizicheskiy Zhurnal, 17, 641-650, 1998.

South Ukraine NPP, Unit 1.Technical Substantiation of Safety, KhIEP (Karkov Energoproject Institute), Kharkov, 1991.

SSHAC. "Recommendations for Probabilistic Seismic Hazard Analysis: Guidance on Uncertainty and Use of Experts," Senior Seismic Hazard Analysis Committee: R. J. Budnitz, G. Apostolakis, D. Boore, L. Cluff, K. Coppersmith, A. Cornell and P. Morris, NUREG/CR-6372 (UCRL-ID-122160), Vol. 1, 2, 1997.

Stovba, S., R.A. Stephenson, and M. Kivshik. "Structural Features and Evolution of the DneprDonets Basin, Ukraine, from Regional Seismic Profiles". Tectonophysics, 268, 127-147, 1996.

Subbodin Institute of Geophysics, Simferopol, Kiev 1992."Additional Study of the Geologic and Tectonic Conditions of the Seismic Hazard to the Region and Site of South Ukraine Energetic Complex (Final Report in 3 books. Book 1. Academy of Sciences of Ukraine.

Strakhov, V.N., O.M. Kharitonov, F.F. Aptikayev, E.V. Barkovskiy, O.K. Kedrov, A.V. Kendzera, Yu. F. Kopnichev, V.D. Omel'chenko, and V.P. Paiyenko. "Seismic Events in the Chernobyl Nuclear Plant Area". Geofizicheskiy Zhurnal, 19, 3-15, 1997 (in Ukrainian).

Tacis, Re-evaluation of seismic input for Chernobyl NPP, Final Report to the European Union Tacis Programme prepared by ISMES and the Academy of Sciences of the Ukraine, Institute of Geophysics, vol. 1, Seriate, Italy, $61 \mathrm{p}$.

Toro, G. R., N. Abrahamson, and J. F. Schneider. "Model of Strong Ground Motions from Earthquakes in the Central and Eastern United States," in Guidelines for Determining Design Basis Ground Motion. EPRI TR-102293, J. F. Schneider, ed. Electric Power Research Institute, 1993.

Toro, G. R., N. Abrahamson, and J. F. Schneider. Model of Strong Ground Motions from Earthquakes in Central and Eastern America: Best Estimates and Uncertainties, Seismological Research Letters, Vol. 68, No. 1, January/February 1997.

Toro, G. R. and R. McGuire. "An Investigation into Earthquake Ground Motion Characteristics in Eastern North America," Bull. Seis. Soc. Am., 77, pp. 468-489, 1987.

Trifunac, M. D. and A. G. Brady. "On the Correlation of Seismic Intensity Scales with Peak Recorded Strong Motion,” Bull. Seis. Soc. Am., Vol. 65, no. 1, pp. 139-162, 1975. 
U.S. Nuclear Regulatory Commission. "Development of Criteria for Design Review of Sclected Nuclear Power Plants," NUREG/CR-0098, N.M. Newmark, W. J. Hall, 1978.

U.S. Nuclear Regulatory Commission; 1992: Appendix B of 10 CFR 100: Seismic and geologic siting criteria for nuclear power plants. NRC, Washington DC.

Van Wees, J.D., R.A. Stephenson, S.M. Stovba, and V.A. Shymanovskyi. "Tectonic Variation in the Dnepr-Donnets Basin from Automated Modelling of Backstripped Subsidence Curves". Tectonophysics, 268, 257-280, 1996.

Wells, D.L. and K.J. Coppersmith, New empirical relationships among magnitude, rupture length, rupture width, rupture area, and surface displacement, Bull. Seismol. Soc. Am., 84, pp. 974-1002, 1994.

Wenzel, F., U. Achauer, D. Enescu, E. Kissling, R. Russo, V. Mocanu, and G. Musacchio. "Detailed Look at Final Stage of Plate Break-off is Target of Study in Romania". EOS, Trans. Amer. Geophys. Union, 79(48), 589-594, 1998.

Wheeler, R.L., Geologic controls of earthquakes in Iapetan rifts and grabens, southeastern North America, manuscript preprint, 1998.

Youngs, R. R., and K. J. Coppersmith. "Implications of Fault Slip Rates and Earthquake Recurrence Models to Probabilistic Seismic Hazard Estimates," Bull. Seis. Soc. Am., 75, pp. 939-964, 1985. 


\begin{tabular}{|c|c|c|c|c|c|c|c|c|}
\hline \multirow{3}{*}{$\begin{array}{l}\text { Zone } \\
\text { No. }\end{array}$} & \multirow{3}{*}{ Source Zone } & \multicolumn{2}{|c|}{ Distance from Site } & \multicolumn{2}{|c|}{\begin{tabular}{|l|} 
Observed \\
$\mathbf{M}_{\max }$ \\
\end{tabular}} & \multirow{2}{*}{\multicolumn{3}{|c|}{$\begin{array}{c}\mathbf{M}_{\max } \\
\text { Distribution }\end{array}$}} \\
\hline & & \multirow{2}{*}{$\begin{array}{l}D_{\min } \\
(\mathbf{k m})\end{array}$} & \multirow{2}{*}{$\begin{array}{c}\text { NPP Site } \\
\text { Name }\end{array}$} & \multirow{2}{*}{$\mathbf{M}$} & \multirow{2}{*}{ Date } & & & \\
\hline & & & & & & low & $\begin{array}{c}\bmod \\
\mathrm{e}\end{array}$ & high \\
\hline 1 & $\begin{array}{l}\text { Active Tectonic } \\
\text { Carpathian }\end{array}$ & 140 & Khmelnytskyy & 5.3 & 1875 & 6.0 & 6.5 & 6.7 \\
\hline $2 b$ & East Carpathian extension (EEC) & & & & & & & \\
\hline 3 & Zakarpatye & 300 & Khmelnytskyy & $5.4^{2}$ & 1778 & 5.4 & 6.0 & 6.8 \\
\hline 4 & Vrancea (Deep events) & 360 & South-Ukraine & 7.7 & 1940 & 7.7 & 7.8 & 7.9 \\
\hline 5 & Dobrogea- W.-Black Sea & 280 & South-Ukraine & 6.4 & 1865 & 6.4 & 6.5 & 6.9 \\
\hline 6 & West Crimea & 280 & Zapor./S.Ukra. & 5.7 & 1957 & 5.7 & 5.8 & 7.2 \\
\hline 7 & Crimea-Kerch-Caucasus & 230 & Zaporizhzya & 5.8 & $63 \mathrm{BC}$ & 5.3 & 5.8 & 6.0 \\
\hline 8 & Deformed Black Sea Plate & 280 & Zaporizhzya & 5.8 & 1966 & 5.8 & 6.0 & 6.3 \\
\hline 9 & Yalta & 280 & Zaporizhzya & 6.8 & 1927 & 6.8 & 6.9 & 7.3 \\
\hline $2 \mathrm{a}$ & $\begin{array}{l}\text { Stable Continent } \\
\text { Western EEC }\end{array}$ & 80 & Khmelnytskyy & 4.8 & 1842 & 4.8 & 5.0 & 5.3 \\
\hline 10 & Pripyat-Dnicpro-Don. Rift (PDDR) & $\sim 10$ & Chernobyl & 4.8 & 1972 & 4.8 & 5.0 & 5.3 \\
\hline 11 & $\begin{array}{l}\text { Eastern European Craton } \\
\text { Other Zones }\end{array}$ & All & es are in EEC & 4.8 & 1954 & 4.8 & 5.0 & 5.3 \\
\hline 12 & Black Sea background & 210 & Zaporizhzya & N/A & N/A & 6.4 & 6.5 & 6.9 \\
\hline 13 & Vrancea (Shallow events) & 360 & South-Ukraine & N/A & N/A & 5.0 & 5.3 & 6.0 \\
\hline 14 & PDDR (Large rare events) & $\sim 10$ & Chernobyl & N/A & N/A & 7.5 & 7.5 & 7.5 \\
\hline
\end{tabular}

Note: 1 . Zone $2 \mathrm{~b}$ is undistinguishable from Zone 1 .

2. Magnitude 6.8 possibly in 1834 .

Table 3.3.1.1: Preliminary characterization of the source zones 


\begin{tabular}{|c|c|c|c|c|c|c|c|c|c|c|c|}
\hline \multirow[t]{2}{*}{ Zone } & \multirow{2}{*}{$\begin{array}{c}\text { Area } \\
\left(\mathbf{k m}^{2}\right) \\
\end{array}$} & \multicolumn{3}{|c|}{$M_{\max }{ }^{3}$} & \multicolumn{3}{|c|}{$f(3.5)^{1}$} & \multicolumn{4}{|c|}{$f\left(m_{1}\right)^{2}$} \\
\hline & & $\bmod$ & low & high & $\bmod$ & low & high & $\mathbf{m}_{1}$ & $\bmod$ & low & high \\
\hline 1. East Carpathian & 200668 & 6.5 & 6.0 & 6.7 & .12 & .01 & .35 & 6.0 & .0063 & .003 & .012 \\
\hline 2a. Western EEC & 79287 & 5.3 & 5.0 & 5.5 & .009 & .006 & .02 & 4.5 & .003 & .002 & .0061 \\
\hline 2b. EC Extension & 16765 & 5.3 & 5.0 & 5.5 & .03 & .002 & .005 & 4.5 & .005 & .001 & .003 \\
\hline 3. Zakarpatye & 23192 & 6.0 & 5.4 & 6.8 & .06 & .03 & .12 & 5.0 & .0025 & .002 & .006 \\
\hline 4. Vrancea Deep & 11774 & 7.8 & 7.7 & 7.9 & $1.047^{4}$ & $.112^{4}$ & $2.238^{4}$ & 6.5 & .05 & .04 & .13 \\
\hline 5. Dobrogea & 30751 & 6.5 & 6.4 & 6.9 & .006 & .004 & .008 & 6.0 & .0012 & .001 & .0025 \\
\hline 6. West Crimea & 6802 & 5.8 & 5.7 & 6.2 & .02 & .013 & .03 & 5.5 & .003 & .002 & .004 \\
\hline 7. Crimea Kerch Caucasus & 43163 & 5.8 & 5.8 & 6.0 & .045 & .03 & .06 & 5.5 & .0036 & .003 & .007 \\
\hline 8. Deformed Black Sea Plate (FBS) & 62214 & 6.0 & 5.8 & 6.3 & .08 & .06 & .14 & 5.5 & .008 & .006 & .014 \\
\hline 9. Yalta & 4528 & 6.9 & 6.8 & 7.3 & .13 & .07 & .2 & 6.5 & .004 & .0025 & .006 \\
\hline $10 P D D R^{5}$ & 141343 & 5.0 & 4.8 & 5.3 & $1.3 \mathrm{e}-3$ & $7.7 \mathrm{e}-4$ & $2.6 \mathrm{e}-3$ & 4.5 & $5.0 \mathrm{e}-5$ & $3.3 \mathrm{e}-4$ & $8.8 \mathrm{e}-4$ \\
\hline 11. East European Craton & 639669 & 5.0 & 4.8 & 5.3 & .006 & .0035 & .012 & 4.5 & .0023 & .0015 & .004 \\
\hline 12. Background Black Sea & 91676 & 6.5 & 6.4 & 6.8 & .0173 & .013 & .034 & 4.5 & .00116 & .001 & .004 \\
\hline 13.Vrancea Shallow & 11774 & 5.3 & 5.0 & 6.0 & .7 & .3 & 1.4 & 5.0 & .125 & .07 & .25 \\
\hline 14.PDDR Large rare events (PDDRL) & 141343 & 7.5 & 7.5 & 7.6 & $1.3 \mathrm{e}-3$ & $8.0 \mathrm{e}-4$ & $2.7 e-3$ & 7.5 & $5.0 \mathrm{e}-5$ & $1.0 \mathrm{e}-6$ & $1.0 \mathrm{e}-4$ \\
\hline
\end{tabular}

\section{Table 3.3.1.3.1: Seismicity rates modeling of the seismic source zones used in the Ukraine PSHA study}

Note: $1 \mathrm{f}(3.5)=$ Number of events greater than M 3.5 per year

$2 \mathrm{f}\left(\mathrm{m}_{1}\right)=$ Number of events greater than magnitude $\mathrm{m}_{1}$

$3 \mathrm{M}_{\max }=$ Absolute magnitude possible in the zone.

$f(3.5), f\left(m_{1}\right)$ and $M_{\max }$ are described by triangular probability density functions with mode, lower bound and upper bound given by "mod", "low" and "high" in the table.

4 The Vrancea source zone is divided into Shallow and Deep. The deep events are characterized by events greater than magnitude 5.0. Thus these estimates are $f(5.0)$.

5 PDDR is given the same seismicity rates per $\mathrm{km}^{2}$ than the EEC for the alternative to the large rare events. 


\begin{tabular}{|c|c|c|c|}
\hline \multirow{2}{*}{ Model Index } & $\begin{array}{c}\text { Group 1: } \\
\text { Craton }\end{array}$ & $\begin{array}{c}\text { Group 2: } \\
\text { Vrancea Deep }\end{array}$ & $\begin{array}{c}\text { Group 3: } \\
\text { Vrancea Shallow }\end{array}$ \\
\cline { 2 - 4 } & Weight in \% & Weight in \% & Weight in \% \\
\hline BA95 & 45 & & 25 \\
\hline SP87 & 20 & & 10 \\
\hline TA97 & 35 & & 25 \\
\hline AB97 & & 50 & \\
\hline ISMES97 & & 40 & \\
\hline ROM1 & & 10 & \\
\hline ROM3 & & & 40 \\
\hline Total & 100 & 100 & 100 \\
\hline
\end{tabular}

Table 3.3.2.1: Weights Assigned to Each of the Seven Attenuation Models Selected for Ukraine 


\section{Table 3.3.2.2: Equations of the median estimates for the Seven} Attenuation Models selected for Ukraine, for Rock

Note: $\mathrm{A}=$ Acceleration in $\mathrm{cm} / \mathrm{sec} / \mathrm{sec}$

$\mathrm{M}=$ Magnitude. $\mathrm{M}_{\mathrm{w}}$ for $\mathrm{BA} 95, \mathrm{AB} 97$ and TA97, $\mathrm{M}_{\mathrm{s}}$ for $\mathrm{M}<5.5-\mathrm{M}_{\mathrm{L}}$ otherwise for others

$\mathrm{d}=$ Epicentral Distance in $\mathrm{km}$

$\ln$ = Common logarithm

$\log =$ Logarithm base 10

BA95:

$\log A=3.79+0.298(M-6)-0.0536(M-6)^{2}-\log R-0.00135 R$

with $\mathrm{R}=\sqrt{d^{2}+100}$

SP87:

$$
\begin{aligned}
\log A & =3.292+0.705 \mathrm{M}-\ln \mathrm{R} \\
& \text { with } \mathrm{R}=\sqrt{d^{2}+5.8^{2}}
\end{aligned}
$$

\section{TA97:}

$\ln \mathrm{A}=9.089+0.81(\mathrm{M}-6)-1.27 \ln \mathrm{R}_{\mathrm{M}}+0.11 \max \left\{\ln \frac{R_{M}}{100}, 0\right\}-0.0021 \mathrm{R}_{\mathrm{M}}$

with $\mathrm{R}_{\mathrm{M}}=\sqrt{R_{J B}^{2}+9.3^{2}}$

and $\mathrm{R}_{J B}=$ Joyner Boore measure of distance

AB97:

$\ln \mathrm{A}=7.569+0.733(\mathrm{M}-6)-\ln \mathrm{R}_{\mathrm{H}}-0.00645 \mathrm{R}_{\mathrm{H}}$

with $\mathrm{R}_{\mathrm{H}}=\sqrt{d^{2}+100^{2}}$

ISMES97:

$\ln \mathrm{A}=1.317-0.826 \ln \mathrm{d}+0.652 \mathrm{M}$

ROM1:

$\ln A=1.96+1.3 \mathrm{M}-1.224 \ln \left(\mathrm{R}_{\mathrm{H}}+40\right)$

with $R_{H}=\sqrt{d^{2}+100^{2}}$

ROM3:

$\ln \mathrm{A}=6.483+0.544-1.333 \ln \left(\mathrm{R}_{\mathrm{H}}+20\right)$

with $\mathrm{R}_{\mathrm{H}}=\sqrt{d^{2}+20^{2}}$ 
Table 3.3.2.3: Characterization of the Aleatory Uncertainty in the Ground Motion Predictions

Note: The standard deviation $\sigma$ is described by triangular probability density function with mode $\sigma_{\text {Mode }}, 5^{\text {th }}$ percentile $\sigma_{\text {L:ower }}$ and $95^{\text {th }}$ percentile $\sigma_{\text {Upper }}$.

\begin{tabular}{|l|c|c|c|}
\hline \multirow{2}{*}{} & \multicolumn{3}{|c|}{ Range of Standard Deviation on } \\
\cline { 2 - 4 } & $\sigma_{\text {Lower }}$ & $\sigma_{\text {Mode }}$ & $\sigma_{\text {Upper }}$ \\
\hline Group 1: Craton & 0.46 & 0.55 & 0.70 \\
\hline Group 2: Deep Vrancea & 0.40 & 0.55 & 0.78 \\
\hline Group 3: Shallow Vrancea & 0.50 & 0.67 & 0.80 \\
\hline
\end{tabular}

Table 3.3.2.4: Stratigraphy and material properties of the Chernobyl site (from ISMES, 1997)

\begin{tabular}{|c|cc|c|}
\hline $\begin{array}{c}\text { Layer } \\
\text { Thickness } \\
(\mathbf{m})\end{array}$ & $\begin{array}{c}\mathbf{V}_{\mathbf{s}} \\
(\mathbf{m} / \mathbf{s e c})\end{array}$ & $\begin{array}{c}\text { Damping } \\
\xi\end{array}$ & $\begin{array}{c}\text { Density } \\
\left(\mathbf{k g} / \mathbf{m}^{\mathbf{3}}\right)\end{array}$ \\
\hline 30 & 180 & 0.025 & 1670 \\
\hline 9 & 180 & 0.025 & 1910 \\
\hline 16 & 214 & 0.025 & 2020 \\
\hline 30 & 250 & 0.010 & 1890 \\
\hline 65 & 320 & 0.005 & 1730 \\
\hline 12 & 380 & 0.005 & 1730 \\
\hline 14 & 890 & 0.003 & 2140 \\
\hline 94 & 1700 & 0.003 & 2500 \\
\hline Bedrock & 3500 & 0.003 & 2500 \\
\hline
\end{tabular}




\begin{tabular}{|c|c|c|c|c|c|}
\hline \multirow{2}{*}{$\begin{array}{l}\text { Return } \\
\text { Period }\end{array}$} & \multicolumn{5}{|c|}{ Peak Ground Acceleration Level (cm/s/s) } \\
\cline { 2 - 6 } & CHERNOBYL & KHMELNYSTSKYY & RIVNE & SOUTH UKRAINE & ZAPORIZHYA \\
\hline $100 \mathrm{yr}$ & 40.8 & 45.0 & 41.4 & 54.5 & 42.8 \\
\hline $500 \mathrm{yr}$ & 72.4 & 77.9 & 69.3 & 89.9 & 74.0 \\
\hline $1000 \mathrm{yr}$ & 87.8 & 93.1 & 83.3 & 107.0 & 88.7 \\
\hline $10000 \mathrm{yr}$ & 159.9 & 171.8 & 144.9 & 196.0 & 156.5 \\
\hline $100000 \mathrm{yr}$ & 273.0 & 292.8 & 245.1 & 323.4 & 261.6 \\
\hline
\end{tabular}

\begin{tabular}{|c|c|c|c|c|c|}
\hline \multirow{2}{*}{$\begin{array}{c}\text { Return } \\
\text { Period }\end{array}$} & \multicolumn{5}{|c|}{ Magnitude of the Review Level Earthquake M-bar } \\
\cline { 2 - 6 } & CHERNOBYL & KHMELNYSTSKYY & RIVNE & SOUTH UKRAINE & ZAPORIZHYA \\
\hline $100 \mathrm{yr}$ & 5.80 & 6.00 & 6.00 & 6.20 & 5.90 \\
\hline $500 \mathrm{yr}$ & 6.00 & 6.20 & 6.20 & 6.50 & 6.10 \\
\hline $1000 \mathrm{yr}$ & 6.10 & 6.30 & 6.30 & 6.70 & 6.20 \\
\hline $10000 \mathrm{yr}$ & 6.40 & 6.60 & 6.60 & 7.00 & 6.50 \\
\hline $100000 \mathrm{yr}$ & 6.60 & 6.80 & 6.80 & 7.20 & 6.70 \\
\hline
\end{tabular}

\begin{tabular}{|c|c|c|c|c|c|}
\hline \multirow{2}{*}{$\begin{array}{c}\text { Return } \\
\text { Period }\end{array}$} & \multicolumn{5}{|c|}{ Distance of the Review Level Earthquake D-bar $(\mathbf{k m})$} \\
\cline { 2 - 6 } & CHERNOBYL & KHMELNYSTSKYY & RIVNE & SOUTH UKRAINE & ZAPORIZHYA \\
\hline $100 \mathrm{yr}$ & 88 & 223 & 95 & 346 & 92 \\
\hline $500 \mathrm{yr}$ & 106 & 270 & 124 & 361 & 118 \\
\hline $1000 \mathrm{yr}$ & 115 & 289 & 138 & 366 & 130 \\
\hline $10000 \mathrm{yr}$ & 141 & 334 & 180 & 372 & 169 \\
\hline $100000 \mathrm{yr}$ & 166 & 367 & 215 & 370 & 204 \\
\hline
\end{tabular}

Table 3.4.2.1 Summary of the Review Level earthquake PGA, D-bar and M-bar for the five sites in Ukraine and for five return periods 

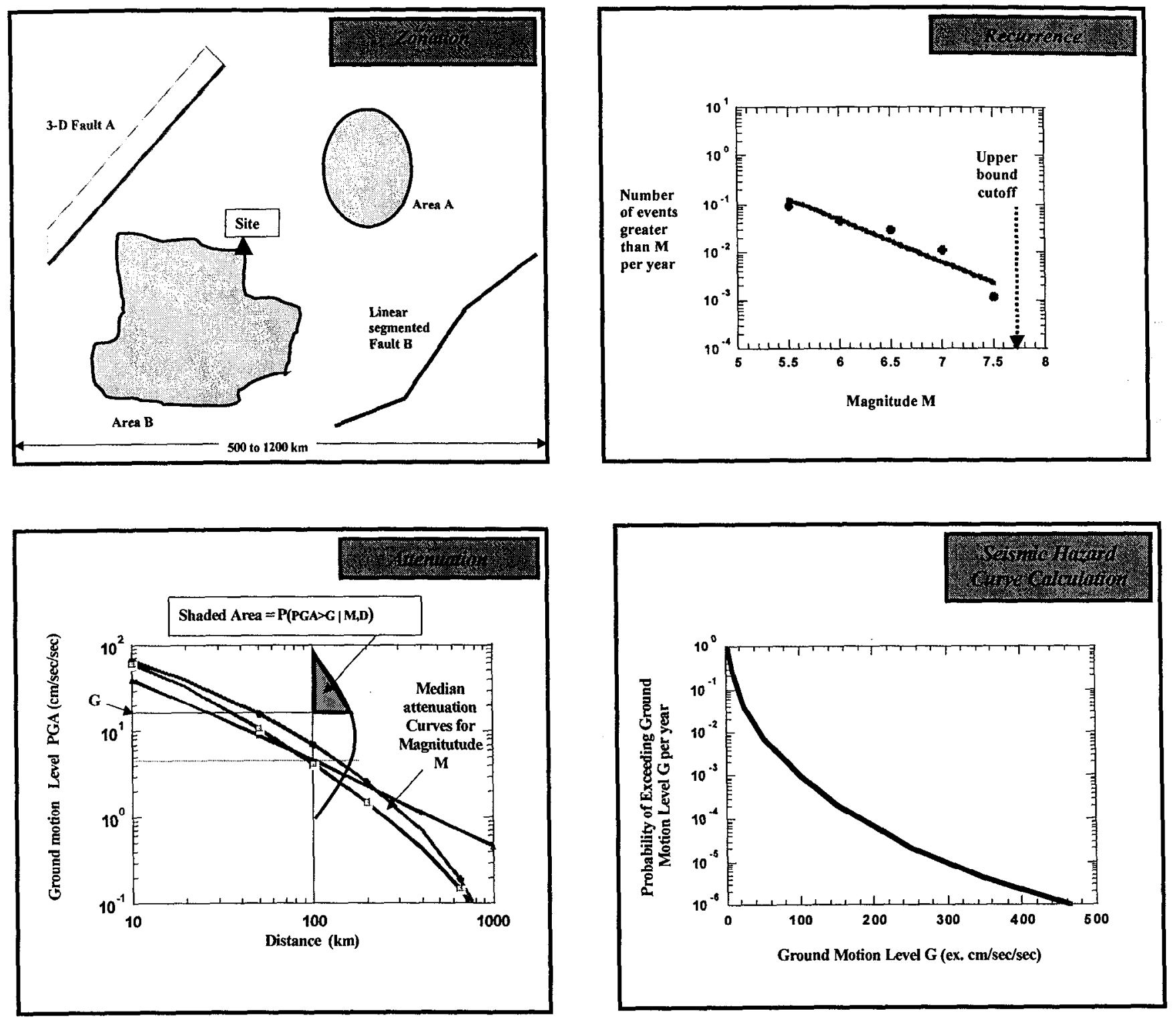

Figure 2.3.1: Basic Steps of the Methodology of assessing Vibratory Ground Motion Probabilistic Hazard. 


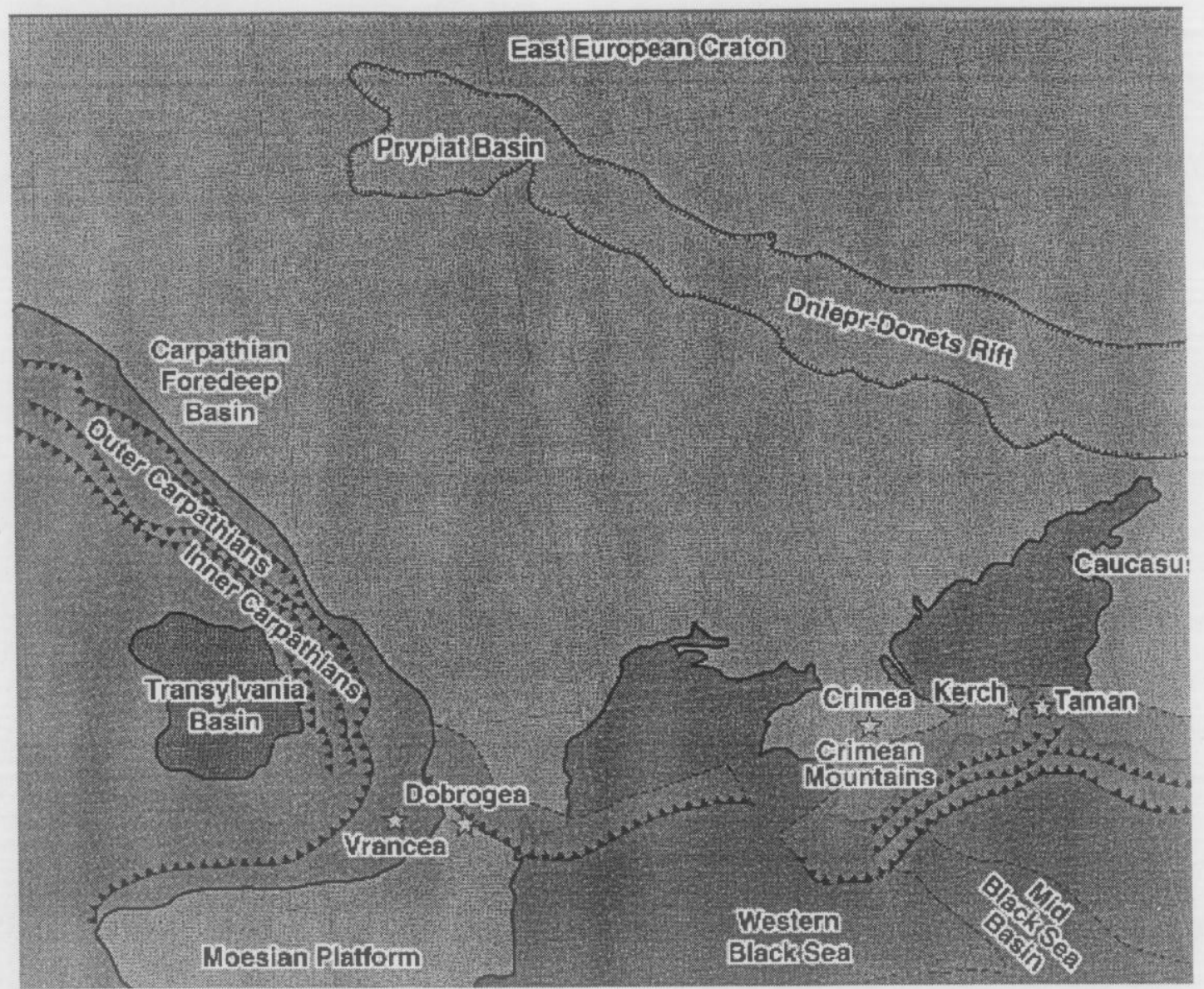

Figure 3.3.1.1: Schematic Tectonic Map of the Ukraine Region 


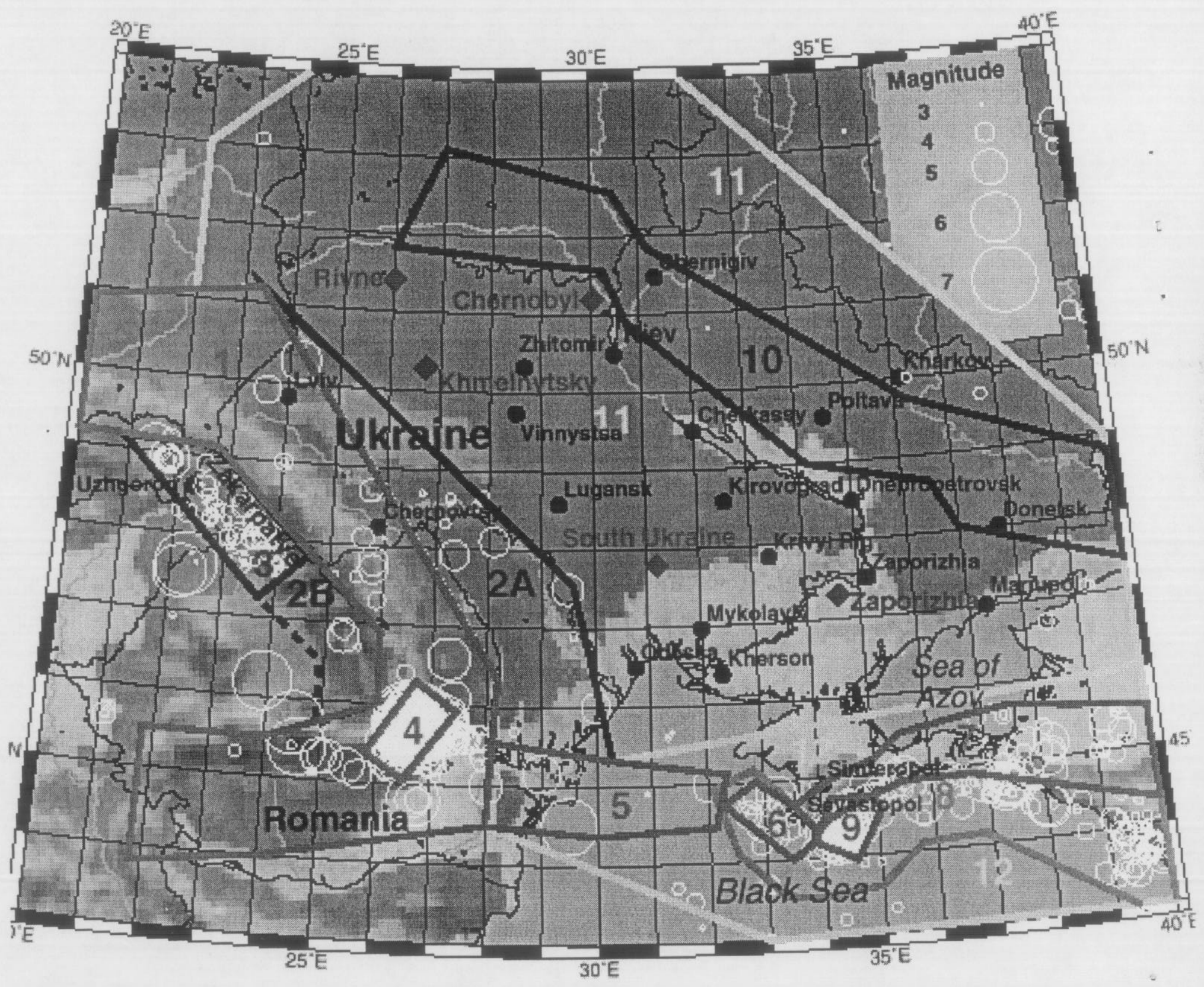

Figure 3.3.1.2: Seismic Source Zones and NGDC/NEIS Commonwealth of Independent States Catalog Seismicity , 150 BC-1989. The Nuclear Power Plant Sites Are Shown in Red. 


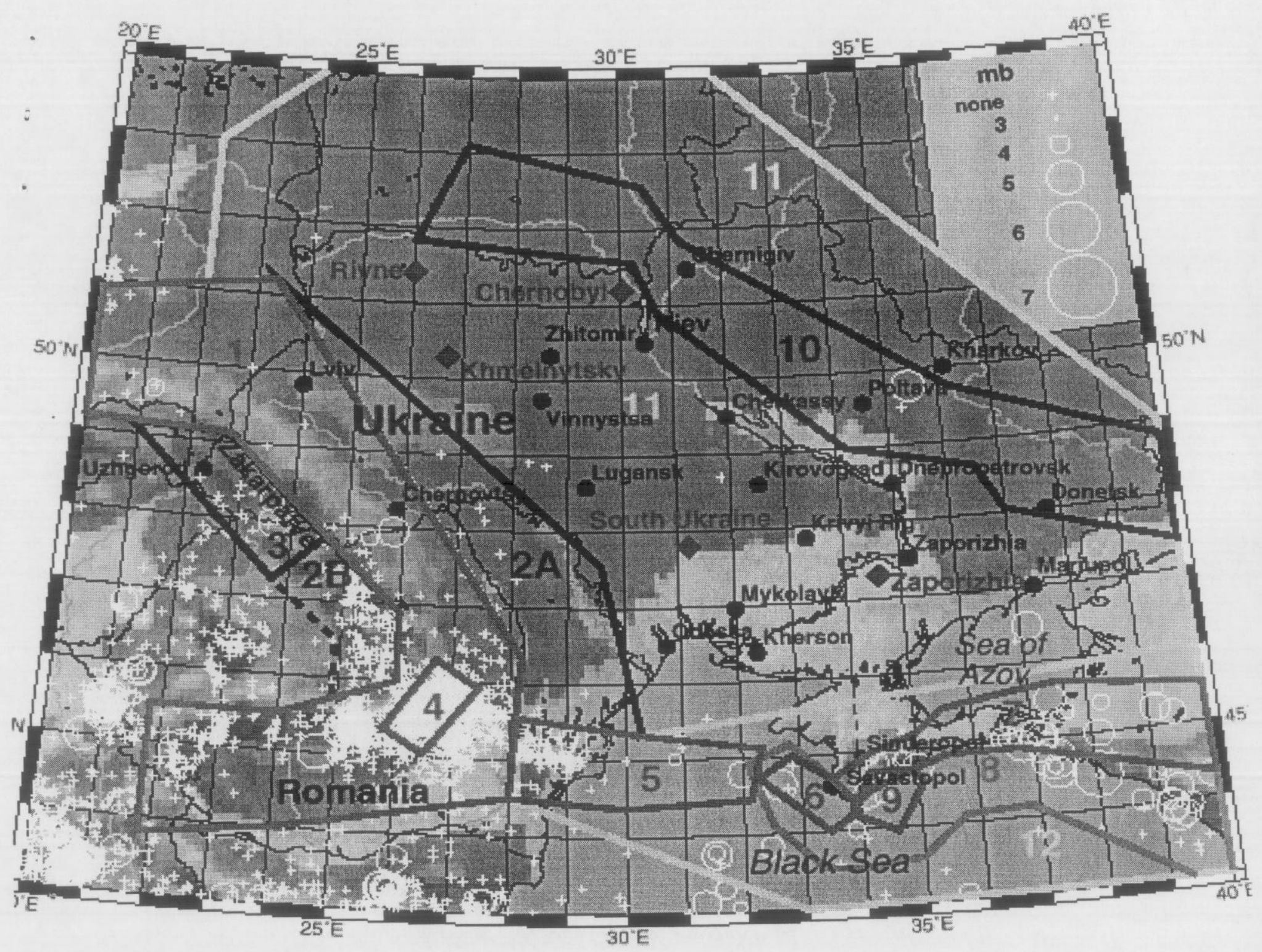

Figure 3.3.1.3: ISC Instrumental Earthquake Locations, 1964-March, 1993. 


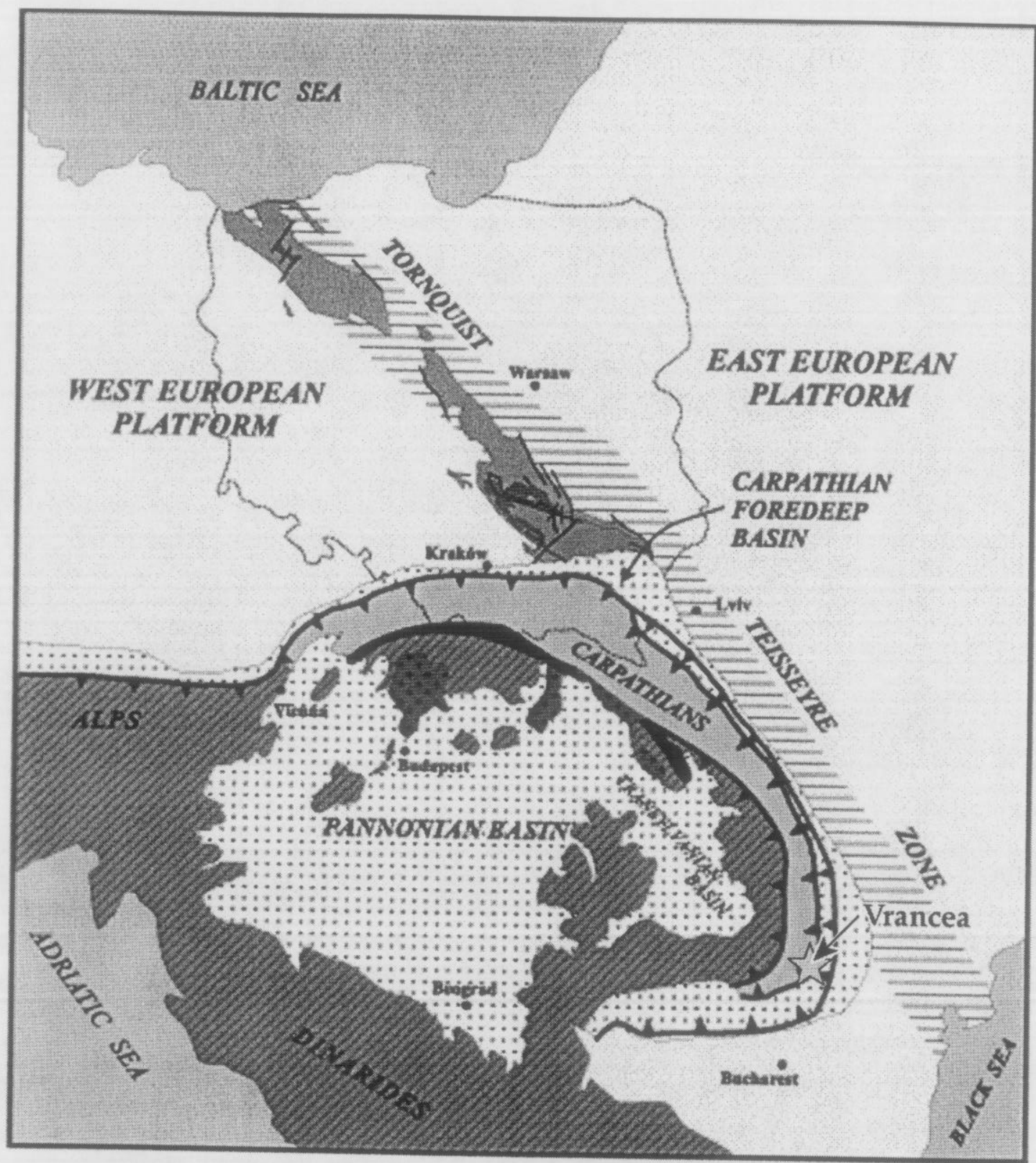

INVERTED POLISH TROUGH: CARPATHO-PANNONIAN DOMAIN:

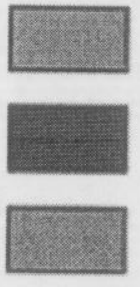

Jurassic

Triassic

Palacozoic and older

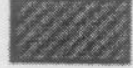

Inner Carpathian/Alpine units :::::- Sym- and post-orogenic

Neogene volcanics

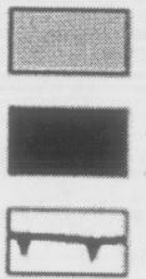

Outer Carpathians

Pieniny Klippen Belt main thrusts

Figure 3.3.1.4: Tectonic Map of the Carpathian System. 


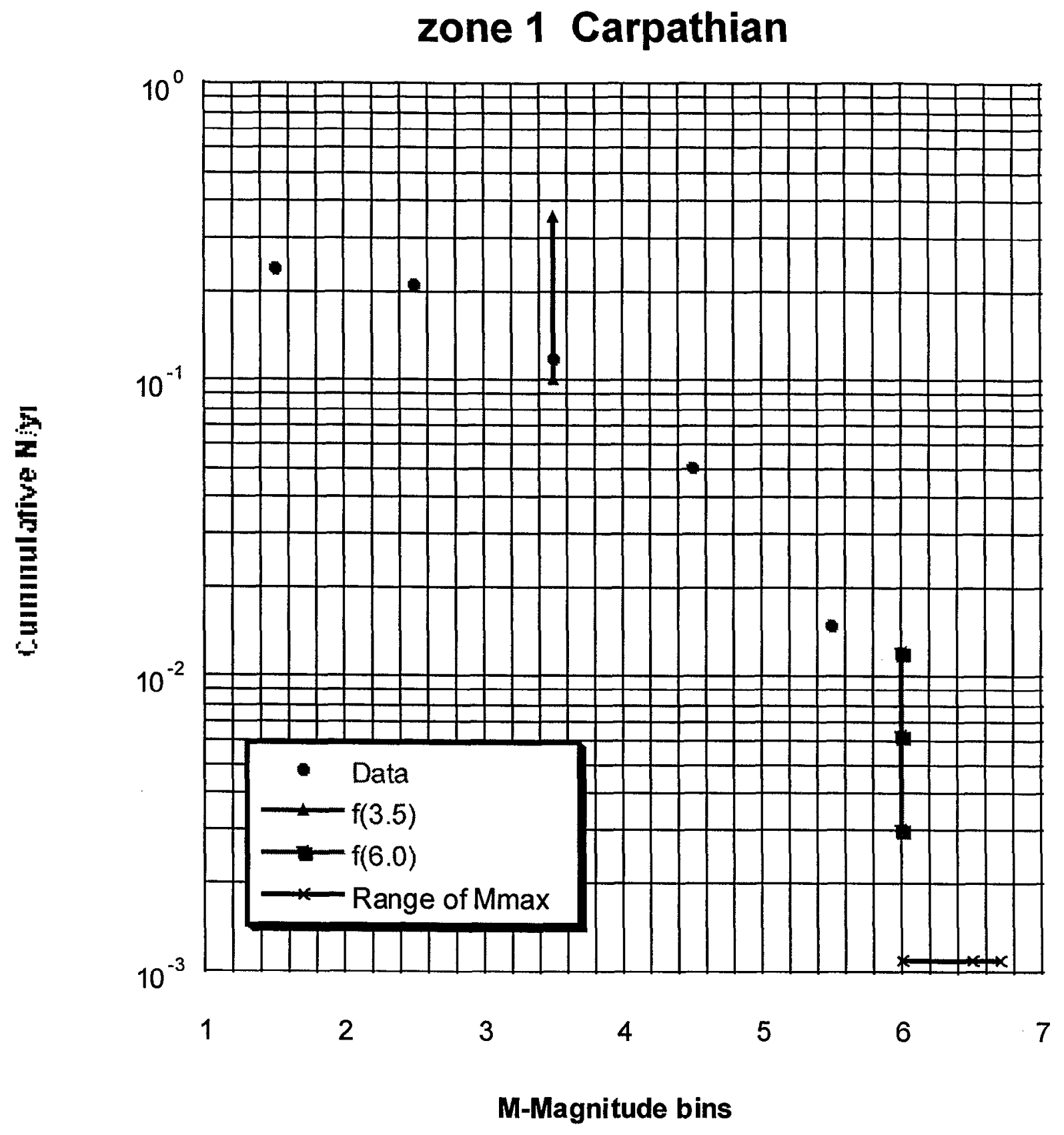

Figure 3.3.1.3.1: Observed cumulative annual number of earthquakes in Zone 1, the Carpathian seismic zone. Estimate of the range of rates of events greater than magnitude 3.5 and $6.0, f(3.5)$ and $f(6.0)$ respectively. The horizontal bar shows the minimum and maximum of the distribution of $\mathbf{M}_{\max }$. 


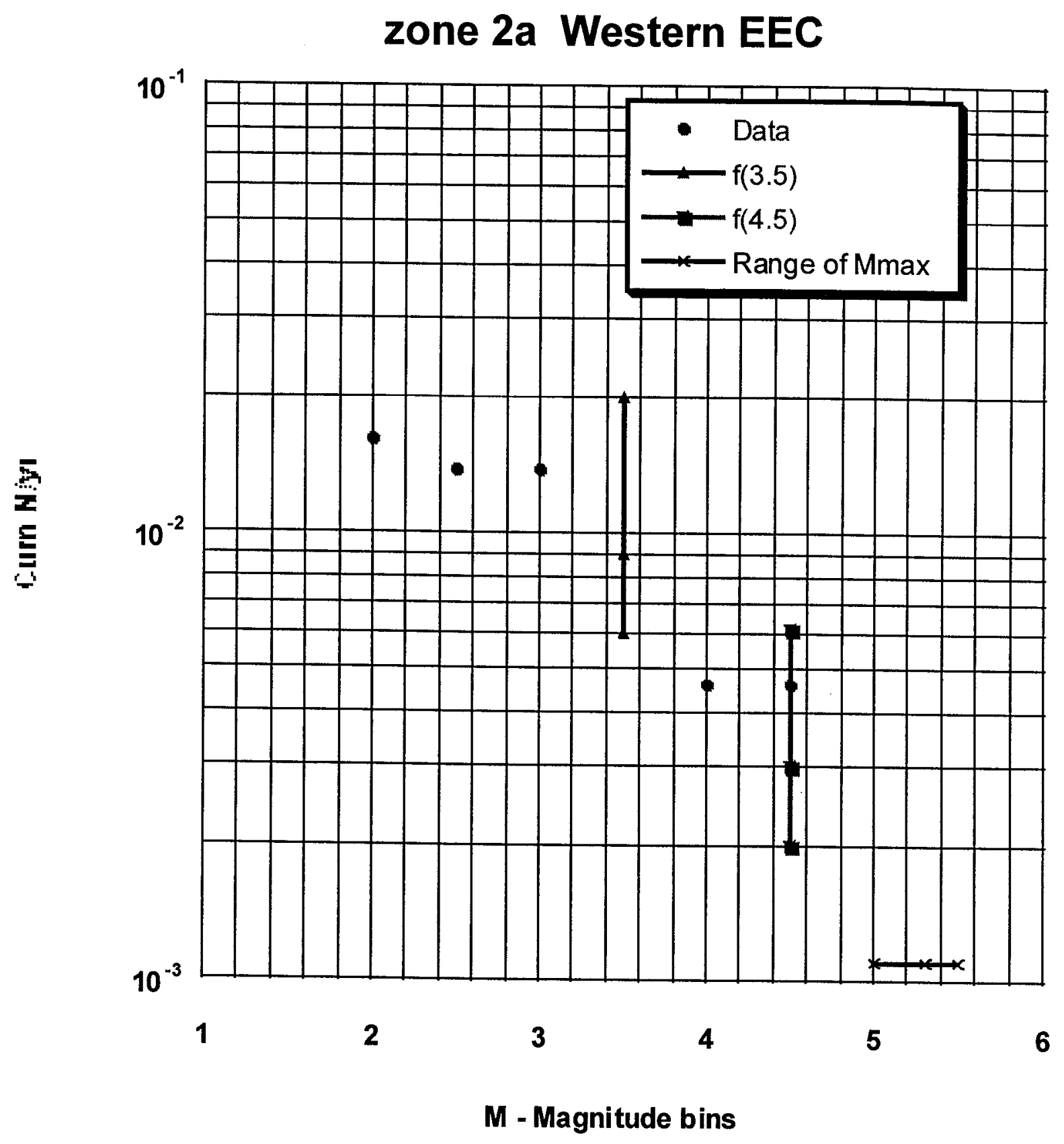

Figure 3.3.1.3.2: Observed cumulative annual number of earthquakes in Zone 2a, Western East European Craton. Estimate of the range of rates of events greater than magnitude 3.5 and $4.5, f(3.5)$ and $f(4.5)$ respectively. The horizontal bar shows the minimum and maximum of the distribution of $M_{\max }$. 
zone 2b East Carpathian Extension

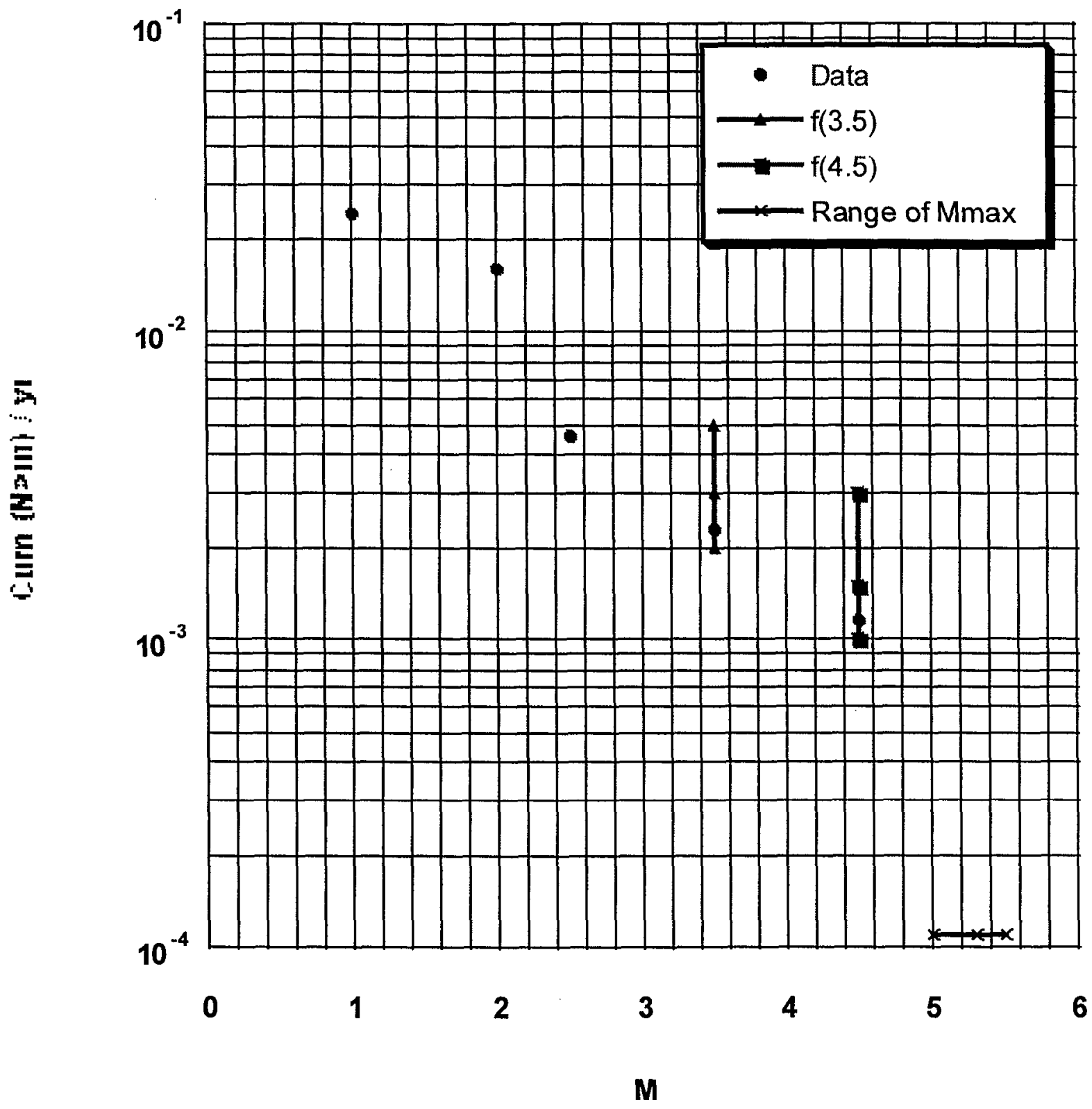

Figure 3.3.1.3.3: Observed cumulative annual number of earthquakes in Zone 2b, the East Carpathian Extension seismic zone. Estimate of the range of rates of events greater than magnitude 3.5 and 4.5, $f(3.5)$ and $f(4.5)$ respectively. The horizontal bar shows the minimum and maximum of the distribution of $M_{\max }$. 


\section{zone 3 Zakarpatye}

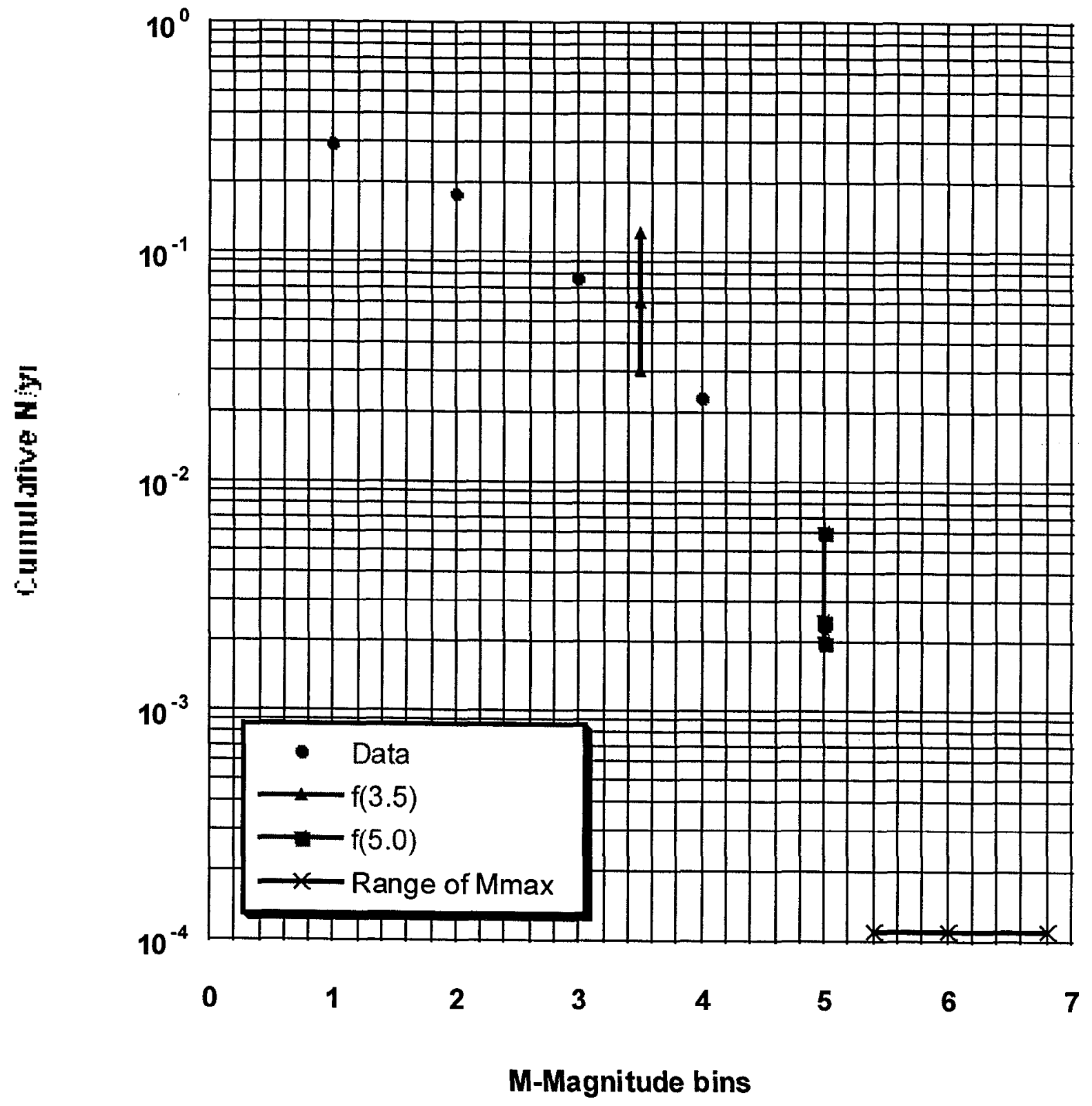

Figure 3.3.1.3.4: Observed cumulative annual number of earthquakes in Zone 3, the Zakarpatye seismic zone. Estimate of the range of rates of events greater than magnitude 3.5 and $5.0, f(3.5)$ and $f(5.0)$ respectively. The horizontal bar shows the minimum and maximum of the distribution of $\mathbf{M}_{\max }$. 


\section{zone 13 Vrancea (Shallow Events)}

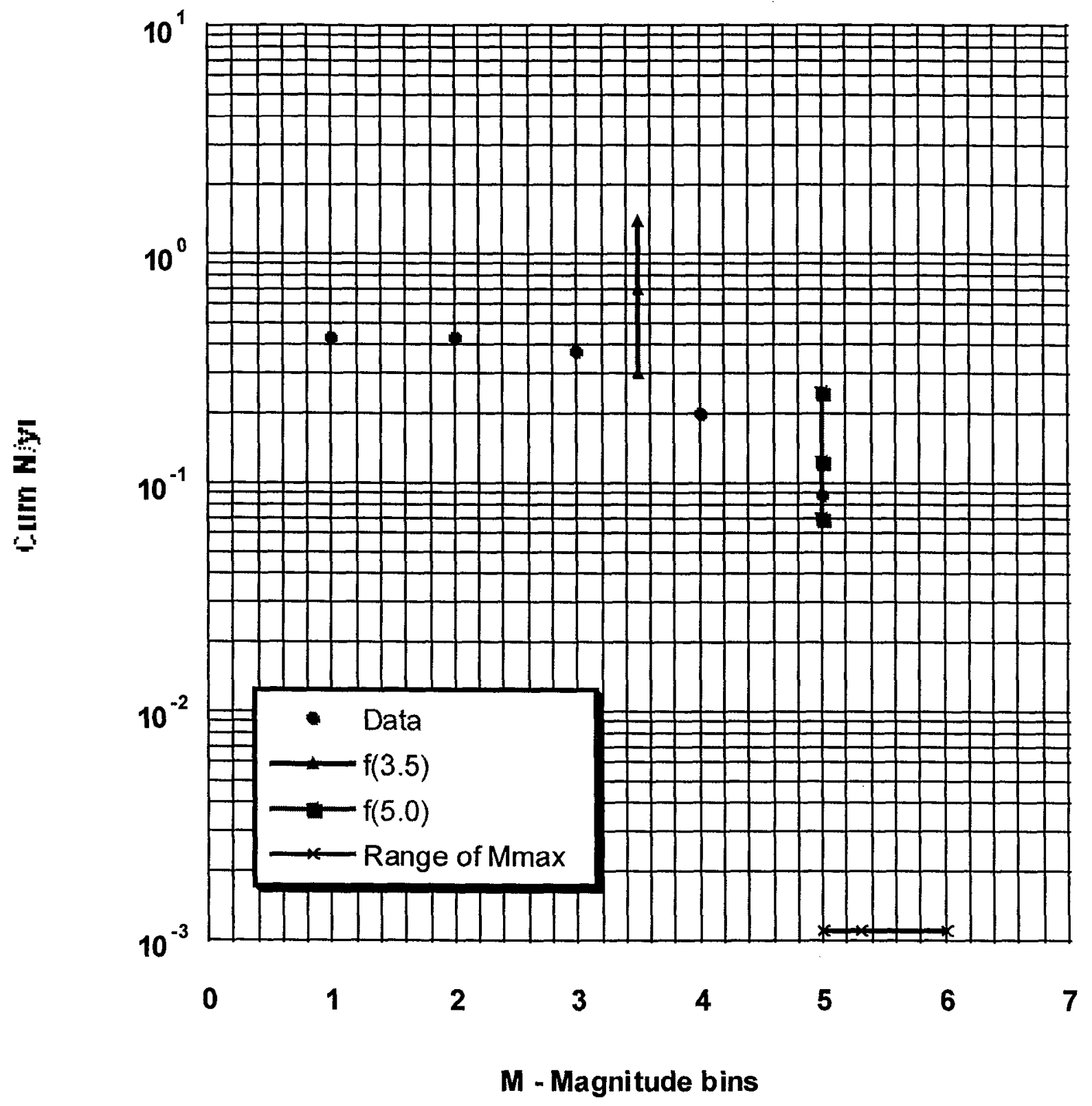

Figure 3.3.1.3.5: Observed cumulative annual number of earthquakes in Zone 13, the Vrancea (Shallow Events) seismic zone. Estimate of the range of rates of events greater than magnitude 3.5 and $5.0, f(3.5)$ and $f(5.0)$ respectively. The horizontal bar shows the minimum and maximum of the distribution of $M_{\max }$. 


\section{Zone 4 Vrancea (Deep Events)}

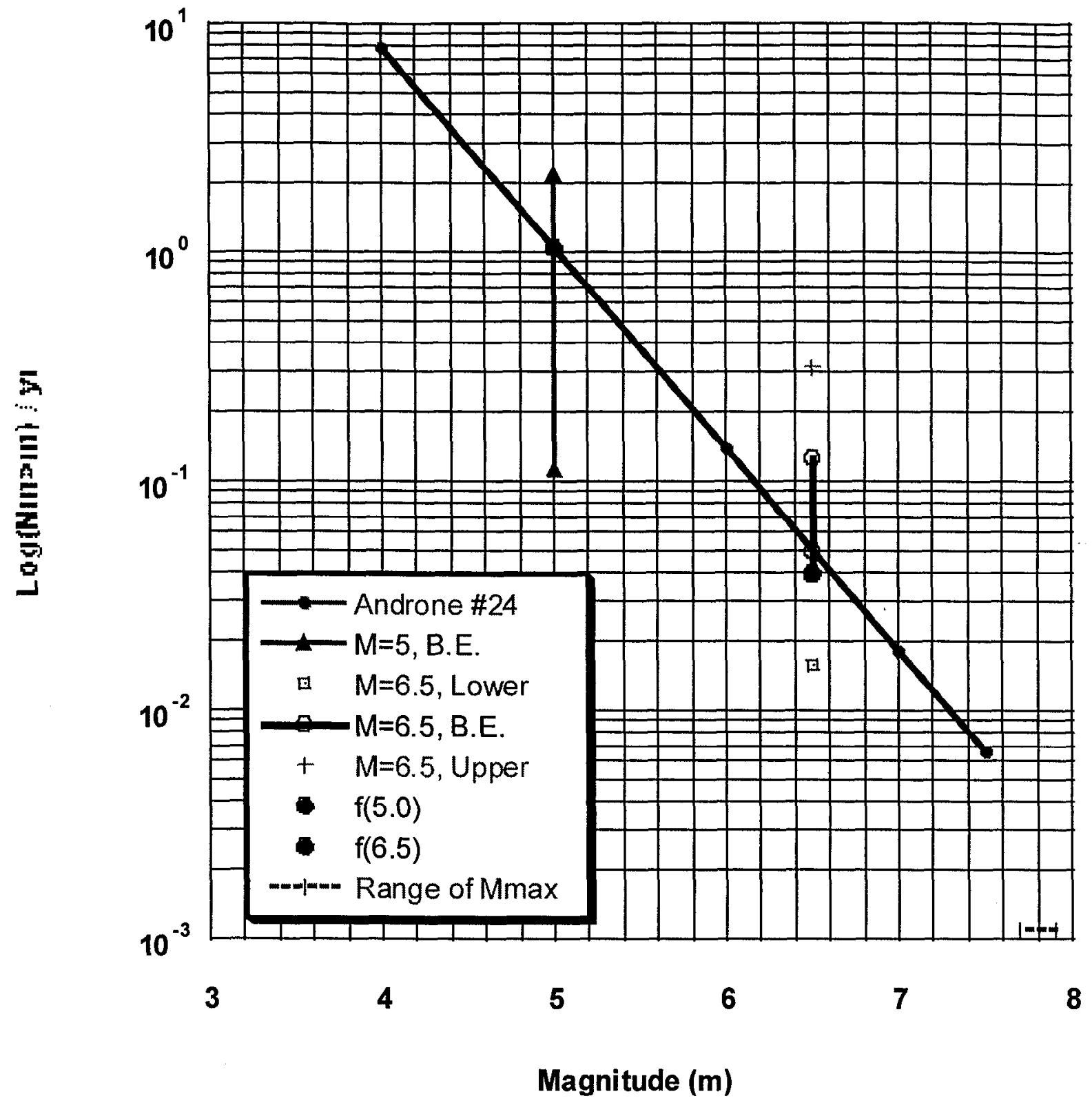

Figure 3.3.1.3.6: Estimates of the seismicity rates from the literature for Zone 4, the Vrancea (Deep Events) seismic zone. $F(5.0)$ and $f(6.5)$ are the estimates of the ranges of annual rates used in this analysis. The horizontal bar shows the range of $M_{\max }$. 


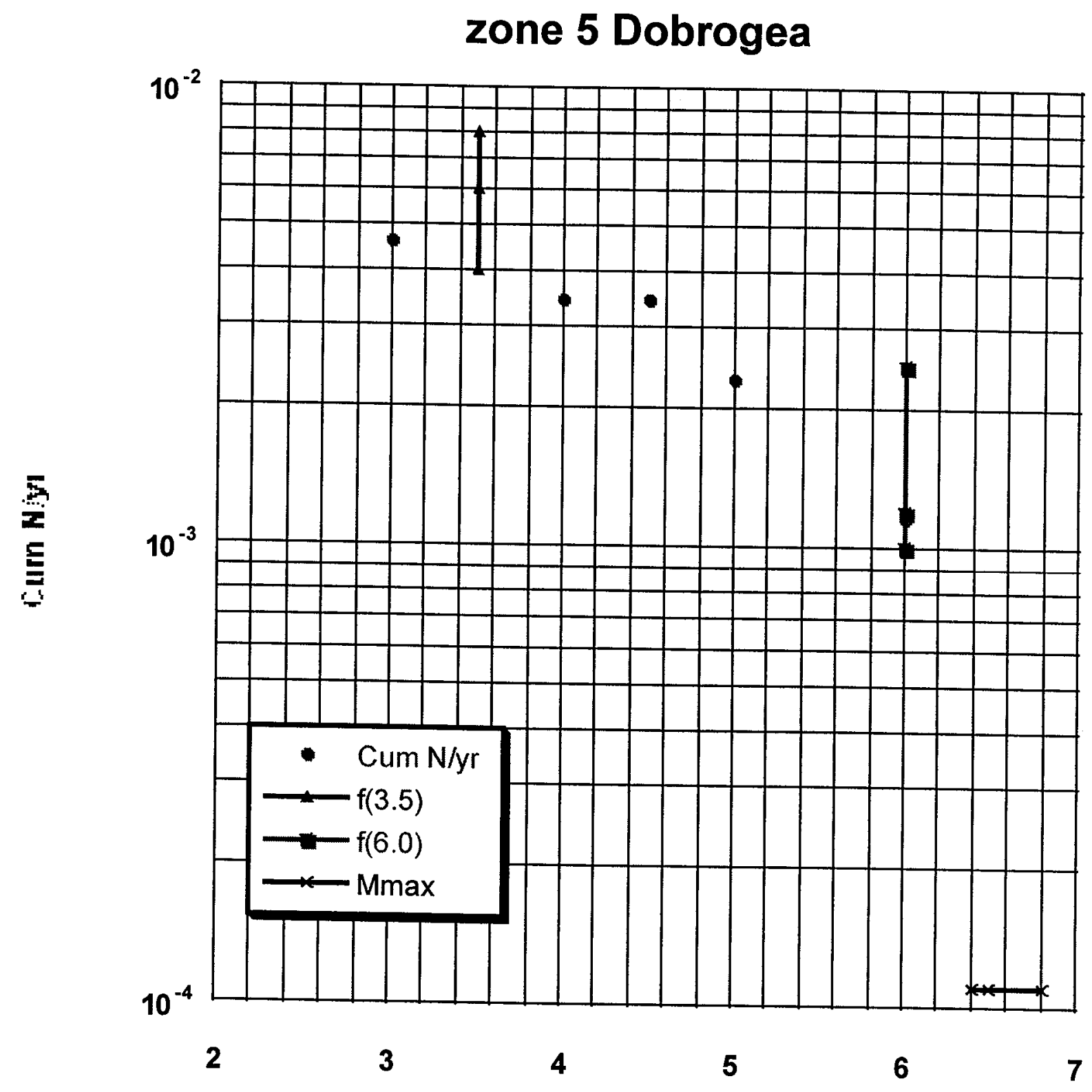

M - Magnitude bins

Figure 3.3.1.3.7: Observed cumulative annual number of earthquakes in Zone 5, the Dobrogea seismic zone. Estimate of the range of rates of events greater than magnitude 3.5 and $6.0, f(3.5)$ and $f(6.0)$ respectively. The horizontal bar shows the minimum and maximum of the distribution of $\mathbf{M}_{\max }$. 


\section{zone 6 West Crimea}

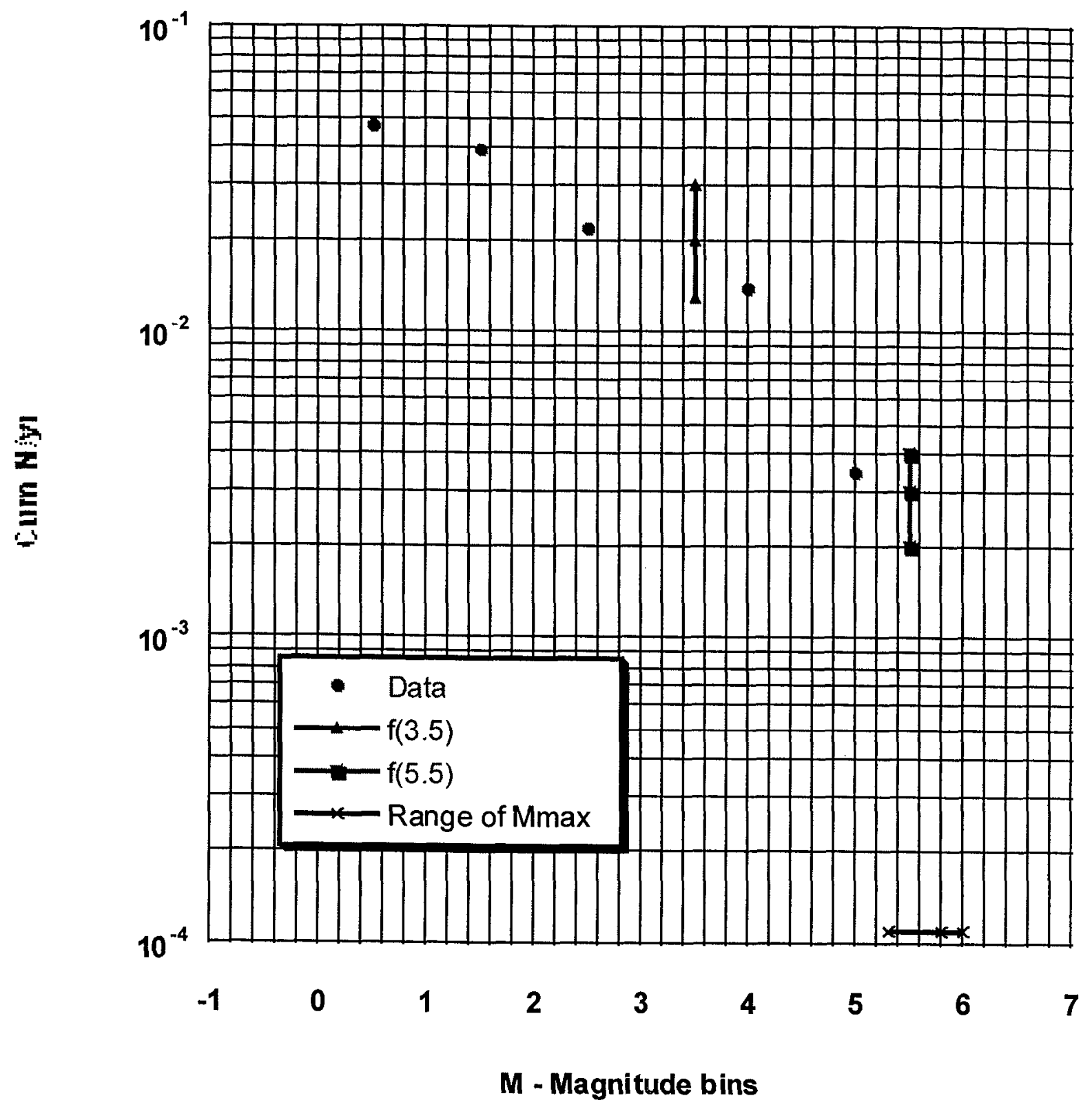

Figure 3.3.1.3.8: Observed cumulative annual number of earthquakes in Zone 6, the West Crimea seismic zone. Estimate of the range of rates of events greater than magnitude 3.5 and $5.5, f(3.5)$ and $f(5.5)$ respectively. The horizontal bar shows the minimum and maximum of the distribution of $\mathbf{M}_{\max }$. 


\section{zone 7 Crimea Kerch Caucasus}

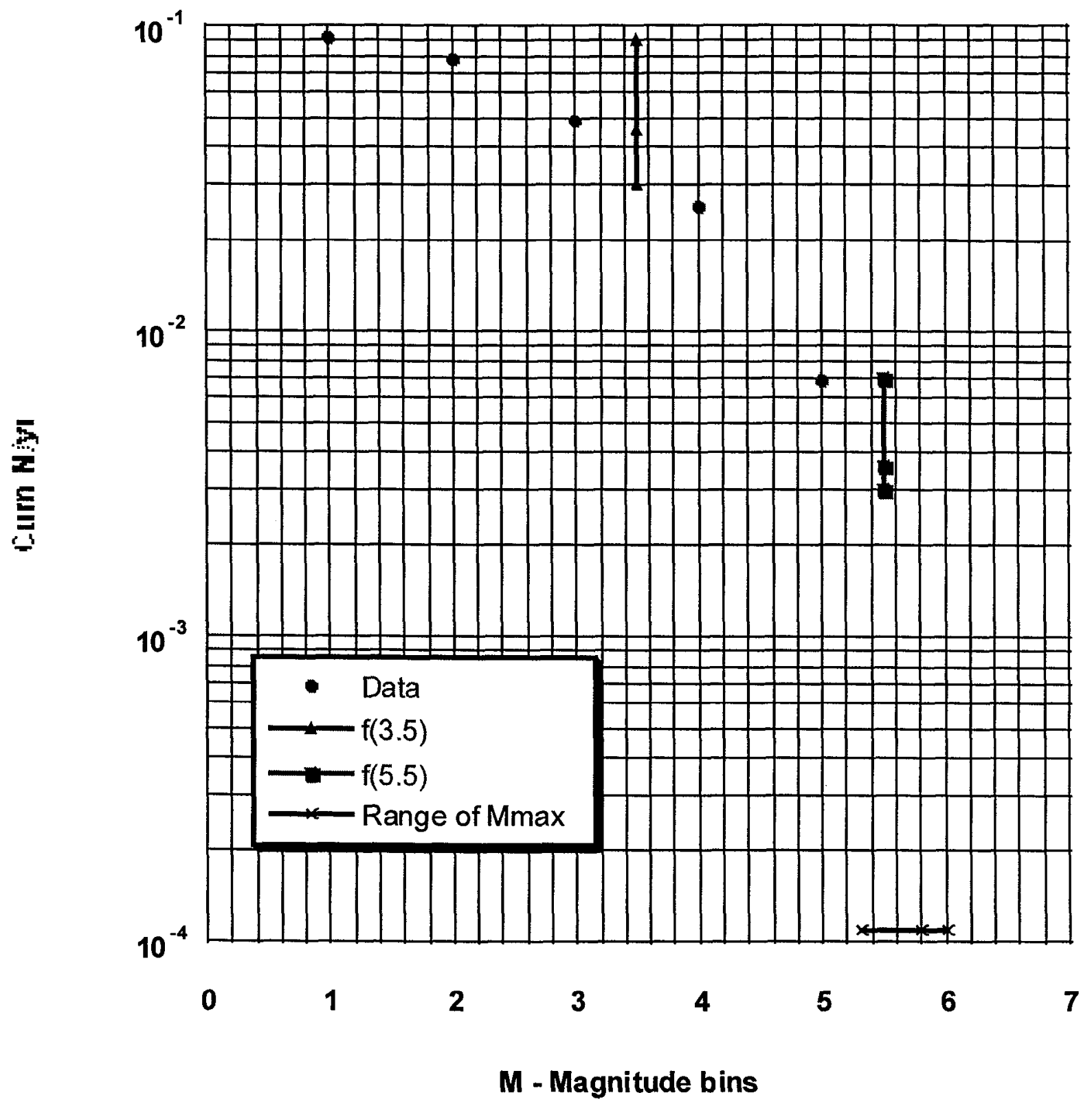

Figure 3.3.1.3.9: Observed cumulative annual number of earthquakes in Zone 7, the Crimea Kerch Caucasus seismic zone. Estimate of the range of rates of events greater than magnitude 3.5 and $5.5, f(3.5)$ and $f(5.5)$ respectively. The horizontal bar shows the minimum and maximum of the distribution of $\mathbf{M}_{\max }$. 
zone 8 Deformed Black Sea Plate

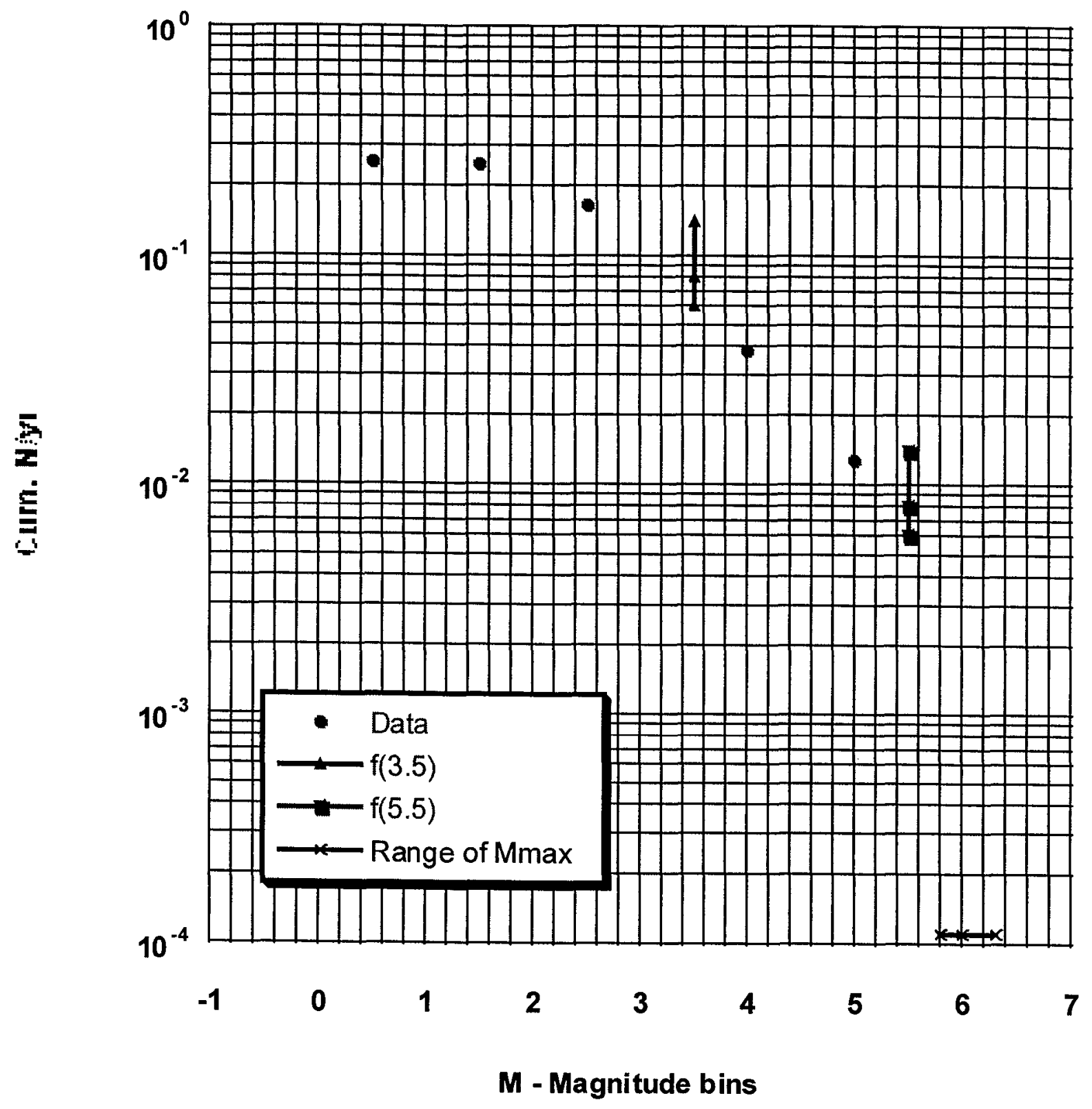

Figure 3.3.1.3.10: Observed cumulative annual number of earthquakes in Zone 8, the Deformed Black Sea Plate seismic zone. Estimate of the range of rates of events greater than magnitude 3.5 and $5.5, f(3.5)$ and $f(5.5)$ respectively. The horizontal bar shows the minimum and maximum of the distribution of $\mathbf{M}_{\max }$. 


\section{zone 9 Yalta}

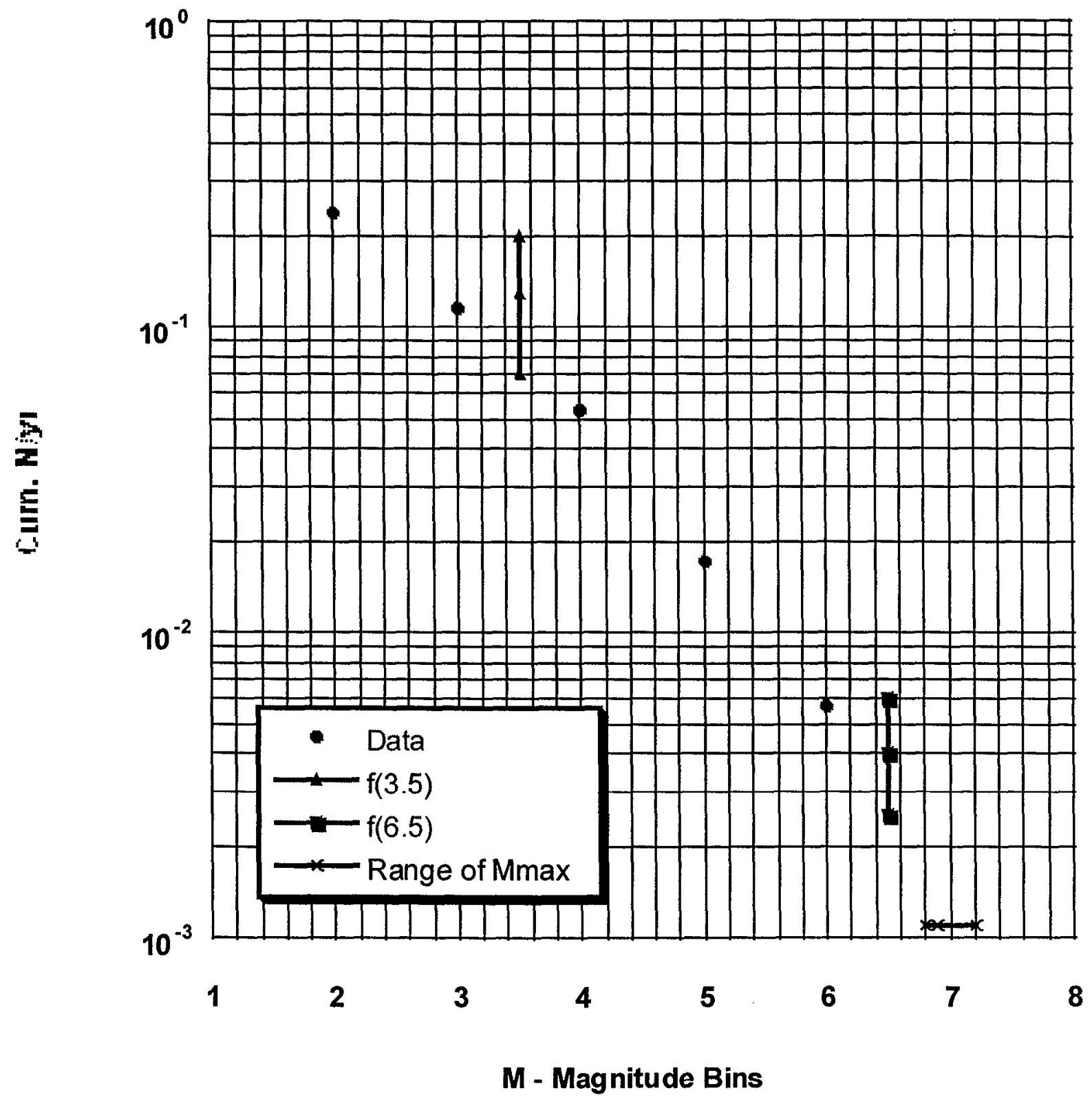

Figure 3.3.1.3.11: Observed cumulative annual number of earthquakes in Zone 9, the Yalta seismic zone. Estimate of the range of rates of events greater than magnitude 3.5 and $6.5, f(3.5)$ and $f(6.5)$ respectively. The horizontal bar shows the minimum and maximum of the distribution of $\mathbf{M}_{\max }$. 


\section{zone 10 PDD Rift}

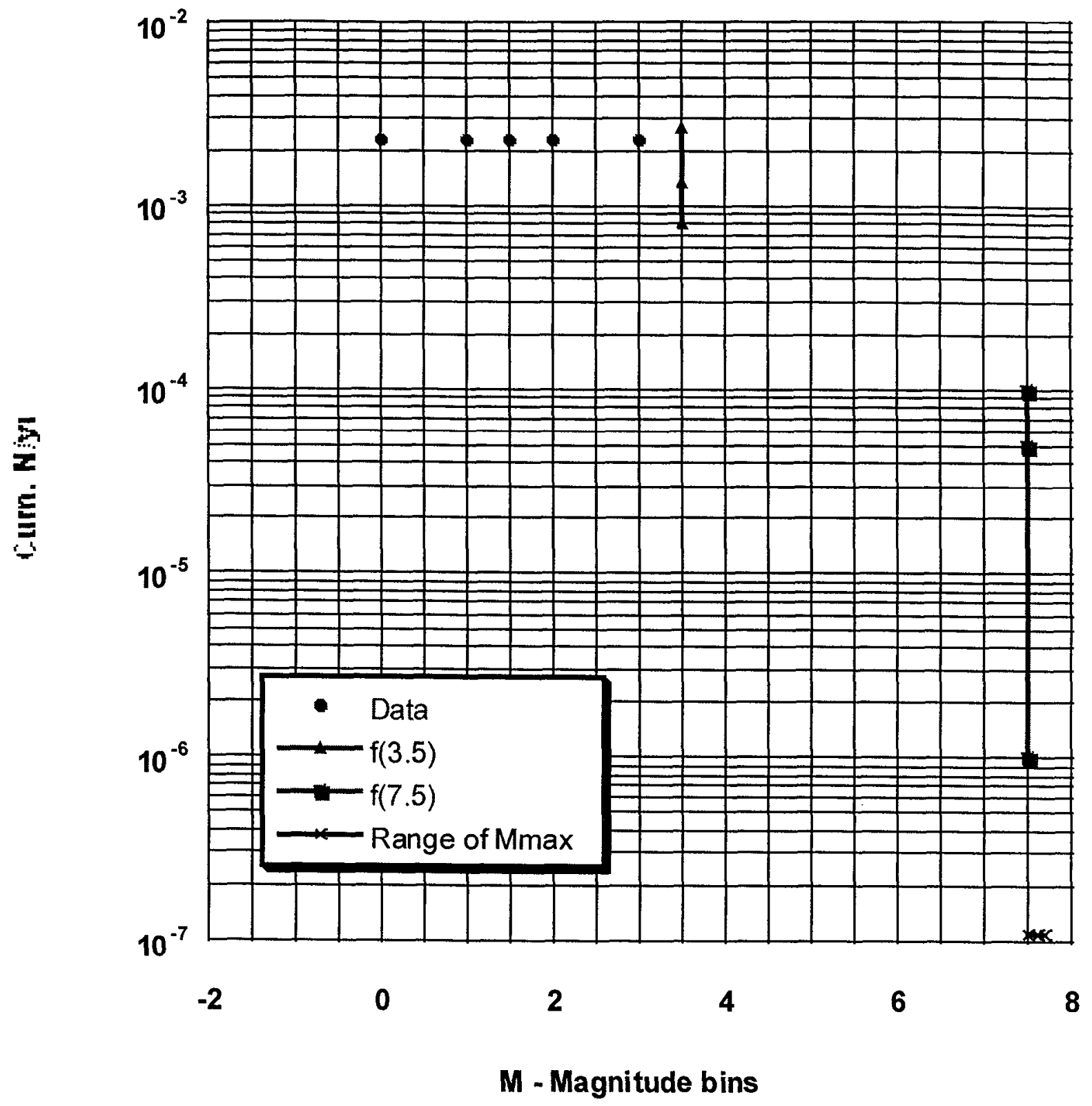

Figure 3.3.1.3.12: Observed cumulative annual number of earthquakes in Zone 14, the Pripyat Dniepro Donnets Rift, rare events, seismic zone. Estimate of the range of rates of events greater than magnitude 3.5 and $7.5, f(3.5)$ and $f(7.5)$ respectively. The horizontal bar shows the minimum and maximum of the distribution of $M_{\max }$. 


\section{zone 11 East European Craton}

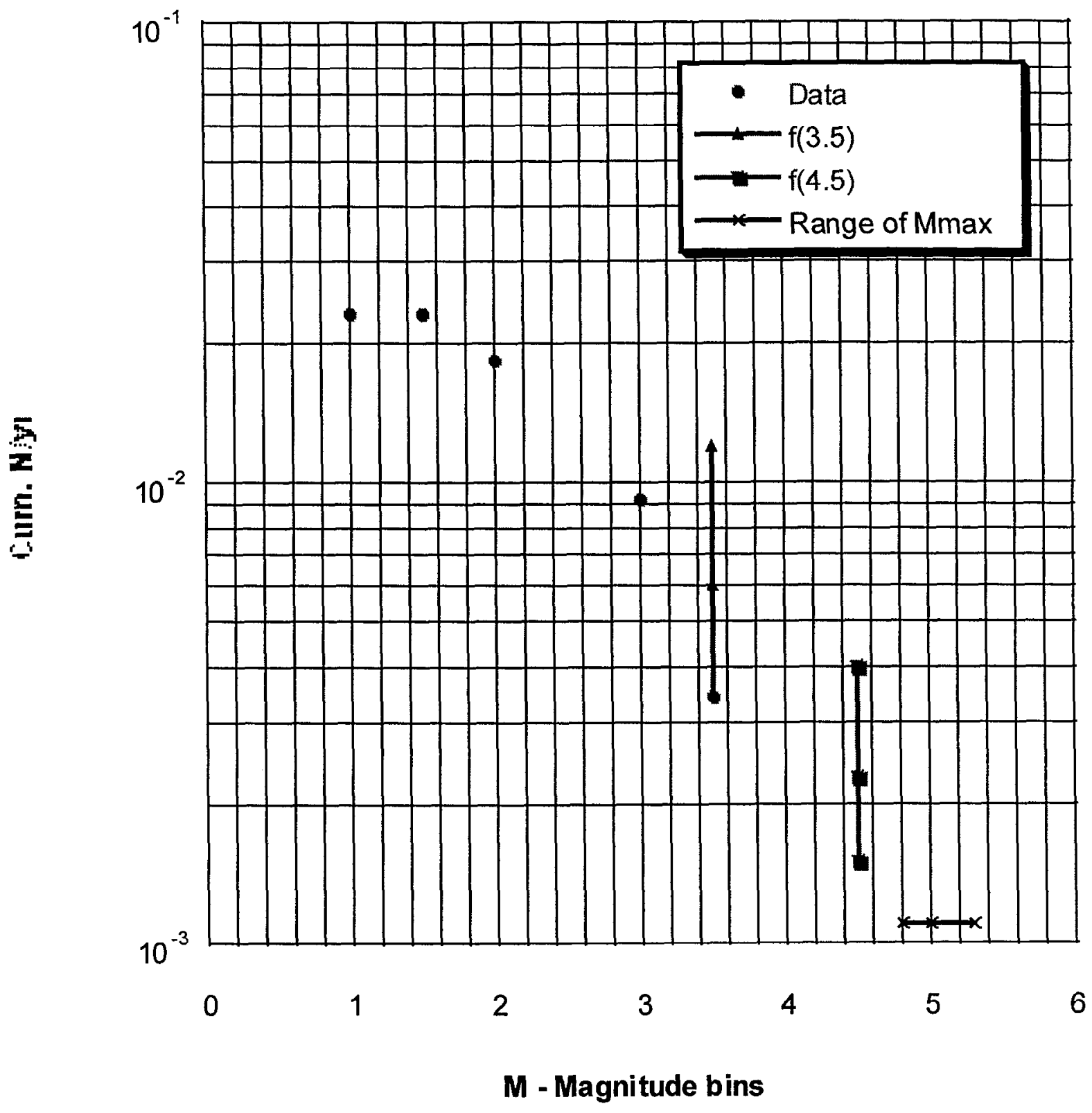

Figure 3.3.1.3.13: Observed cumulative annual number of earthquakes in Zone11, the East European Craton seismic zonc. Estimate of the range of rates of events greater than magnitude 3.5 and $6.5, f(4.5)$ and $f(4.5)$ respectively. The horizontal bar shows the minimum and maximum of the distribution of $M_{\max }$. 


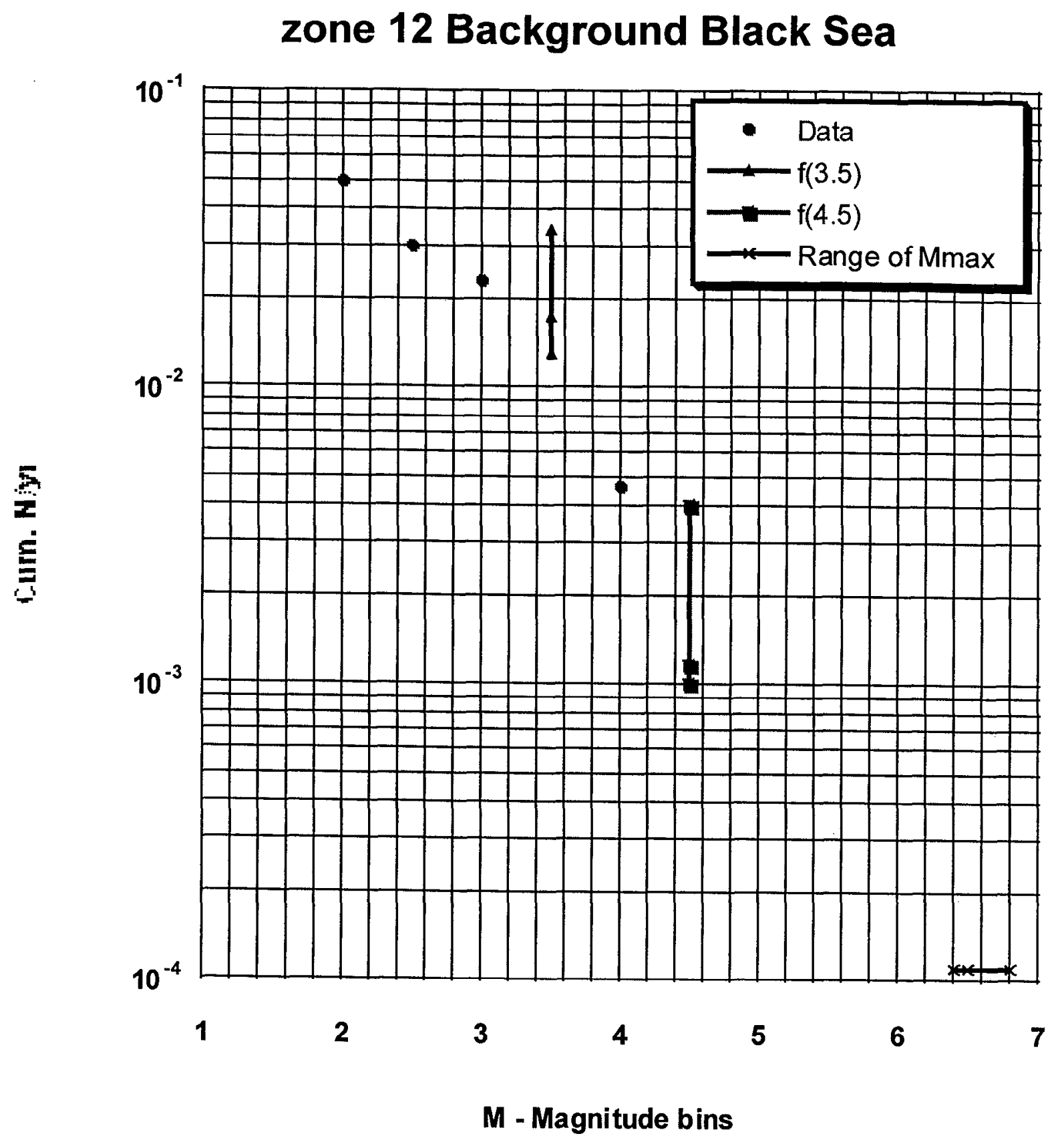

Figure 3.3.1.3.14: Observed cumulative annual number of earthquakes in Zone 12, the Background Black Sea seismic zone. Estimate of the range of rates of events greater than magnitude 3.5 and $4.5, f(3.5)$ and $f(4.5)$ respectively. The horizontal bar shows the minimum and maximum of the distribution of $M_{\text {max }}$. 


\section{Ground Motion Models Comparison Stable Region, Rock, $M=4$}

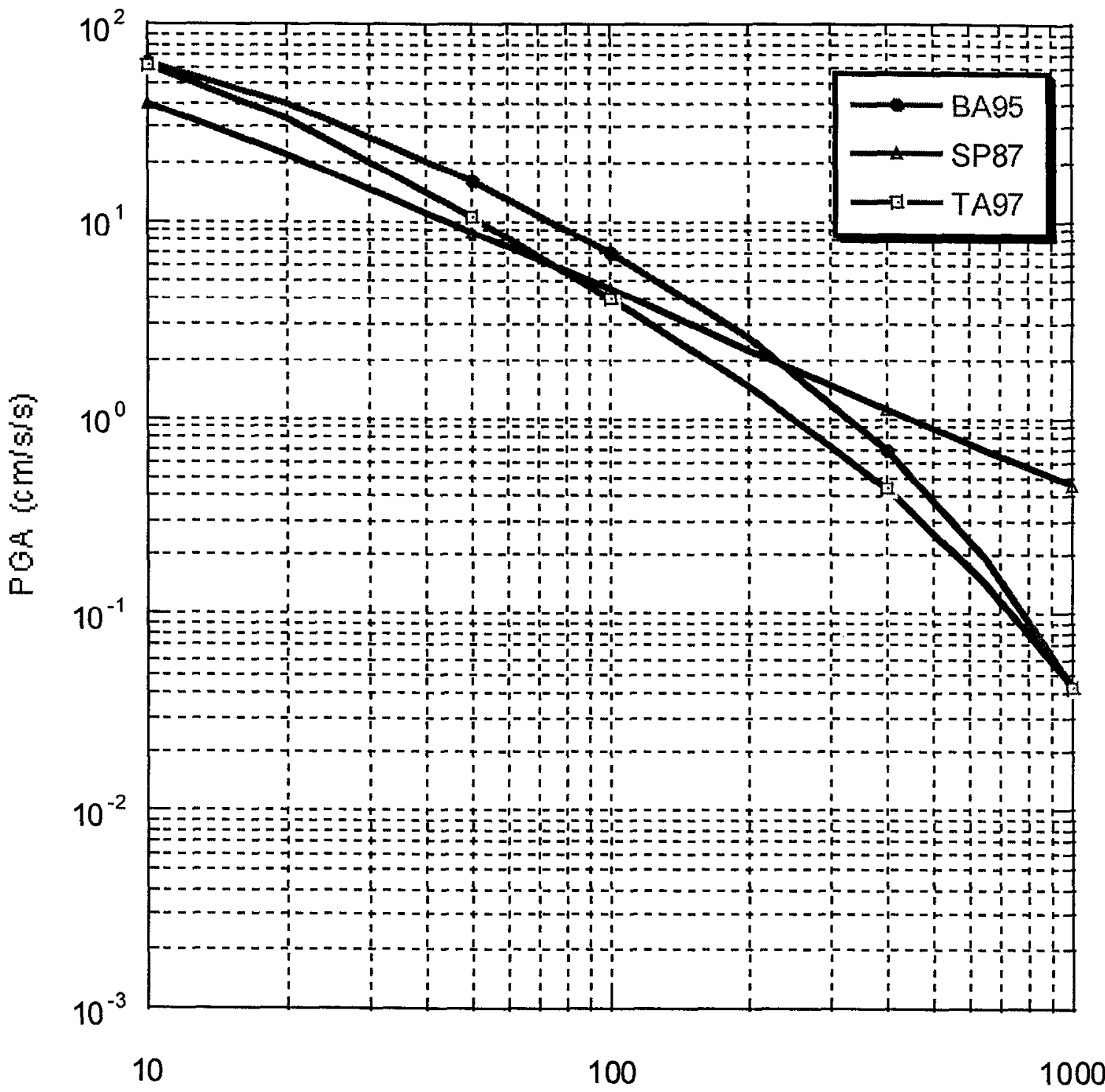

Distance $(\mathrm{km})$

Figure 3.3.2.1: Plot of the Ground Motion Attenuation Models selected for the Stable Region, for Rock Conditions and M4. 


\section{Ground Motion Models Comparison Stable Region, Rock, M = 5}

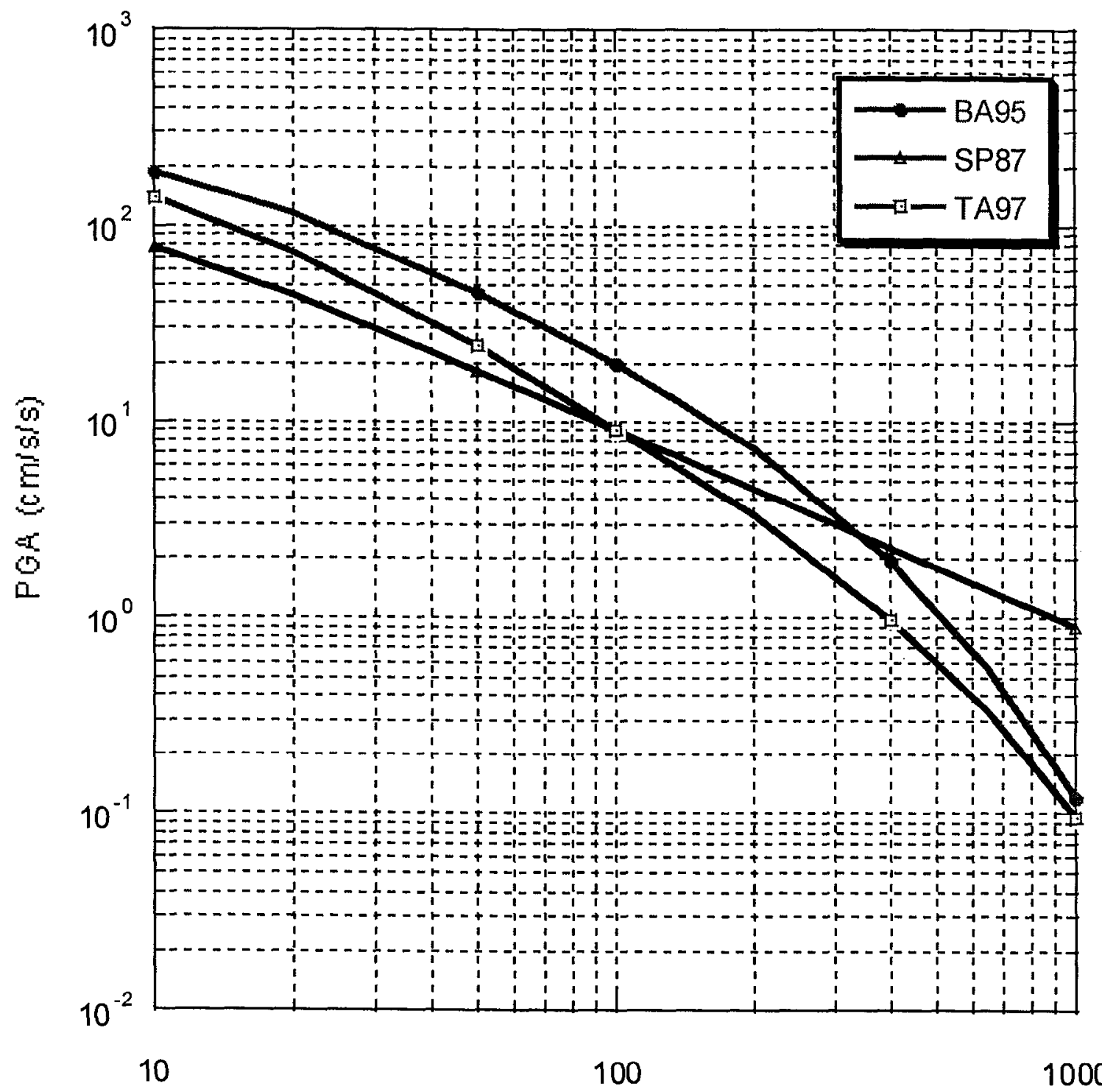

Distance $(\mathrm{km})$

Figure 3.3.2.2: Plot of the Ground Motion Attenuation Models selected for the Stable Region, for Rock Conditions and M5. 


\section{Ground Motion Models Comparison Stable Region, Rock, $M=6$}

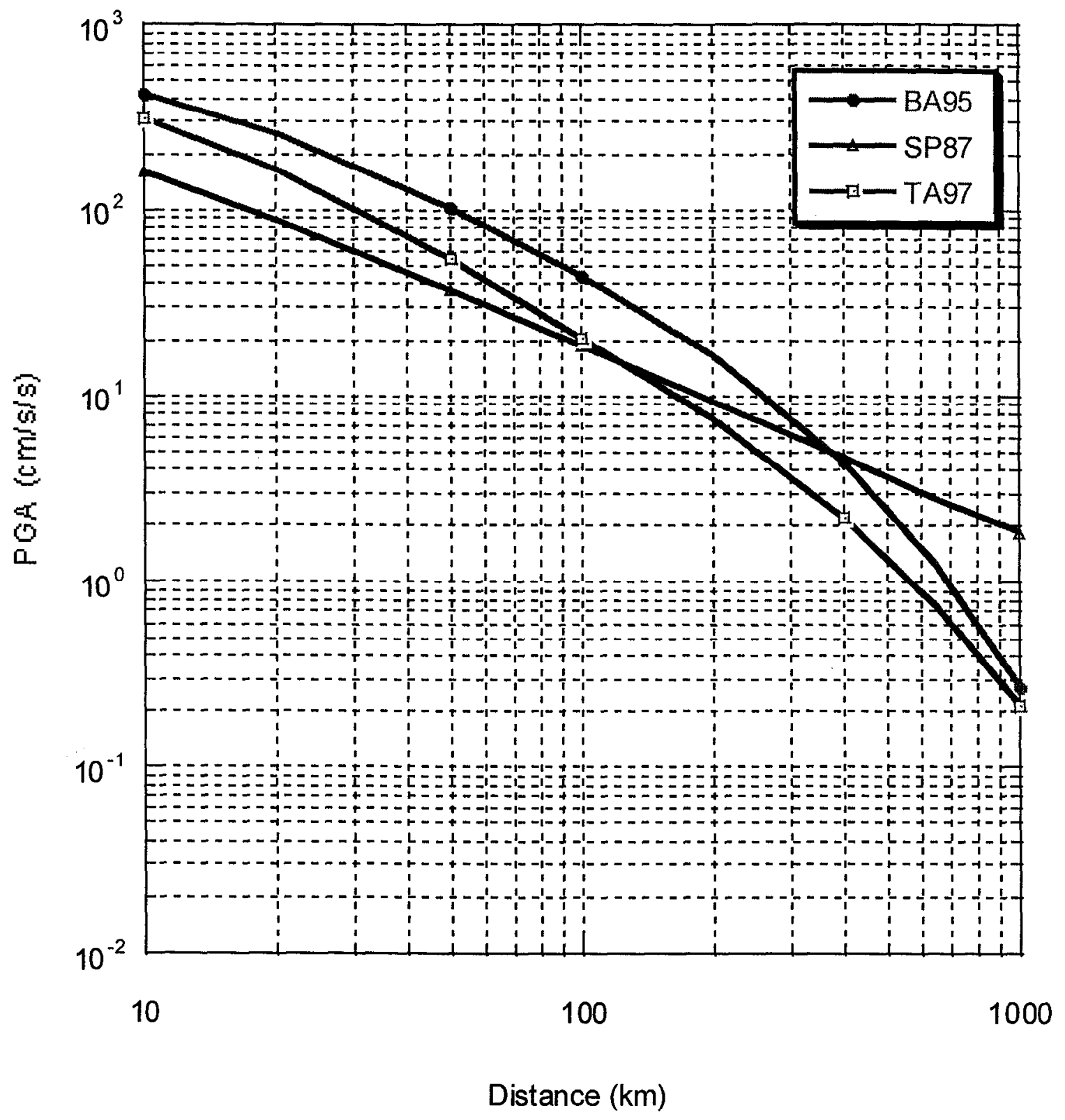

Figure 3.3.2.3: Plot of the Ground Motion Attenuation Models selected for the Stable Region, for Rock Conditions and M6. 


\section{Ground Motion Models Comparison Stable Region, Rock, $M=7$}

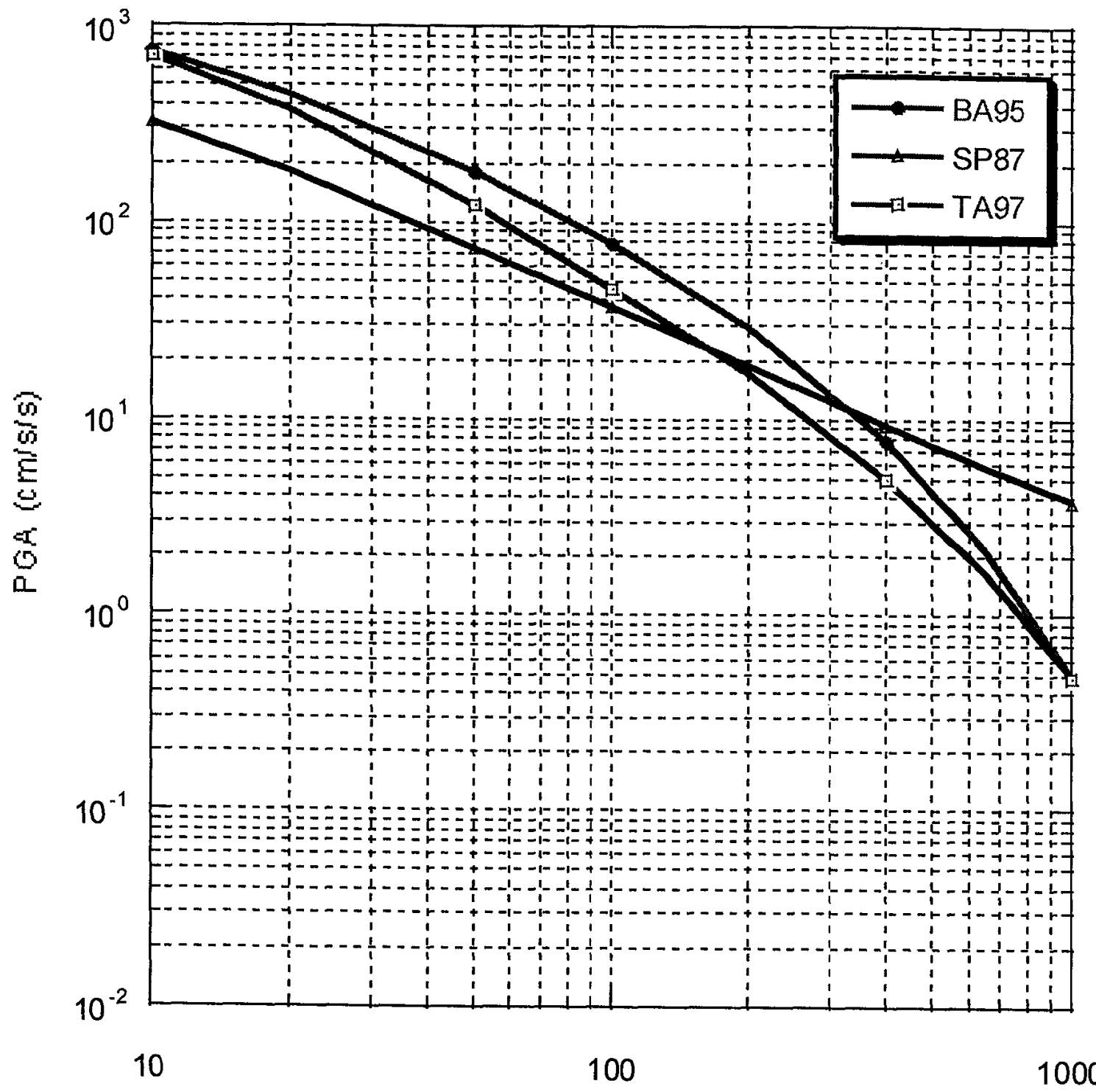

Distance $(\mathrm{km})$

Figure 3.3.2.4: Plot of the Ground Motion Attenuation Models selected for the Stable Region, for Rock Conditions and M7. 


\section{Ground Motion Models Comparison Vrancea Deep Events (h>100km), Rock, $M=4$}

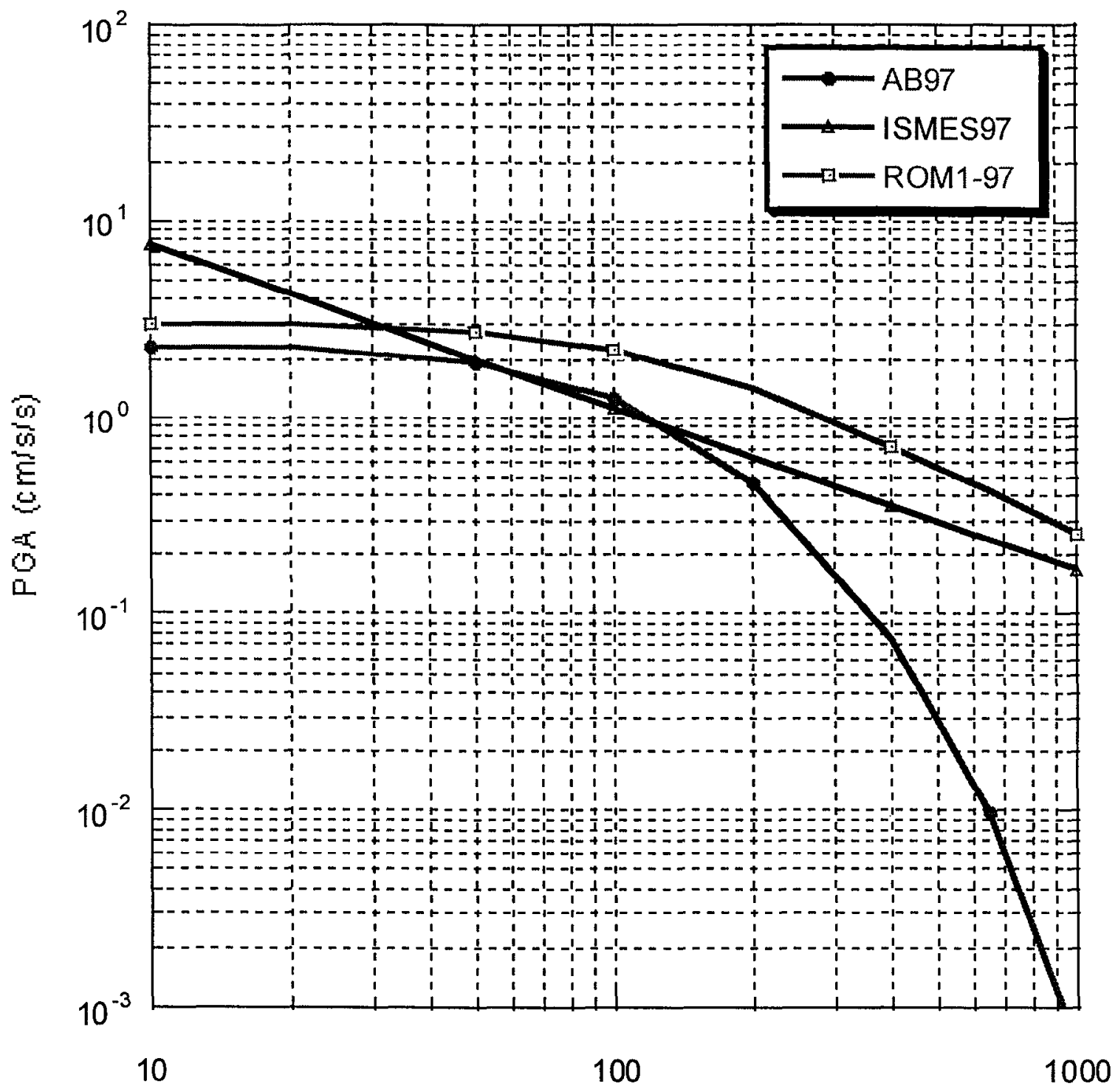

Distance $(\mathrm{km})$

Figure 3.3.2.5: Plot of the Ground Motion Attenuation Models selected for the Vrancea Deep Events, for Rock Conditions and M4. 


\section{Ground Motion Models Comparison Vrancea Deep Events (h>100km), Rock, M = 5}

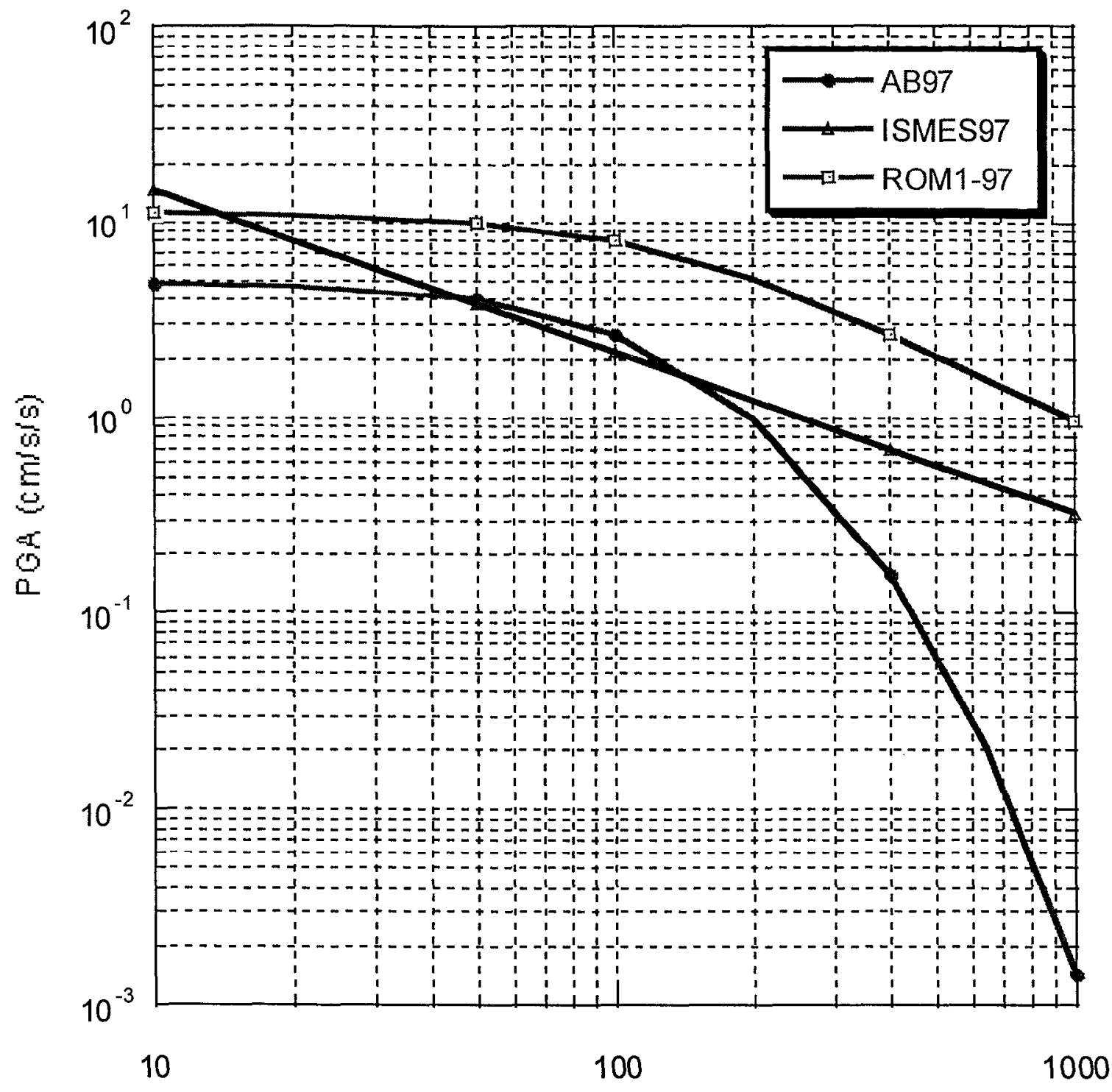

Distance $(\mathrm{km})$

Figure 3.3.2.6: Plot of the Ground Motion Attenuation Models selected for the Vrancea Deep Events, for Rock Conditions and M5. 


\section{Ground Motion Models Comparison Vrancea Deep Events (h>100km), Rock, $M=6$}

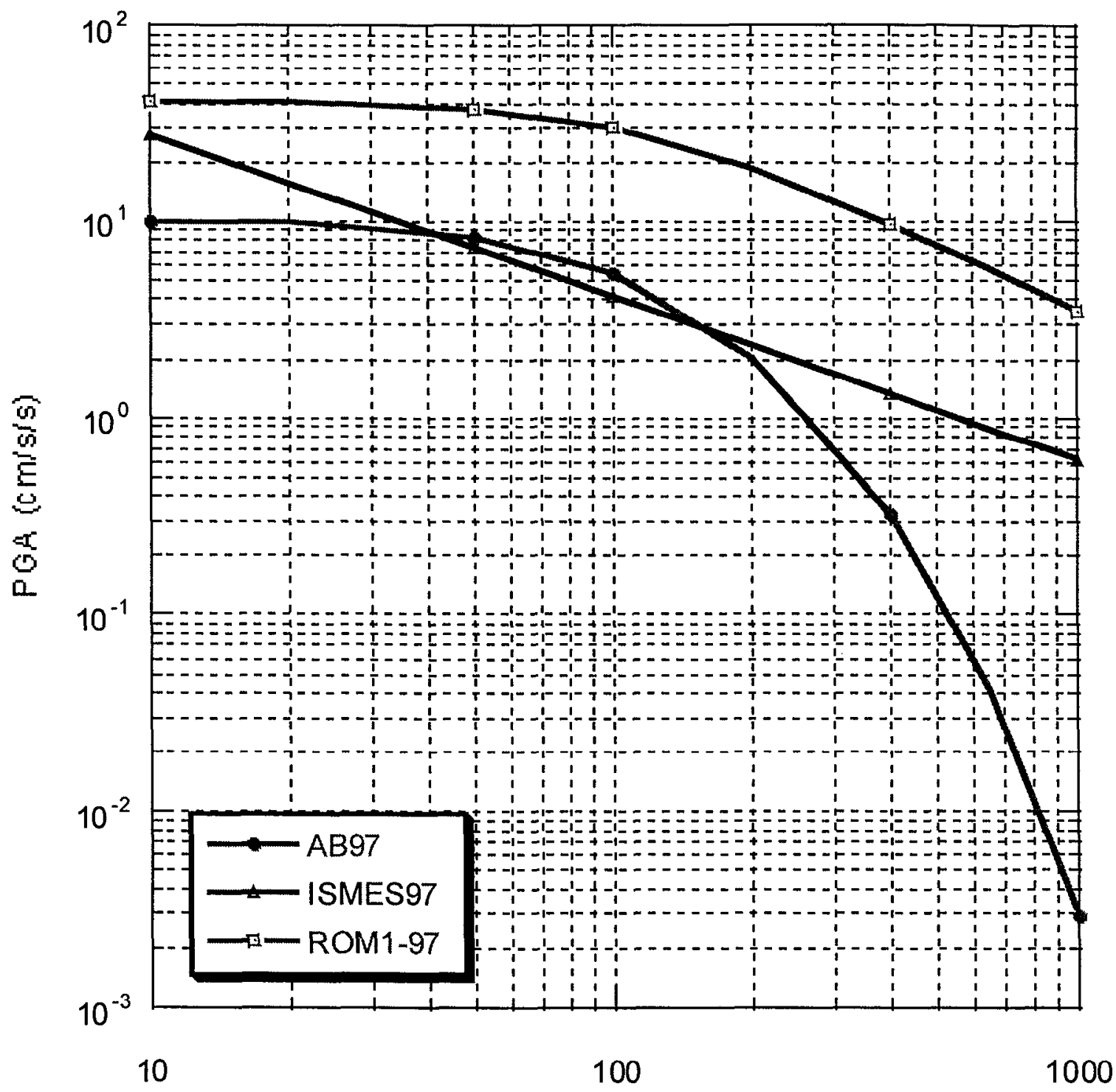

Distance $(\mathrm{km})$

Figure 3.3.2.7: Plot of the Ground Motion Attenuation Models selected for the Vrancea Deep Events, for Rock Conditions and M6. 


\section{Ground Motion Models Comparison Vrancea Deep Events (h>100km), Rock, $M=7$}

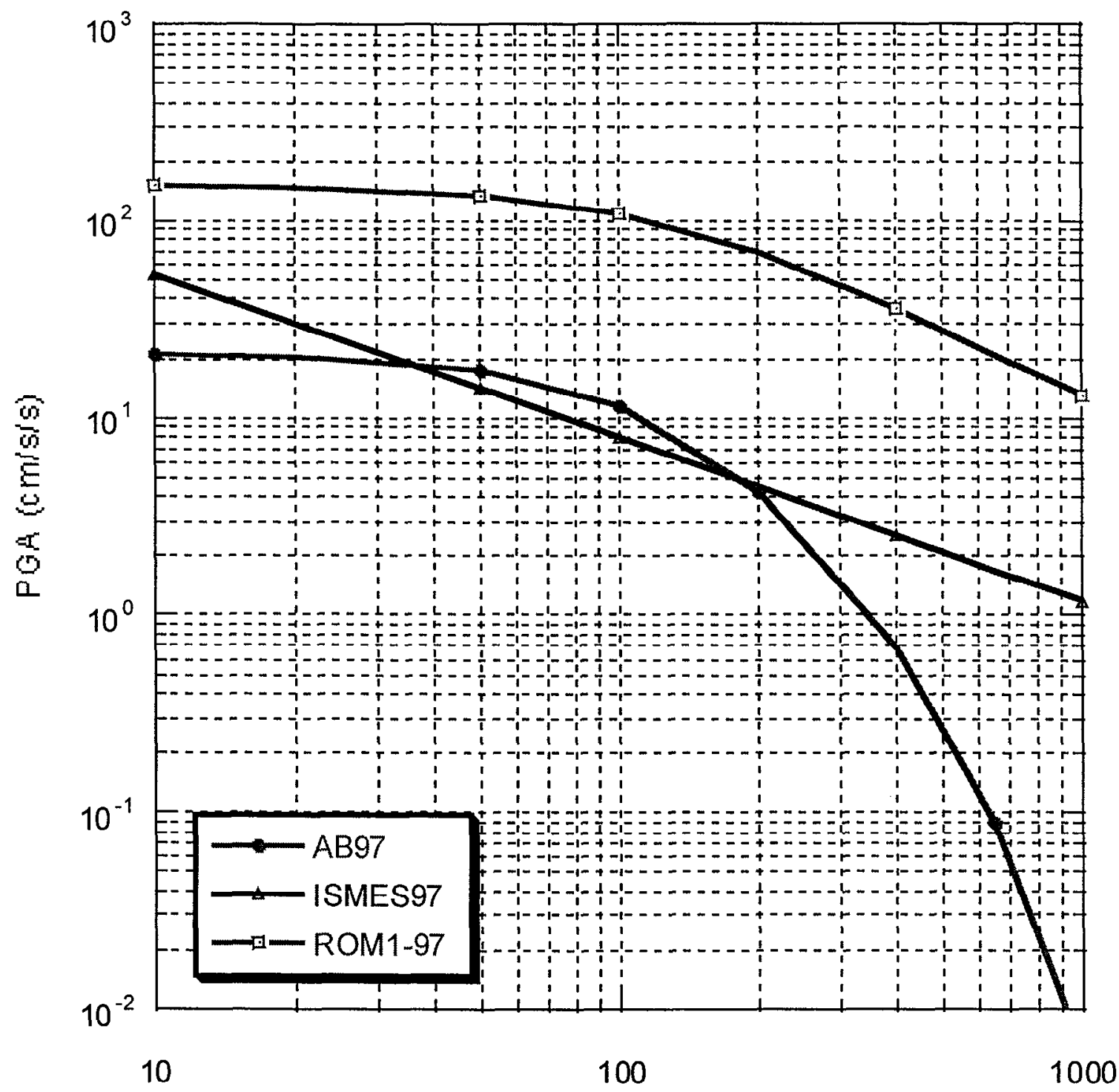

Distance $(\mathrm{km})$

Figure 3.3.2.8: Plot of the Ground Motion Attenuation Models selected for the Vrancea Deep Events, for Rock Conditions and M7. 


\section{Ground Motion Models Comparison \\ Vrancea Shallow Events $(\mathrm{h}<100 \mathrm{~km})$, Rock, $M=4$}

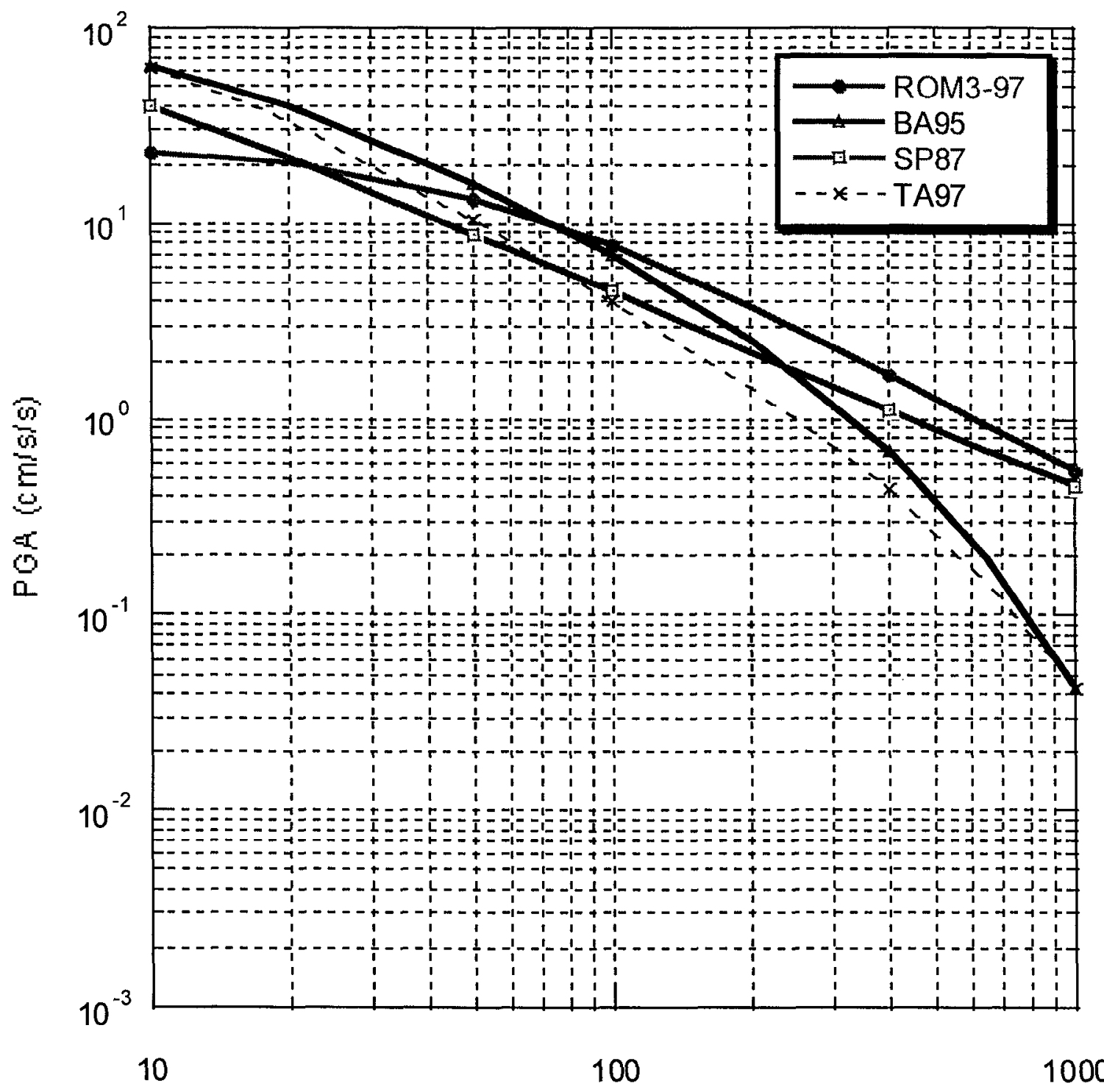

Distance $(\mathrm{km})$

Figure 3.3.2.9: Plot of the Ground Motion Attenuation Models selected for the Vrancea Shallow Events, for Rock Conditions and M4. 


\section{Ground Motion Models Comparison Vrancea Shallow Events $(\mathrm{h}<100 \mathrm{~km})$, Rock, $\mathrm{M}=5$}

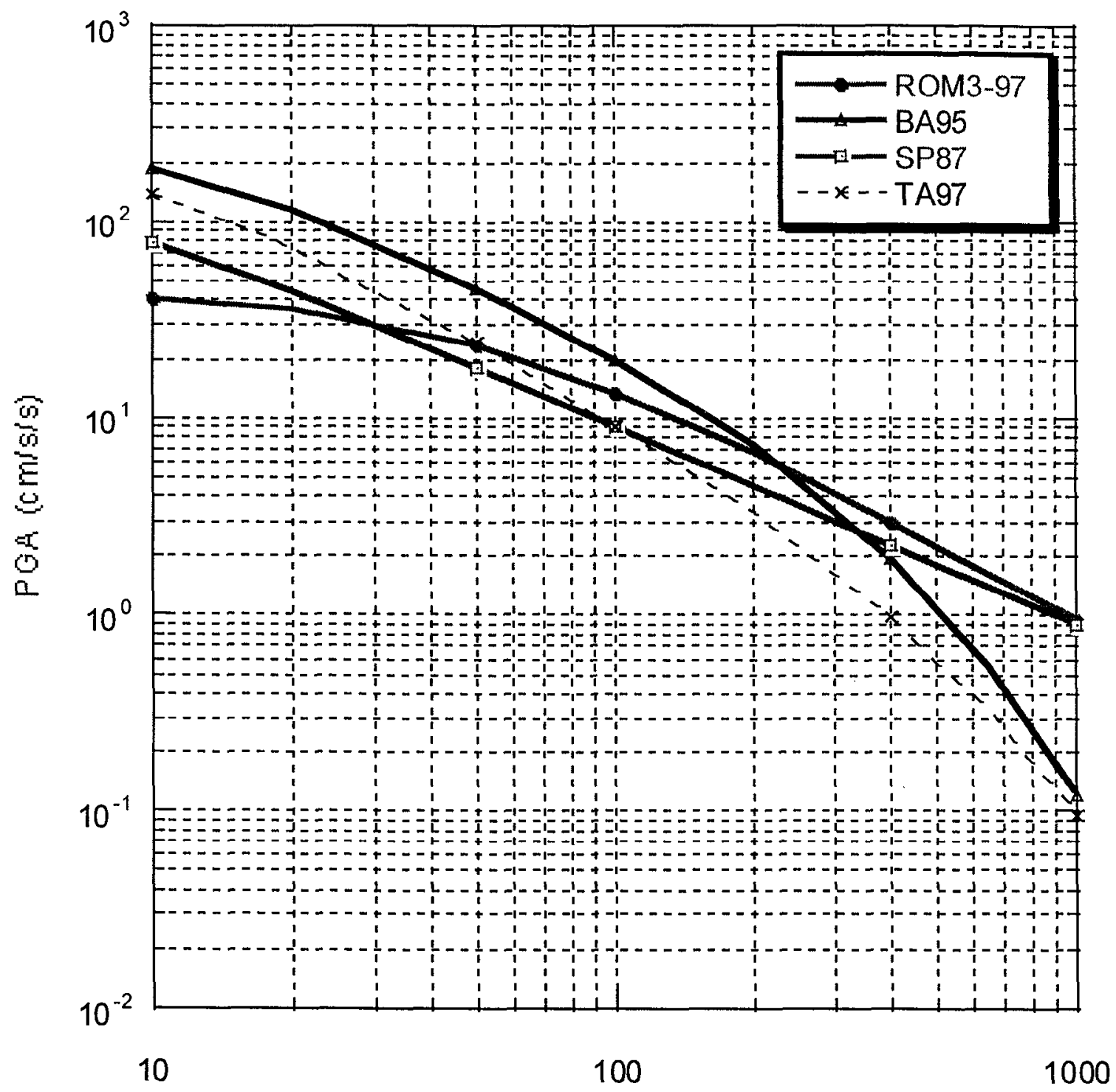

Distance $(\mathrm{km})$

Figure 3.3.2.10: Plot of the Ground Motion Attenuation Models selected for the Vrancea Shallow Events, for Rock Conditions and M5. 


\section{Ground Motion Models Comparison \\ Vrancea Shallow Events ( $<<100 \mathrm{~km})$, Rock, $M=6$}

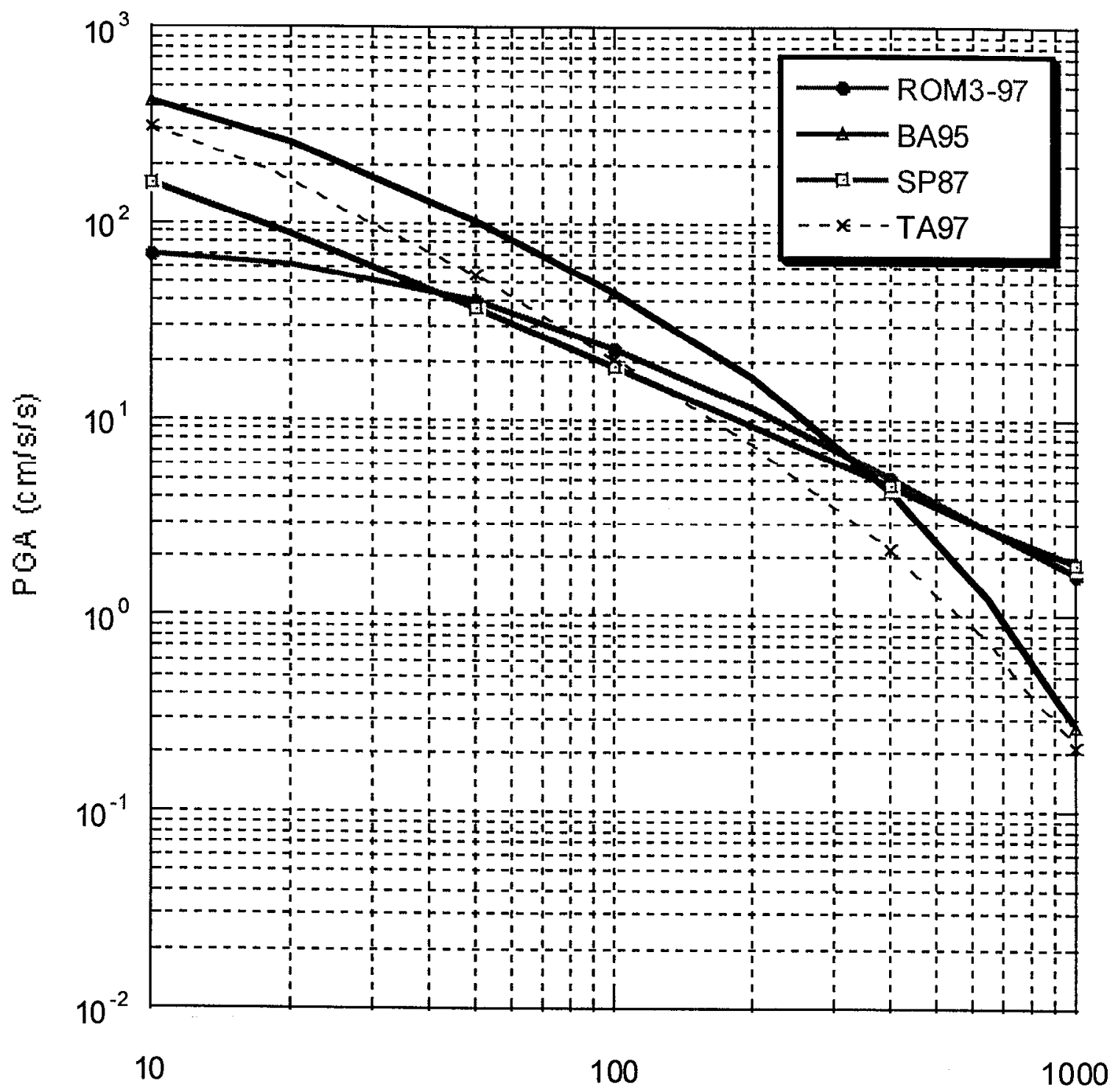

Distance $(\mathrm{km})$

Figure 3.3.2.11: Plot of the Ground Motion Attenuation Models selected for the Vrancea Shallow Events, for Rock Conditions and M6. 


\section{Ground Motion Models Comparison \\ Vrancea Shallow Events (h<100km), Rock, $M=7$}

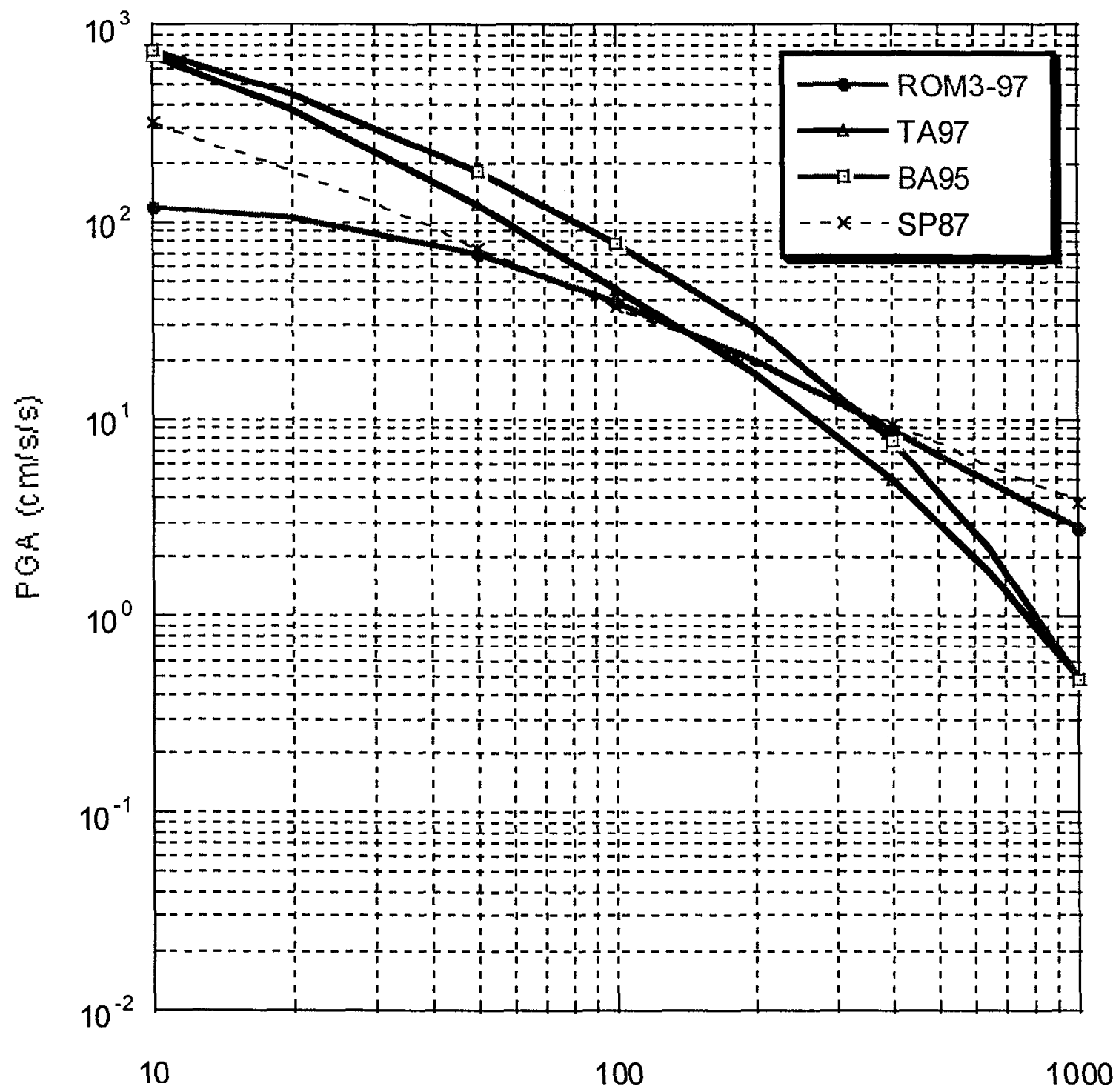

Distance (km)

Figure 3.3.2.12: Plot of the Ground Motion Attenuation Models selected for the Vrancea Shallow Events, for Rock Conditions and M7. 


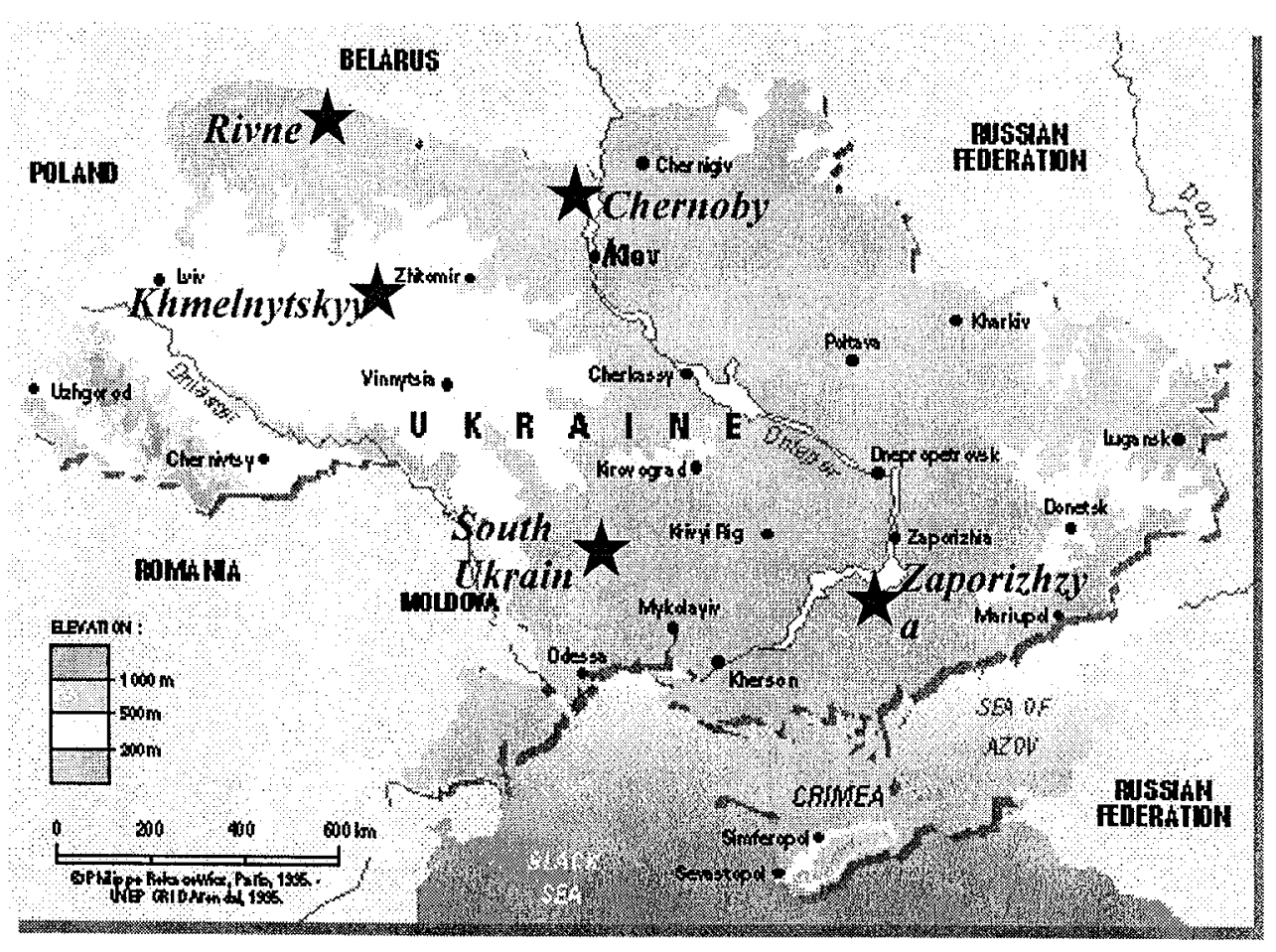

\begin{tabular}{|c|c|c|}
\hline Site & Latitude North & Longitude East \\
\hline ChernobyI & 51.20 & 30.05 \\
Khmelnytskyy & 50.30 & 26.70 \\
Rivne & 51.40 & 26.00 \\
South Ukraine & 47.80 & 31.20 \\
Zaporizhzya & 47.30 & 34.60 \\
\hline
\end{tabular}

Figure 3.4.1: General Geology of Ukraine showing the location of the five nuclear plant sites whose coordinates are given below: 


\section{CHERNOBYL \\ HAZARD ESTIMATES for PGA (Bedrock)}
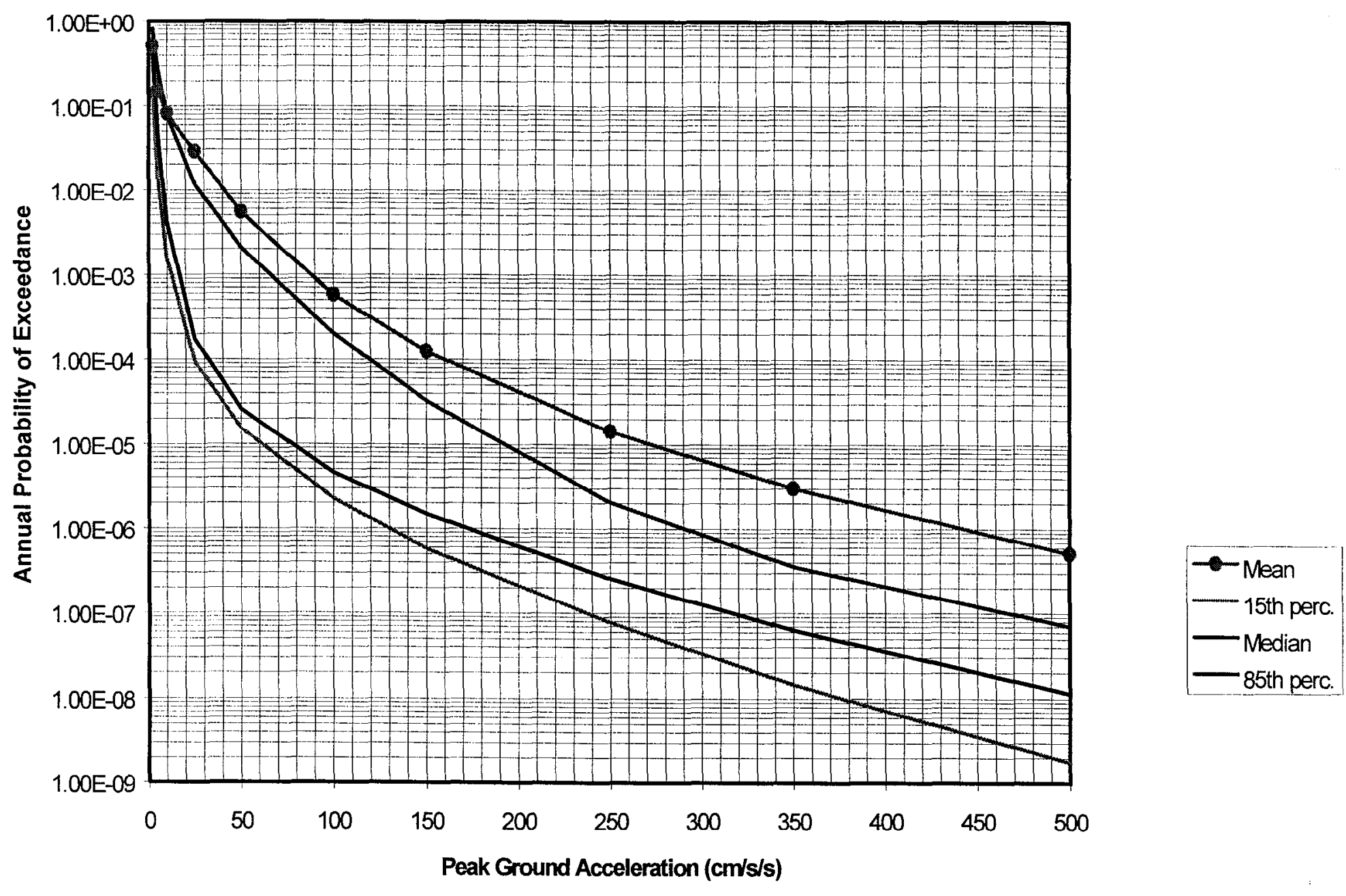

Figure 3.4.2.1 PSHA Results for a rock site at CHERNOBYL, at foundation level, in terms of the $15^{\text {th }}, 50^{\text {th }}, 85^{\text {th }}$ and arithmetic mean of the annual probability of exceedance of Peak Ground Accelcration. 
KMENYTSKYY

SESMC HAZARD ESTIMATES for PGA (Bedrock)

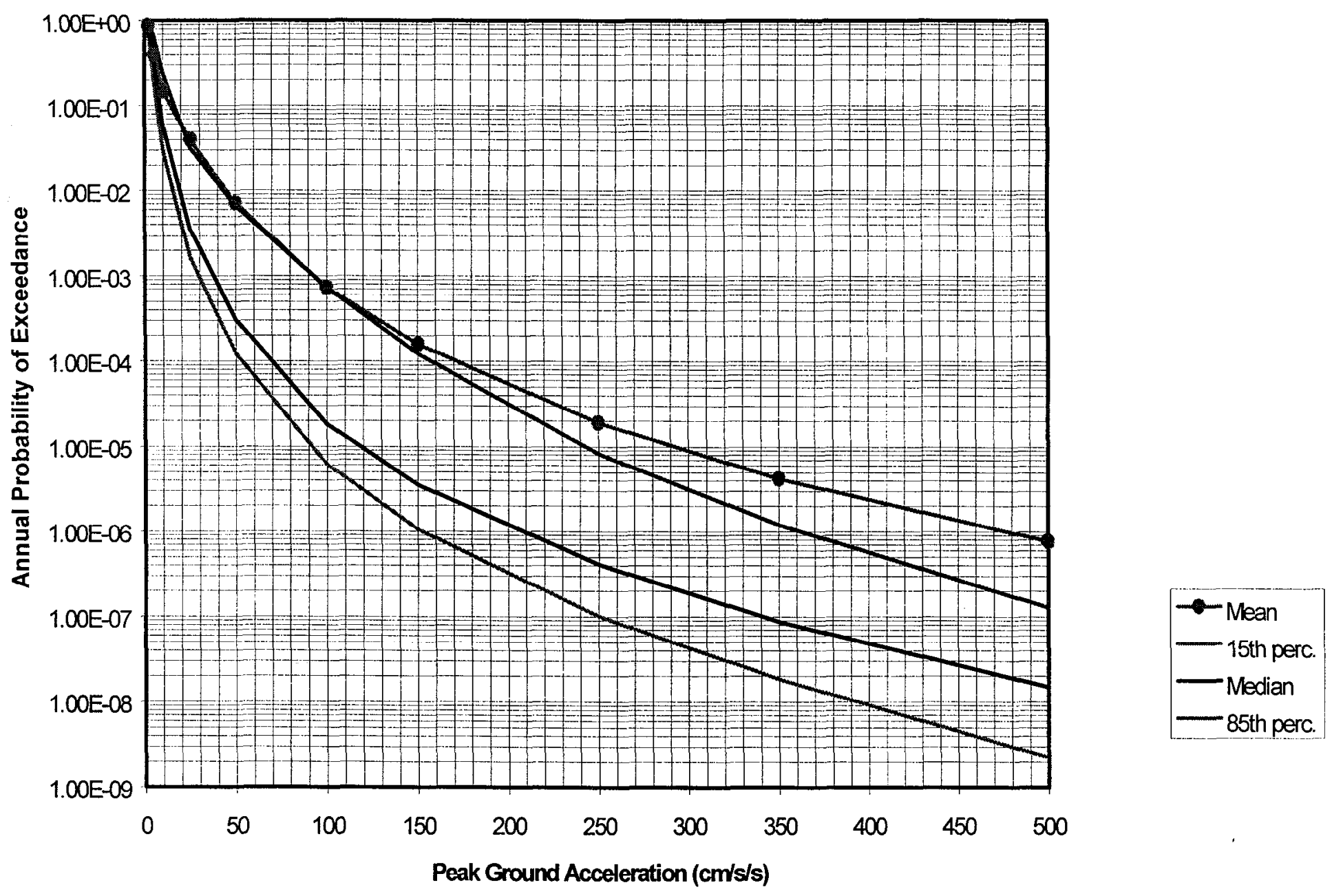

Figure 3.4.2.2 PSHA Results for a rock site at KHMELNYSTSKYY, at foundation level, in terms of the $15^{\text {th }}, 50^{\text {th }}, 85^{\text {th }}$ and arithmetic mean of the annual probability of exceedance of Peak Ground Acceleration. 


\section{RIVNE \\ SEISMIC HAZARD ESTIMATES for PGA (Bedrock)}
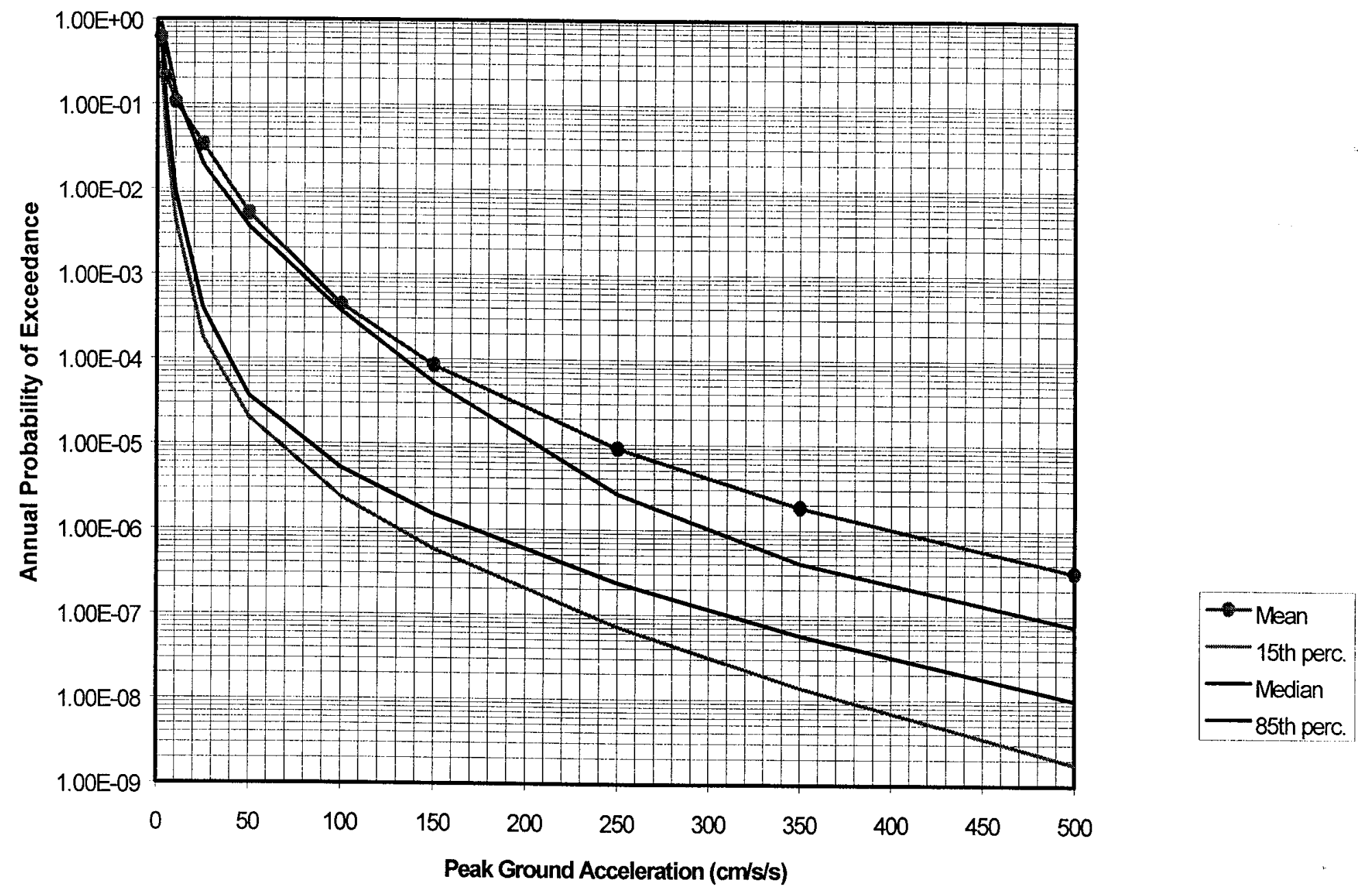

Figure 3.4.2.3 PSHA Results for a rock site at RIVNE, at foundation level, in terms of the 15th, $50 \mathrm{th}, 85$ thand arithmetic mean of the annual probability of exceedance of Peak Ground Acceleration. 


\section{SOUTH UKRAINE \\ SEISMIC HAZARD ESTIMATES for PGA (Bedrock)}
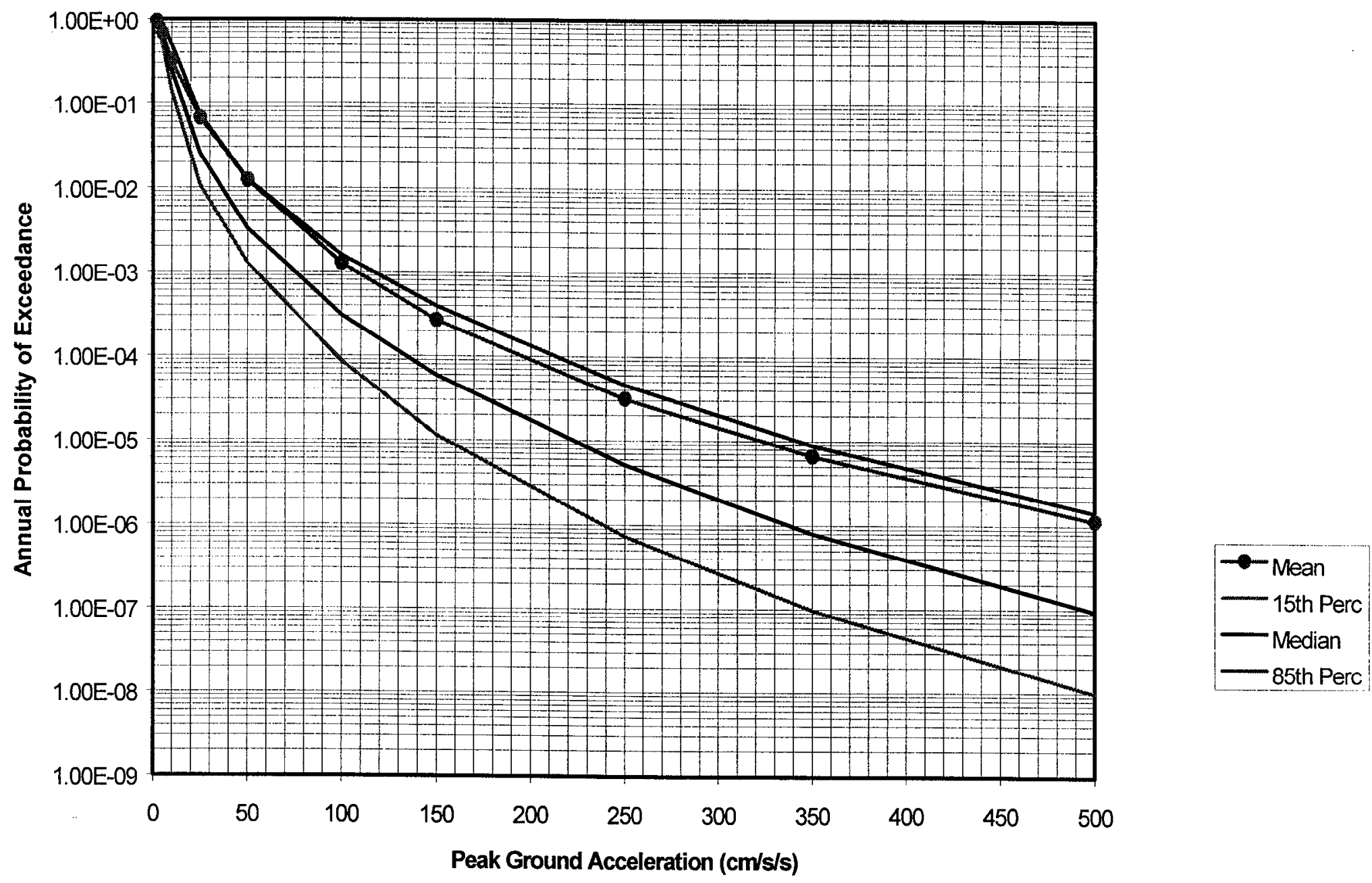

Figure 3.4.2.4 PSHA Results for a rock site at SOUTH-UKRAINE, at foundation level, in terms of the 15th, 50th, 85thand arithmetic mean of the annual probability of exceedance of Peak Ground Acceleration. 


\section{ZAPORYZHZYA \\ SEISMIC HAZARD ESTIMATES for PGA (Bedrock)}
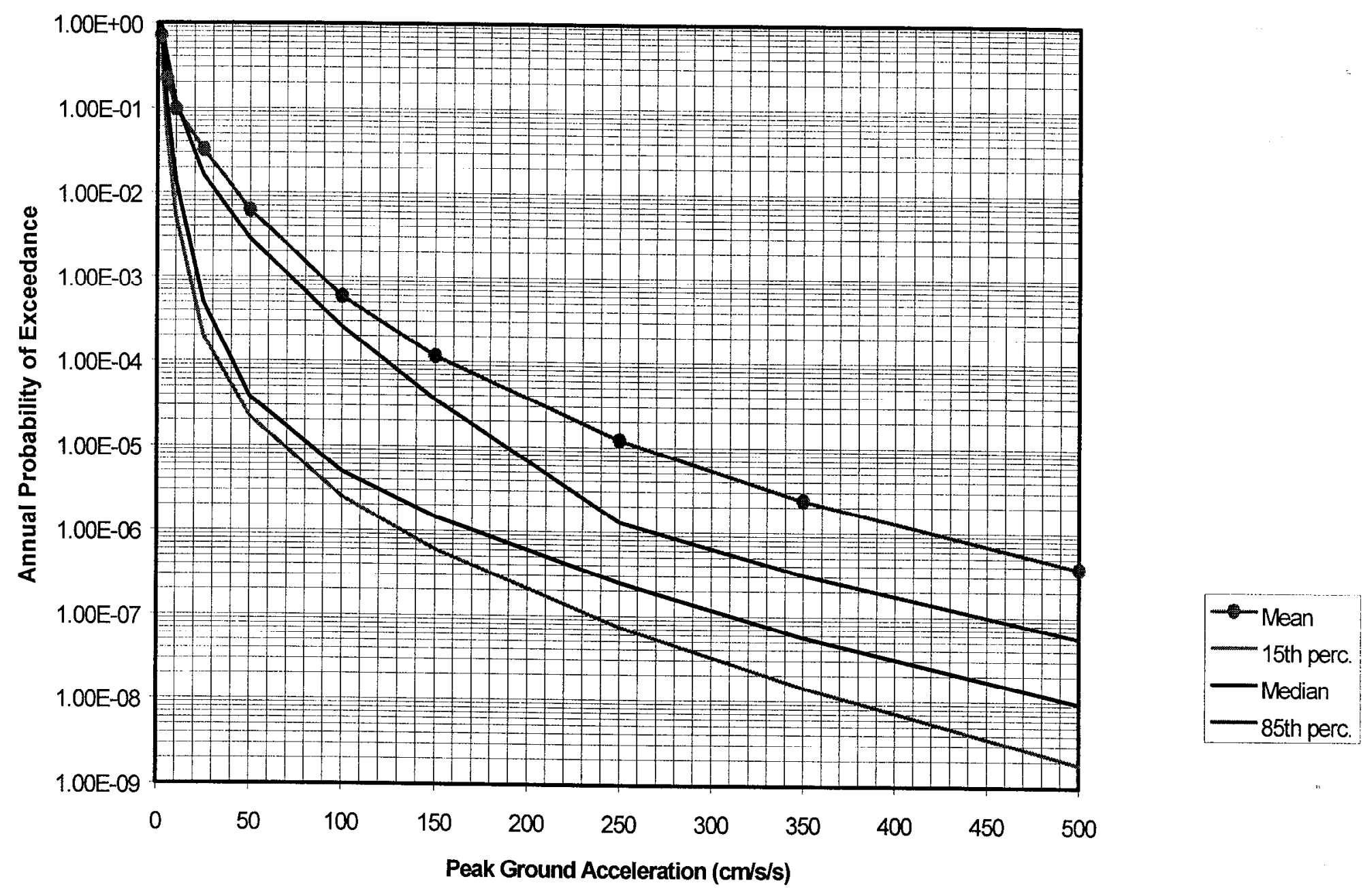

Figure 3.4.2.5 PSHA Results for a rock site at ZAPORIZHZYA, at foundation level, in terms of the 15th, 50th, 85thand arithmetic mean of the annual probability of exceedance of Peak Ground Acceleration. 


\section{Summary of Bedrock PGA Review Level Earthquake in cm/sec/sec}

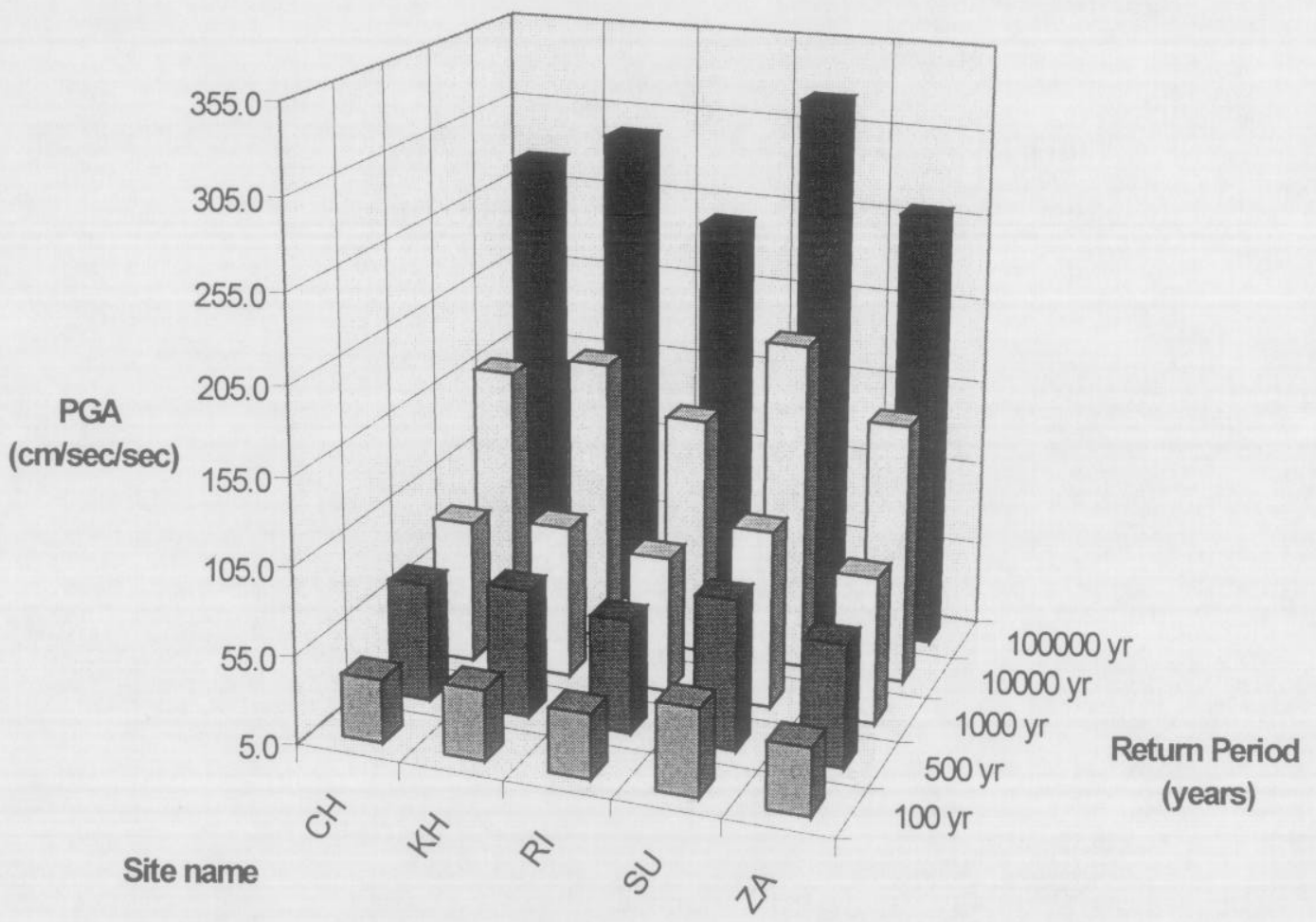

\begin{tabular}{l|c|c|c|c|c|}
\cline { 2 - 6 } & CH & KH & RI & SU \\
\hline$\square 100 \mathrm{yr}$ & 40.8 & 45.0 & 41.4 & 54.5 & ZA \\
\hline $500 \mathrm{yr}$ & 72.4 & 77.9 & 69.3 & 89.9 & 72.8 \\
\hline$\square 1000 \mathrm{yr}$ & 87.8 & 93.1 & 83.3 & 107.0 & 196.0 \\
\hline$\square 10000 \mathrm{yr}$ & 159.9 & 171.8 & 144.9 & 38.7 \\
\hline $100000 \mathrm{yr}$ & 273.0 & 292.8 & 245.1 & 323.4 & 261.6 \\
\hline
\end{tabular}

Figure 3.4.2.7: Summary of the Review Level PGA (cm/s2) for five sites in Ukraine and for 100-yr, 500-yr, 1000-yr, 10,000-yr and 100,000-yr Return Periods. 


\section{Summary of Review Level Earthquake M-bar Values}

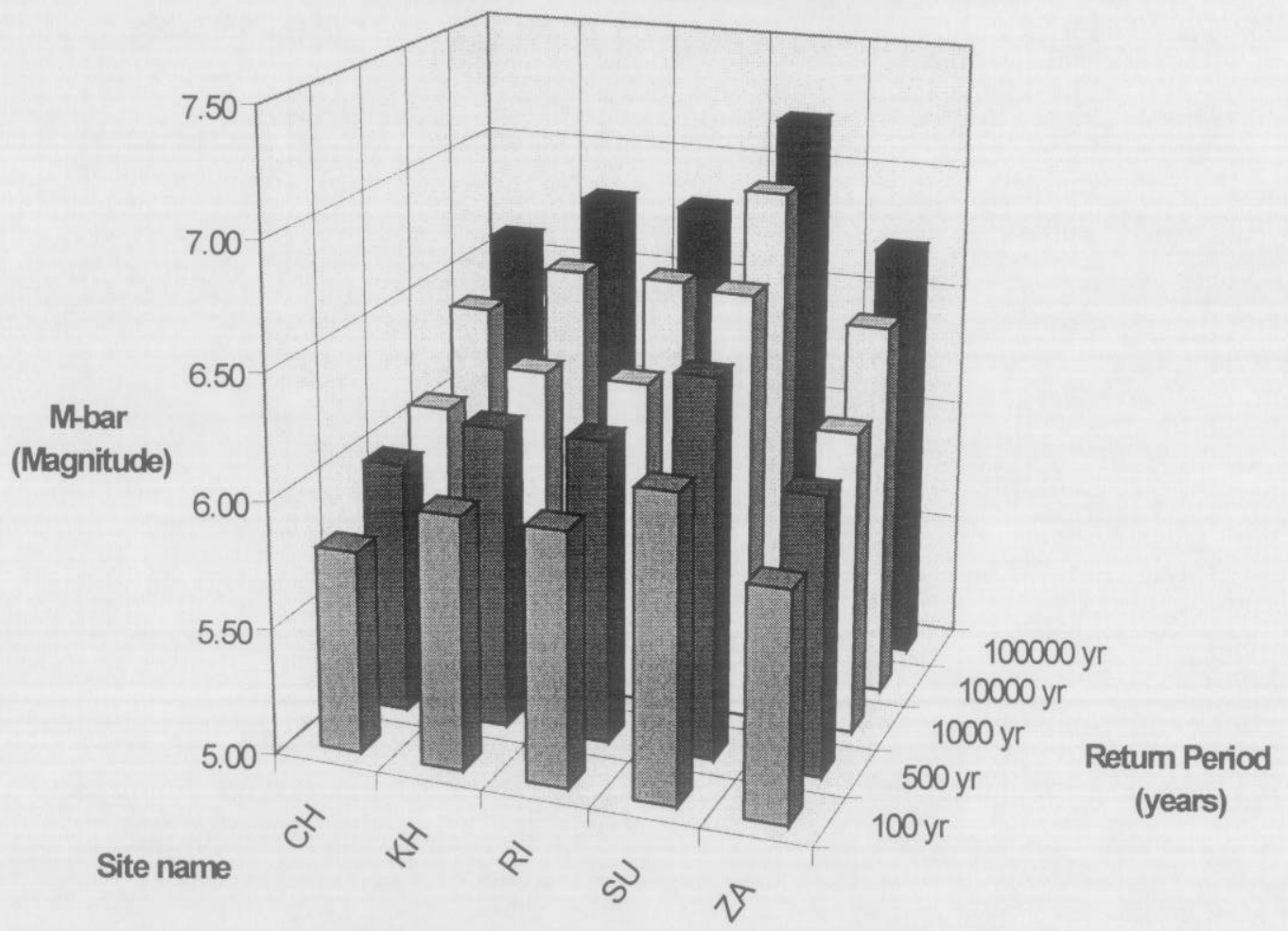

\begin{tabular}{|l|l|l|l|l|l|}
\cline { 2 - 6 } \multicolumn{1}{c|}{} & CH & KH & R & SU & ZA \\
\hline$\square 100 \mathrm{yr}$ & 5.80 & 6.00 & 6.00 & 6.20 & 5.90 \\
\hline $500 \mathrm{yr}$ & 6.00 & 6.20 & 6.20 & 6.50 & 6.10 \\
\hline$\square 1000 \mathrm{yr}$ & 6.10 & 6.30 & 6.30 & 6.70 & 6.20 \\
\hline$\square 10000 \mathrm{yr}$ & 6.40 & 6.60 & 6.60 & 7.00 & 6.50 \\
\hline $100000 \mathrm{yr}$ & 6.60 & 6.80 & 6.80 & 7.20 & 6.70 \\
\hline
\end{tabular}

Figure 3.4.2.8: Summary of the Review Level Magnitude values (M-bar) for five sites in Ukraine and for 100-yr, 500-yr, 1000-yr, 10,000-yr and 100,000-yr Return Periods. 


\section{Summary of Review Level Earthquake D-bar Values}

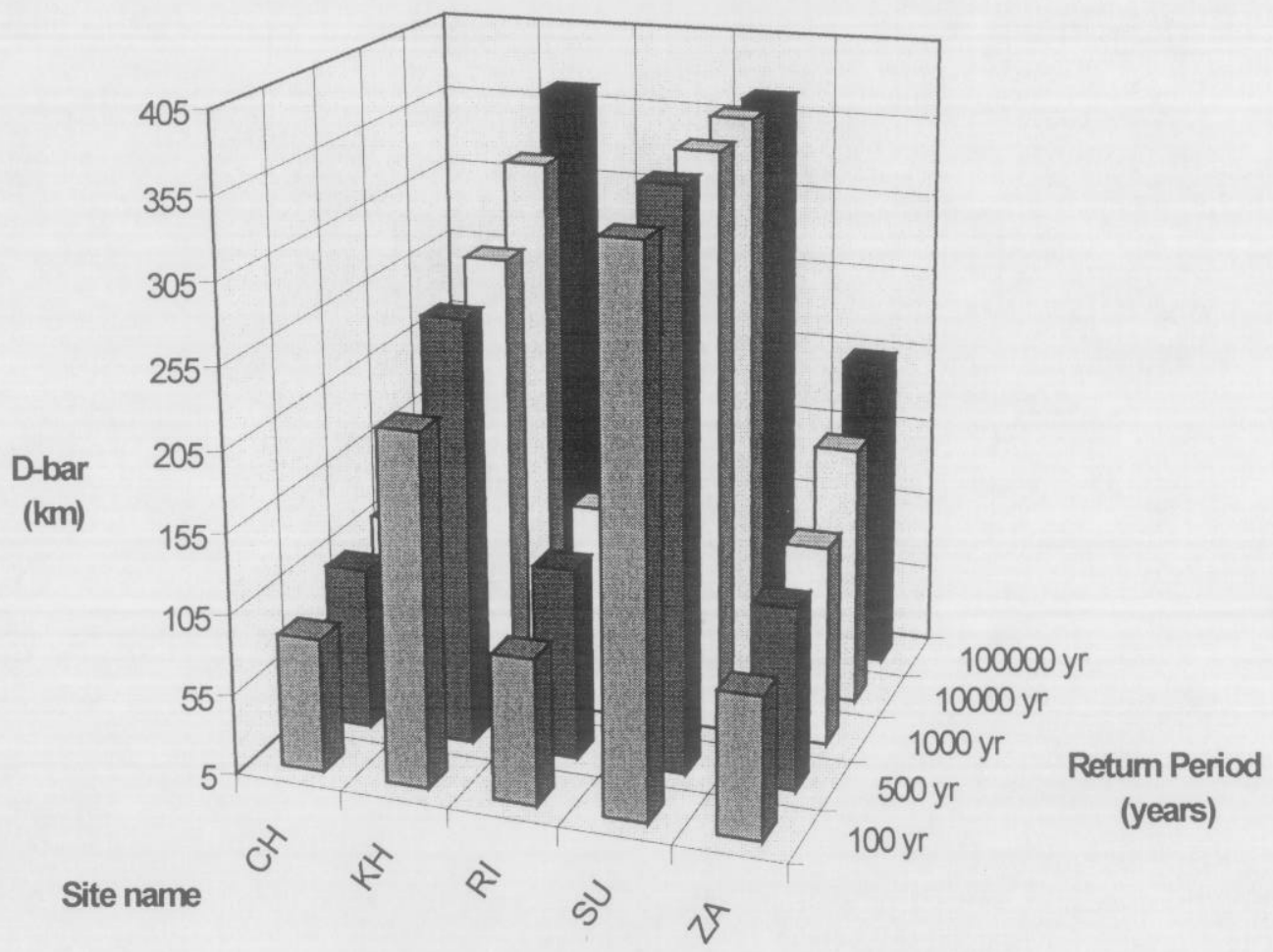

\begin{tabular}{|l|l|l|l|l|l|}
\hline & CH & KH & R & SU & ZA \\
\hline$\square=00 \mathrm{yr}$ & 88 & 223 & 95 & 346 & 92 \\
\hline$\square_{500 \mathrm{yr}}$ & 106 & 270 & 124 & 361 & 118 \\
\hline$\square_{1000 \mathrm{yr}}$ & 115 & 289 & 138 & 366 & 130 \\
\hline$\square_{10000 \mathrm{yr}}$ & 141 & 334 & 180 & 372 & 169 \\
\hline $\mathbf{\square}_{100000 \mathrm{yr}}$ & 166 & 367 & 215 & 370 & 204 \\
\hline
\end{tabular}

Figure 3.4.2.9: Summary of the Review Level D-bar values for five sites in Ukraine and for 100-yr, 500-yr, 1000-yr, 10,000-yr and 100,000-yr Return Periods. 
CHERNOBYL

M-D Bins Contributions

100 yr Return Period

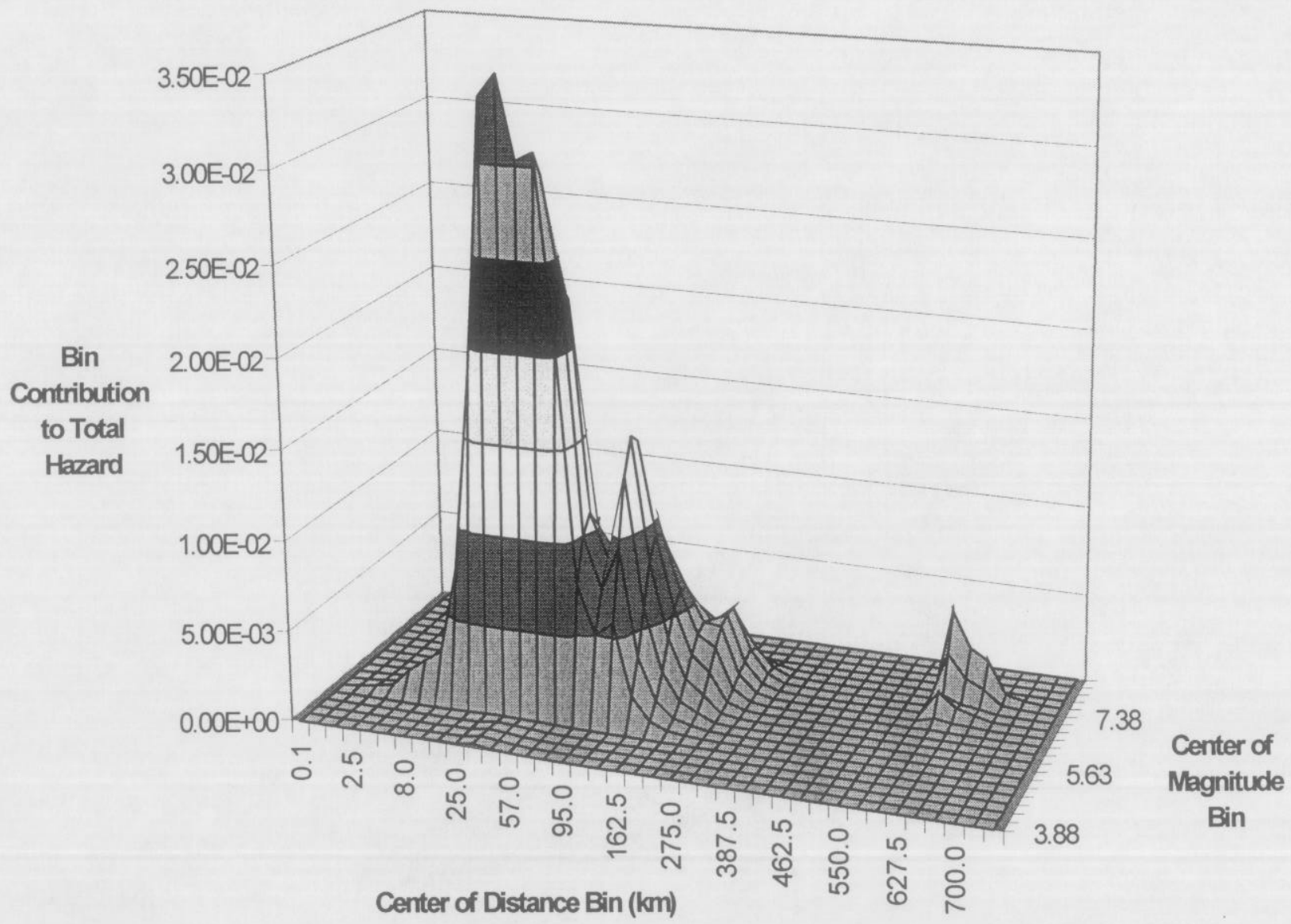

Figure 3.4.3.1: Distance-Magnitude bins contributions to the mean 100yr return period total hazard at Chernobyl, for rock conditions. 
CHERNOBYL

M-D Bins Contributions

1000 yr Retum Period

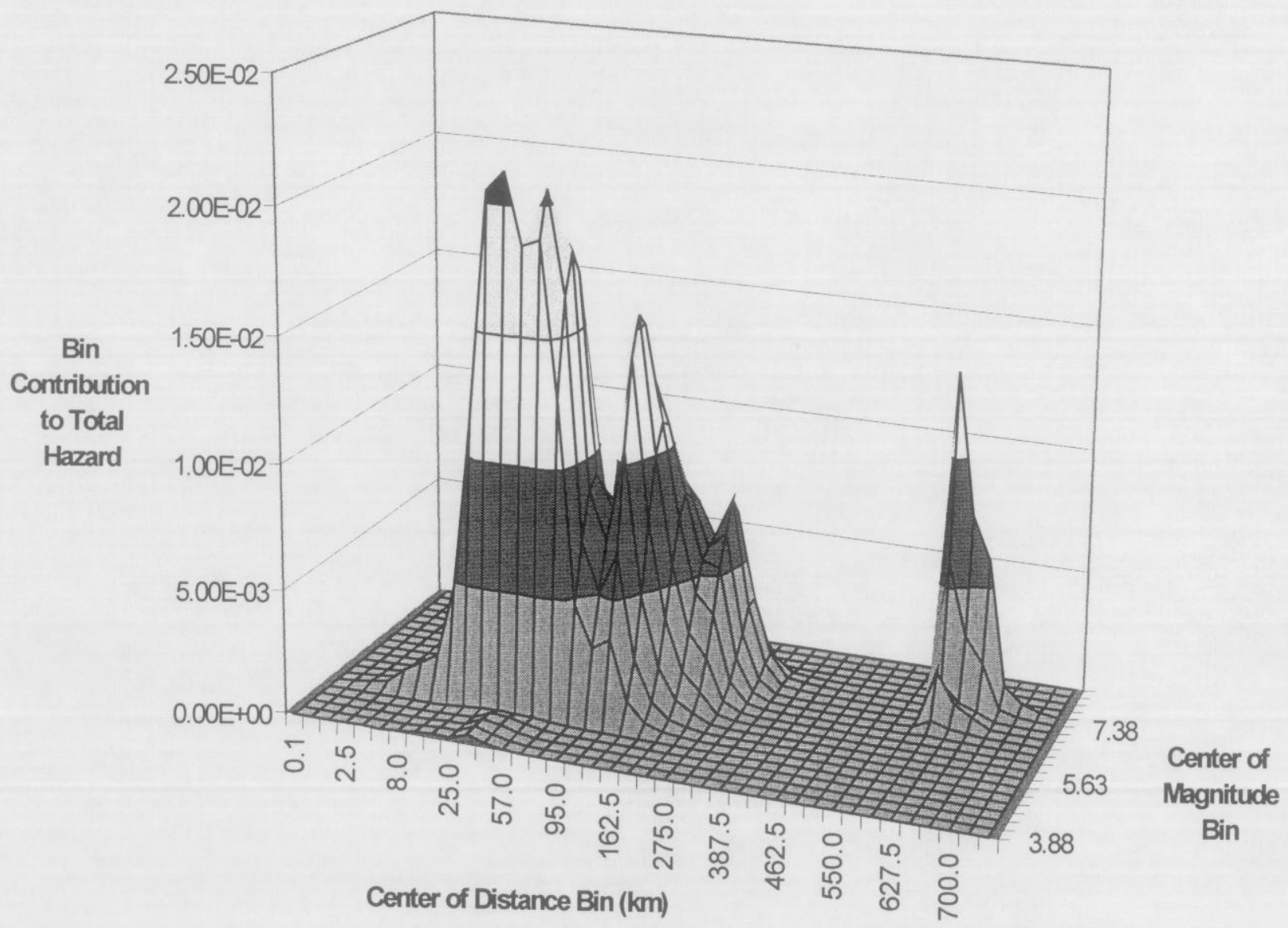

Figure 3.4.3.2: Distance-Magnitude bins contributions to the mean 1000-yr return period total hazard at Chernobyl, for rock conditions. 
CHERNOBYL

M-D Bins Contributions

10000 yr Return Period

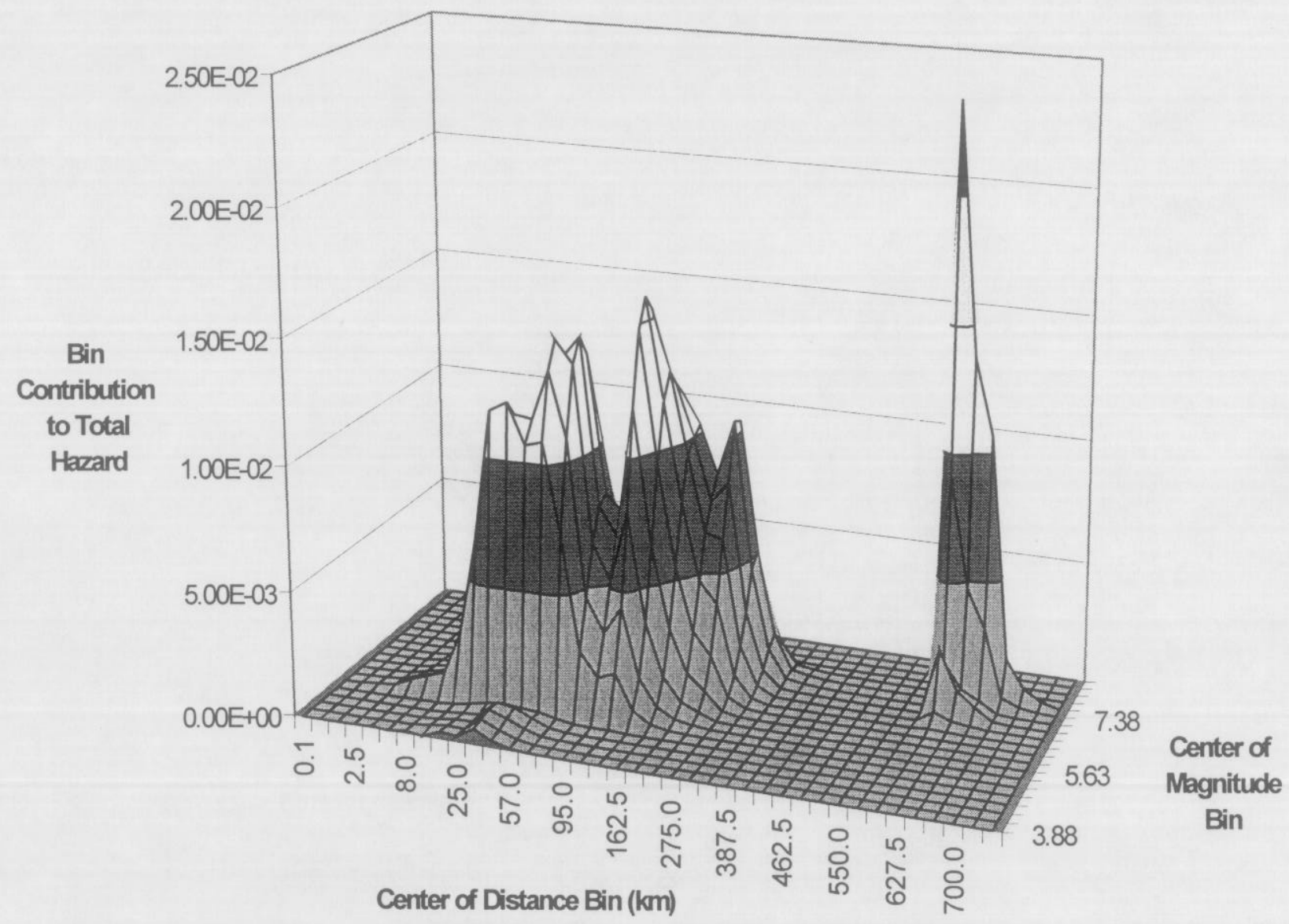

Figure 3.4.3.3: Distance-Magnitude bins contributions to the mean 10,000 -yr return period total hazard at Chernobyl, for rock conditions. 


\section{KMENYTSKYY \\ M-D Bins Contributions \\ 100 yr Retum Period}

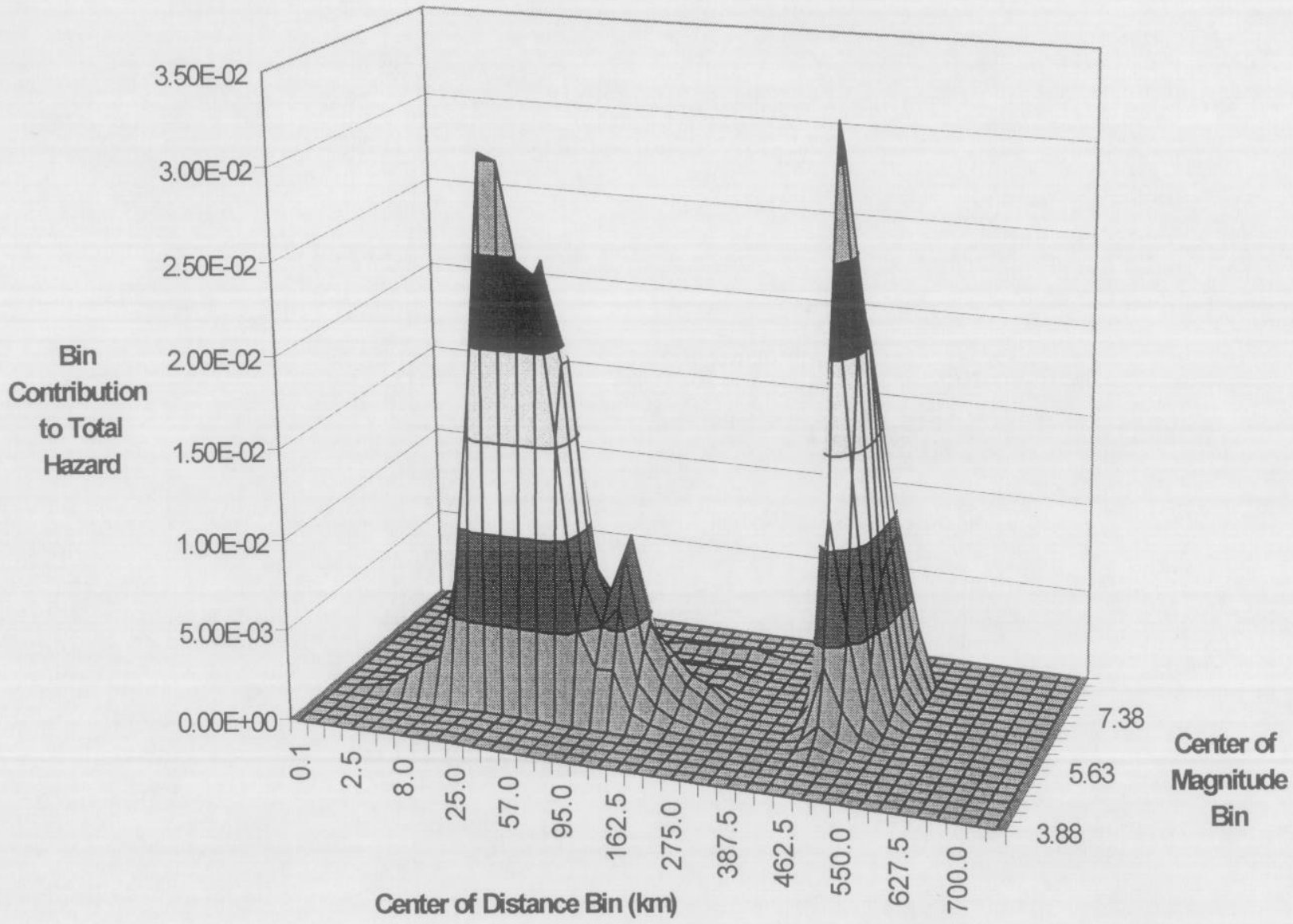

Figure 3.4.3.4: Distance-Magnitude bins contributions to the mean 100yr return period total hazard at Khmelnytskyy, for rock conditions. 


\section{KMENYTSKYY \\ M-D Bins Contributions \\ 1000 yr Return Period}

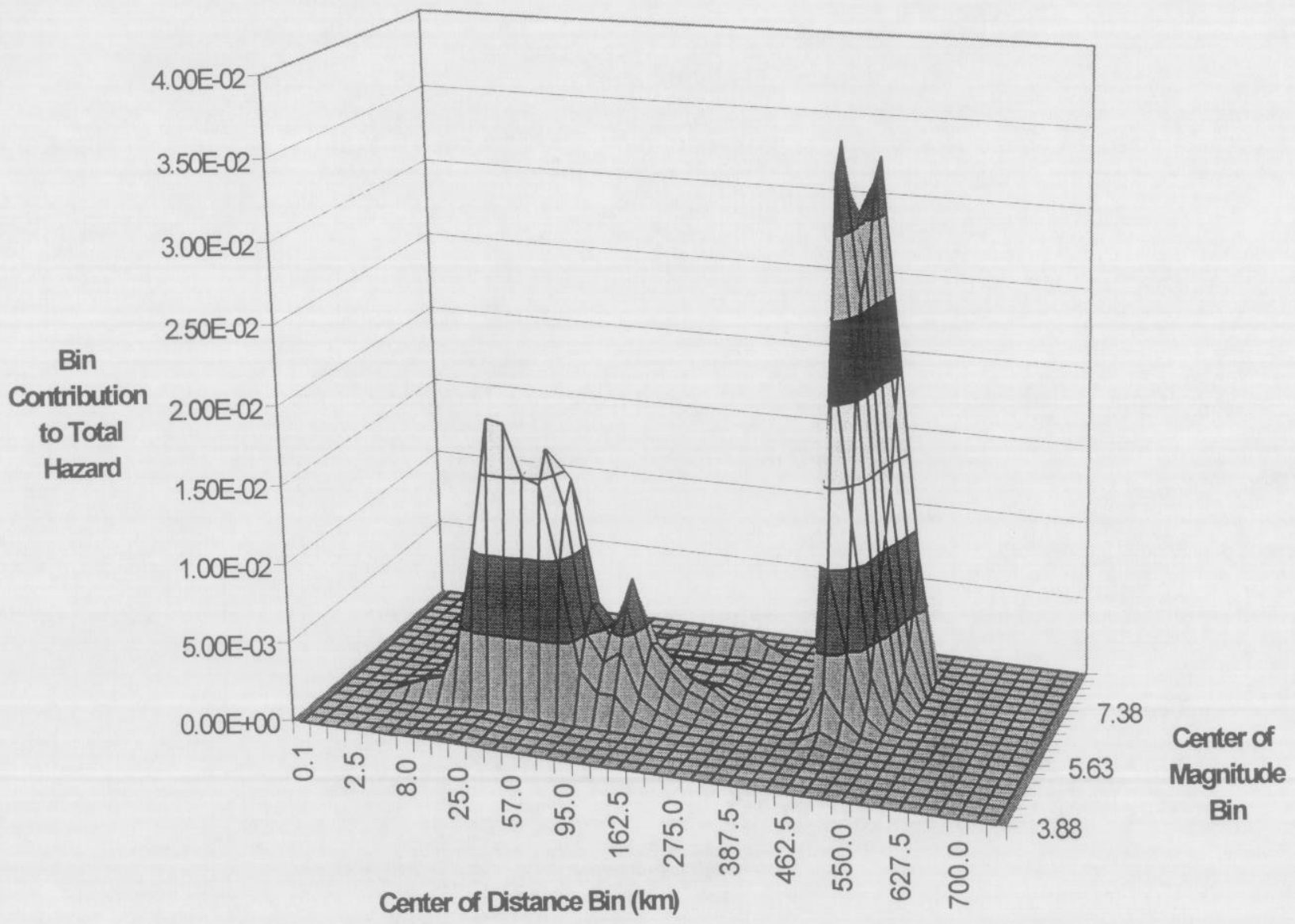

Figure 3.4.3.5: Distance-Magnitude bins contributions to the mean 1000 -yr return period total hazard at Khmelnytskyy, for rock conditions. 


\section{RIVNE}

M-D Bins Contributions

100 yr Return Period

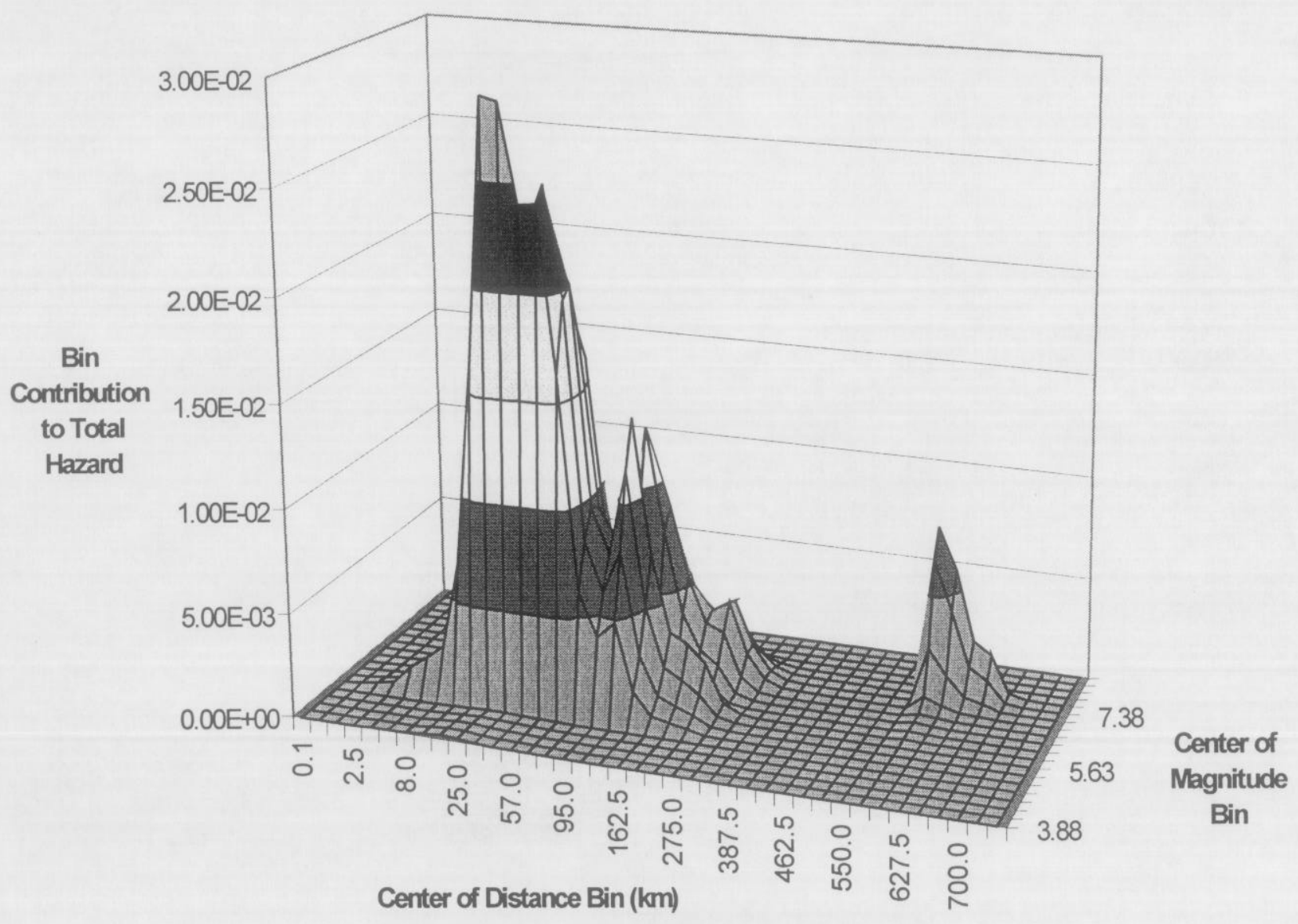

Figure 3.4.3.7: Distance-Magnitude bins contributions to the mean 100yr return period total hazard at Rivne, for rock conditions. 
KME_NYTSKYY

M-D Bins Contributions

10,000 yr Return Period

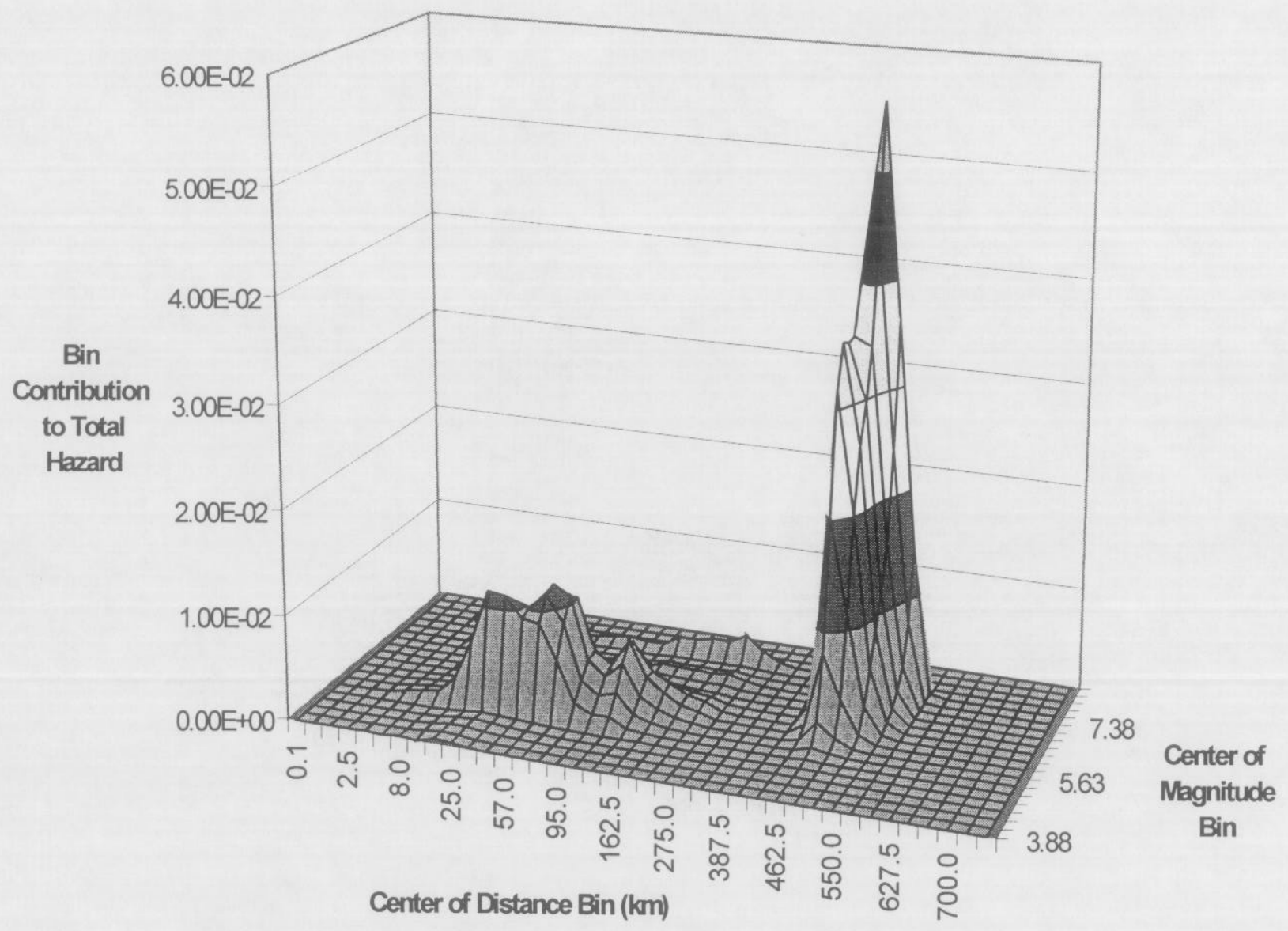

Figure 3.4.3.6: Distance-Magnitude bins contributions to the mean 10,000 -yr return period total hazard at Khmelnytskyy, for rock conditions. 


\section{RIVNE}

M-D Bins Contributions

100 yr Return Period

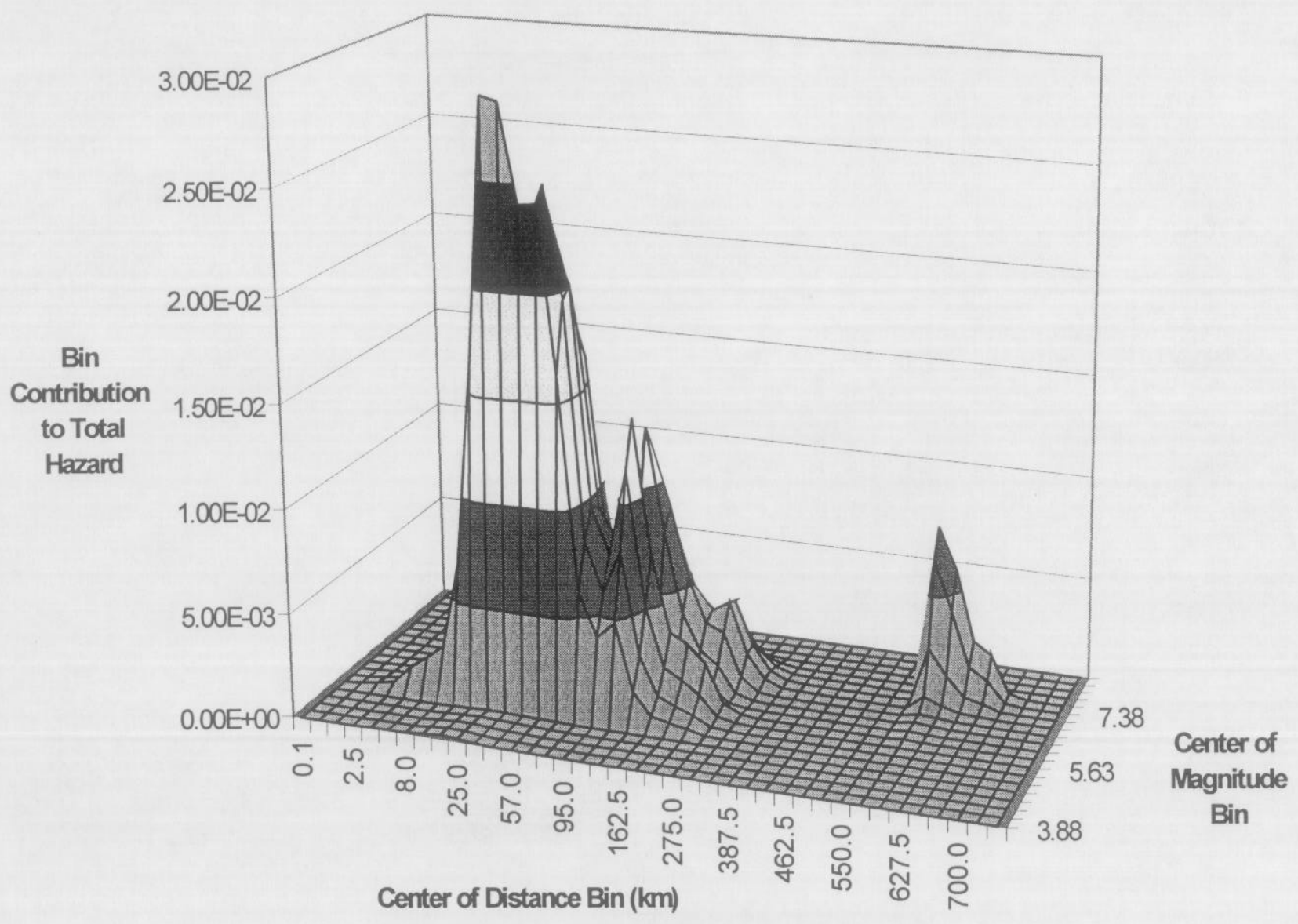

Figure 3.4.3.7: Distance-Magnitude bins contributions to the mean 100yr return period total hazard at Rivne, for rock conditions. 


\section{RIVNE}

M-D Bins Contributions

1000 yr Retum Period

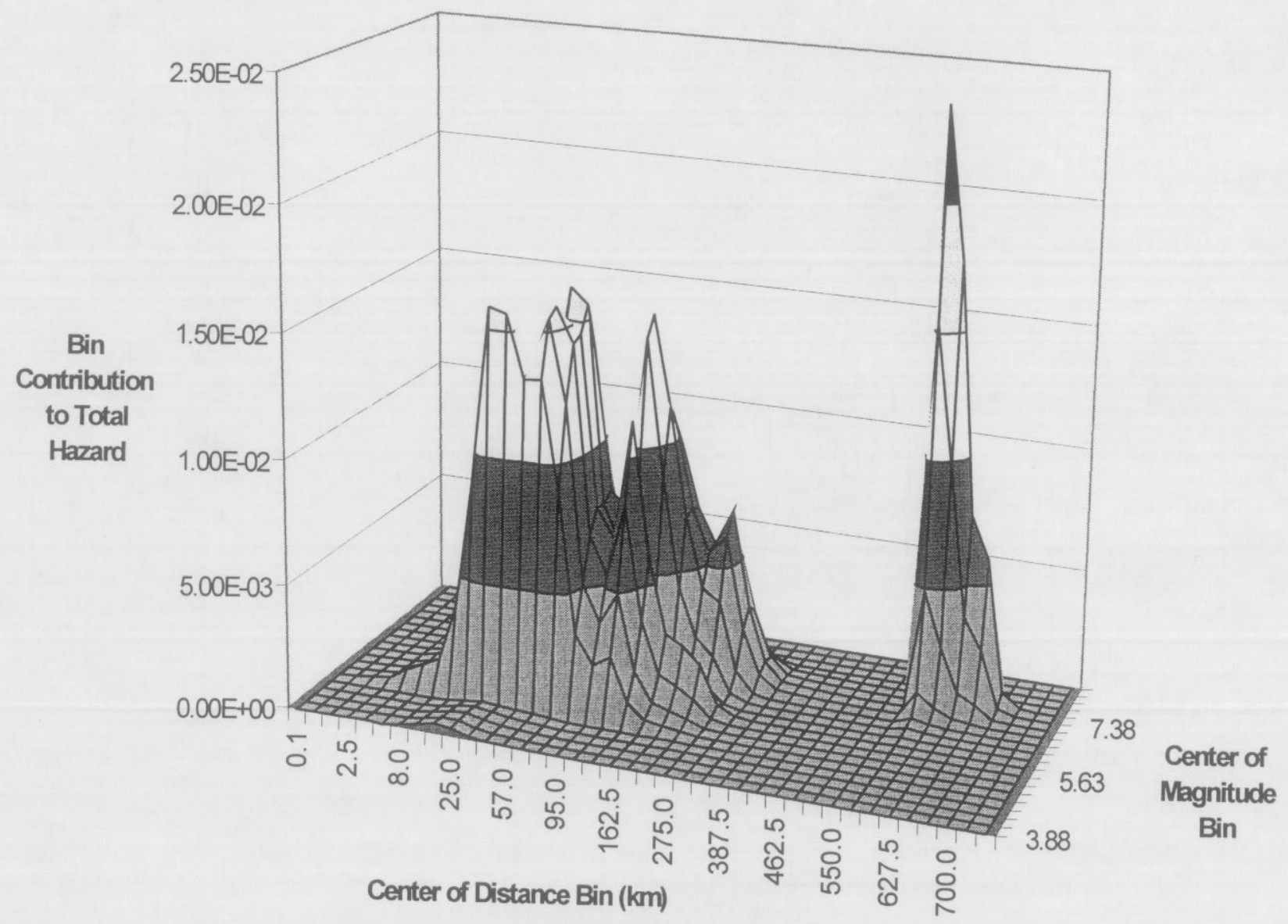

Figure 3.4.3.8: Distance-Magnitude bins contributions to the mean 1000 -yr return period total hazard at Rivne, for rock conditions. 


\section{RVNE}

M-D Bins Contributions

10,000 yr Return Period

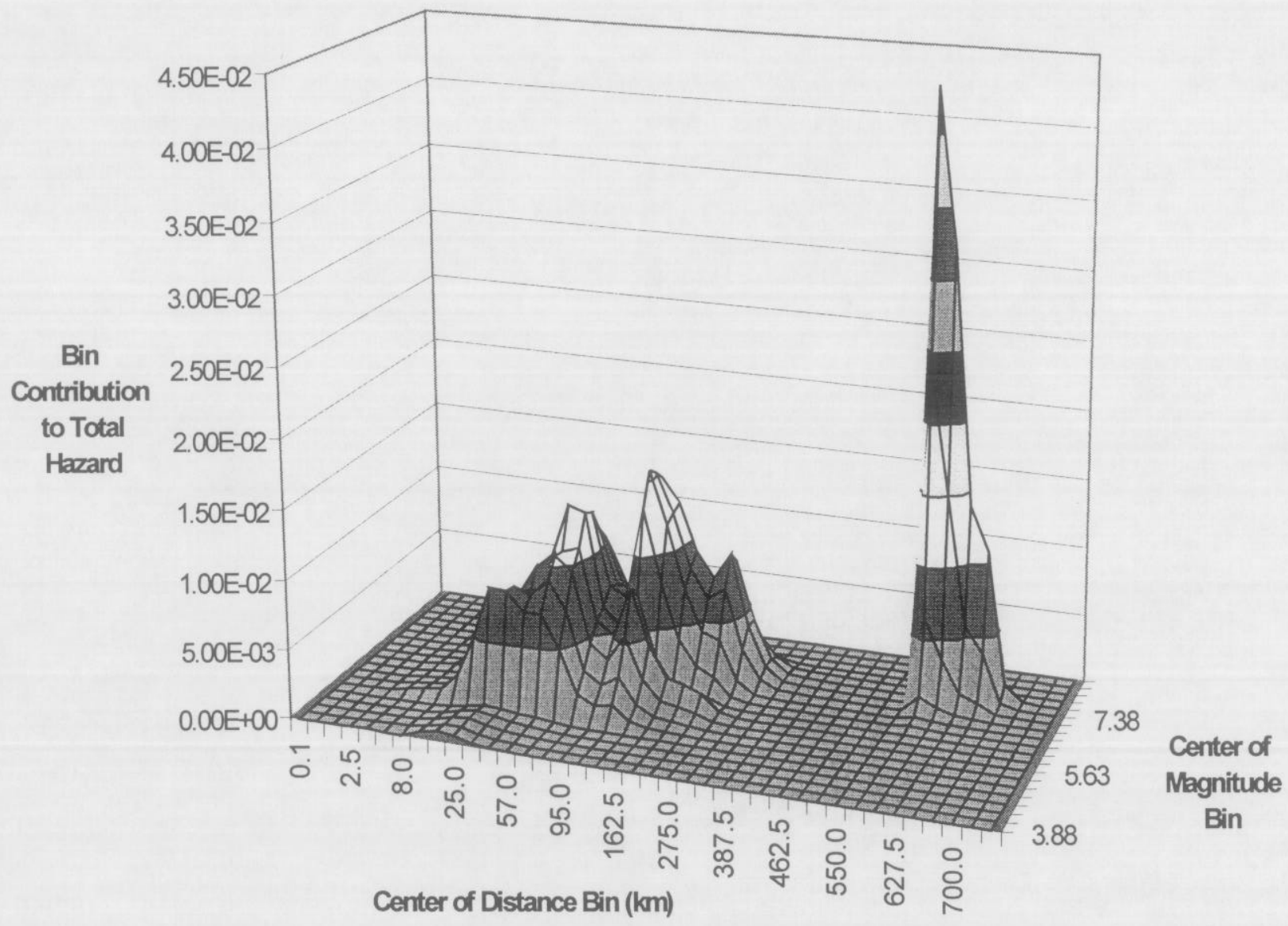

Figure 3.4.3.9: Distance-Magnitude bins contributions to the mean $10,000-y r$ return period total hazard at Rivne, for rock conditions. 


\section{SOUTH UKRAINE \\ M-DBins Contributions \\ 100 yr Return Period}

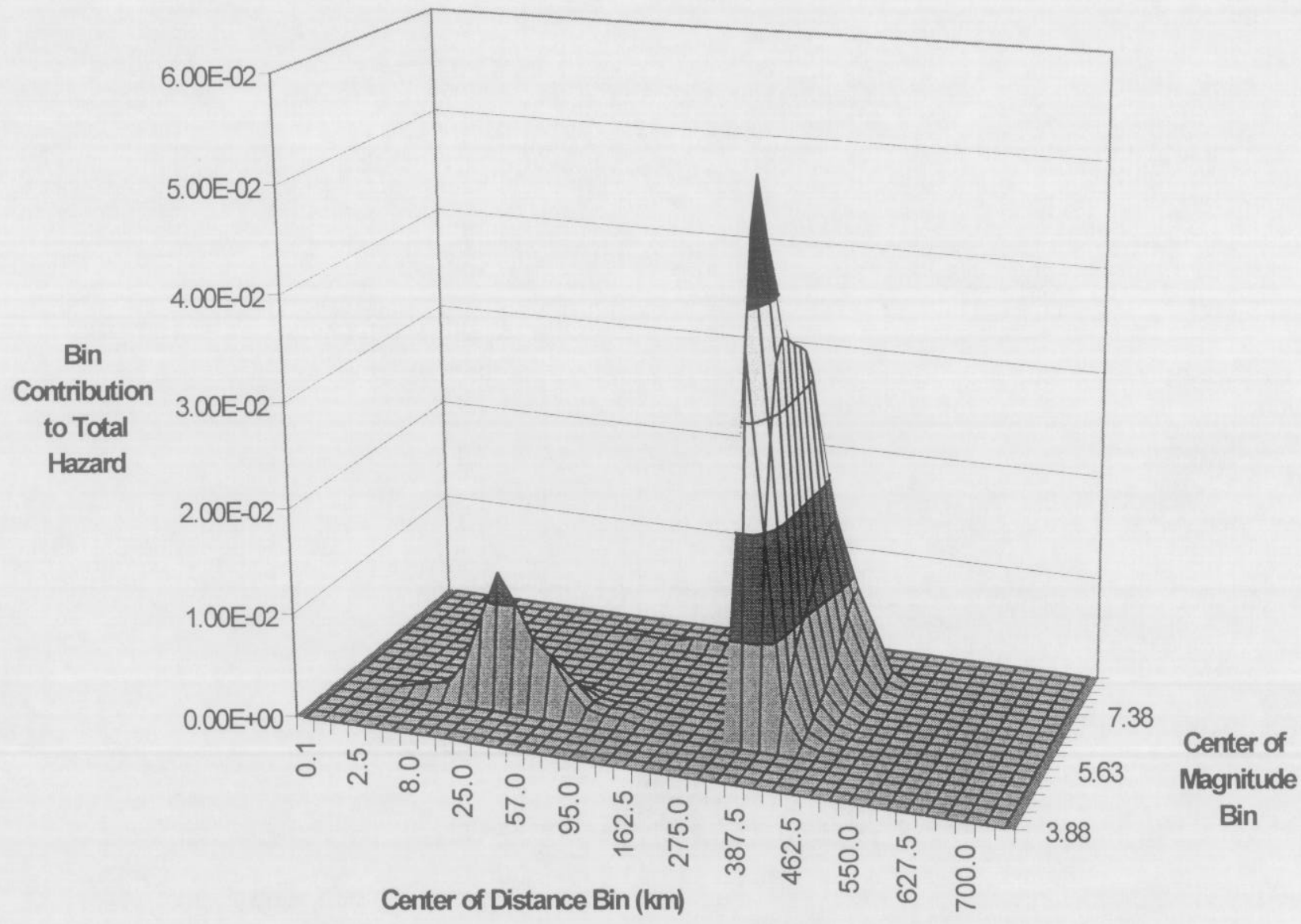

Figure 3.4.3.10: Distance-Magnitude bins contributions to the mean 100-yr return period total hazard at South-Ukraine, for rock conditions. 


\section{SOUTH UKRAINE \\ M-D Bins Contributions \\ 1000 yr Retum Period}

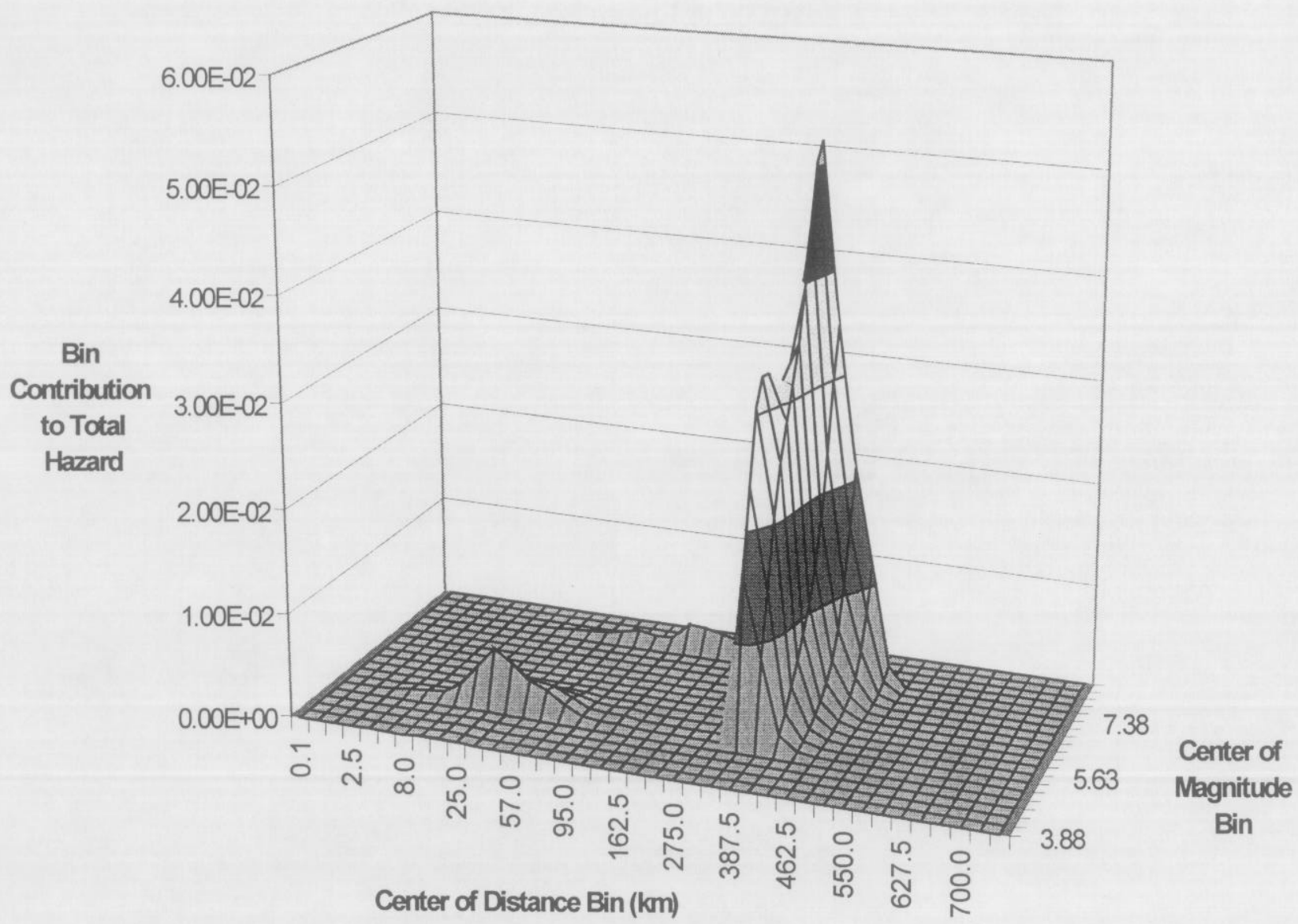

Figure 3.4.3.11: Distance-Magnitude bins contributions to the mean 1000-yr return period total hazard at South-Ukraine, for rock conditions. 


\section{SOUTH UKRAINE}

M-D Bins Contributions

10,000 yr Retum Period

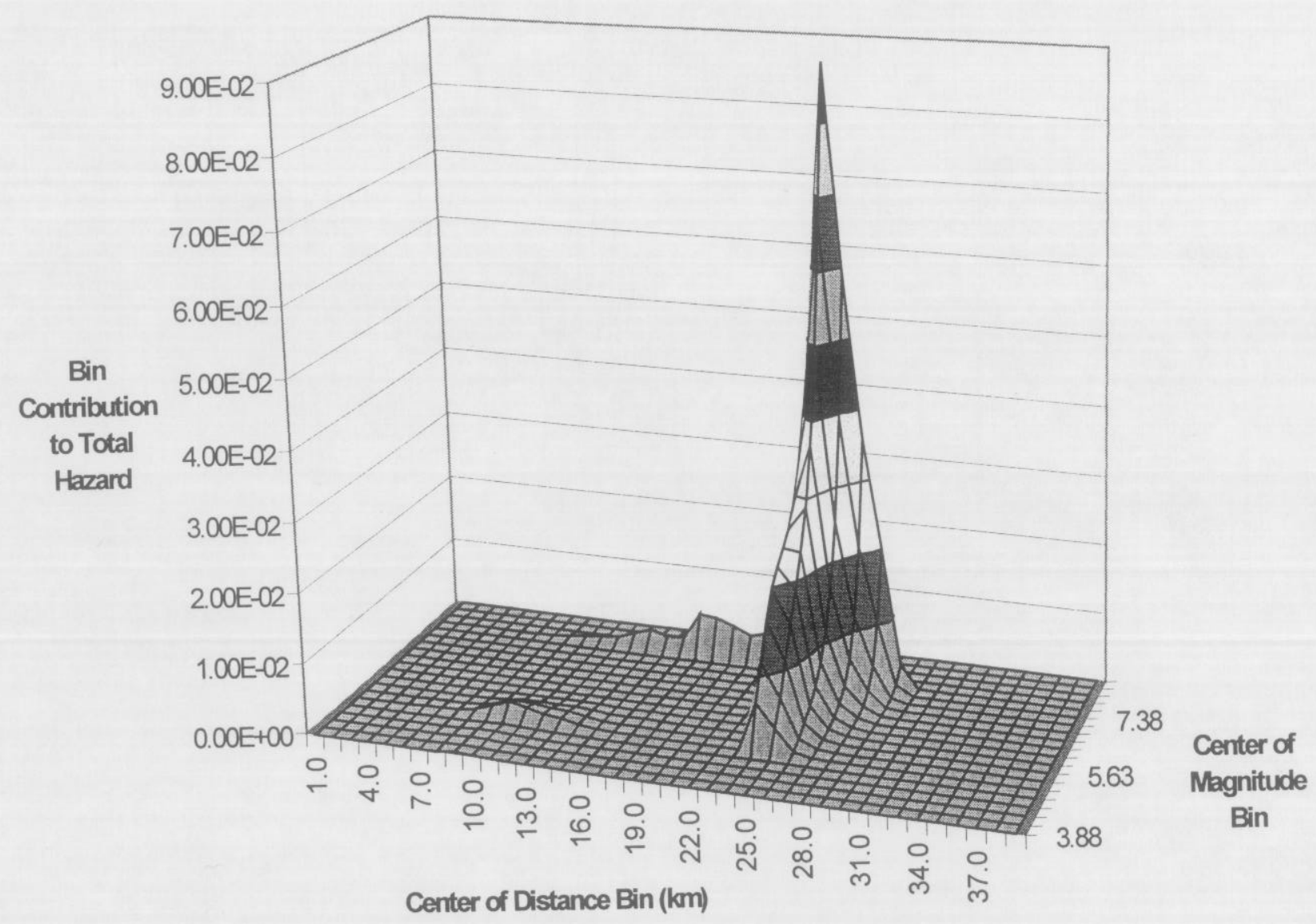

Figure 3.4.3.12: Distance-Magnitude bins contributions to the mean 10,000 -yr return period total hazard at South-Ukraine, for rock conditions. 


\section{ZAPORYZ-ZYA \\ M-DBins Contributions \\ 100 yr Return Period}

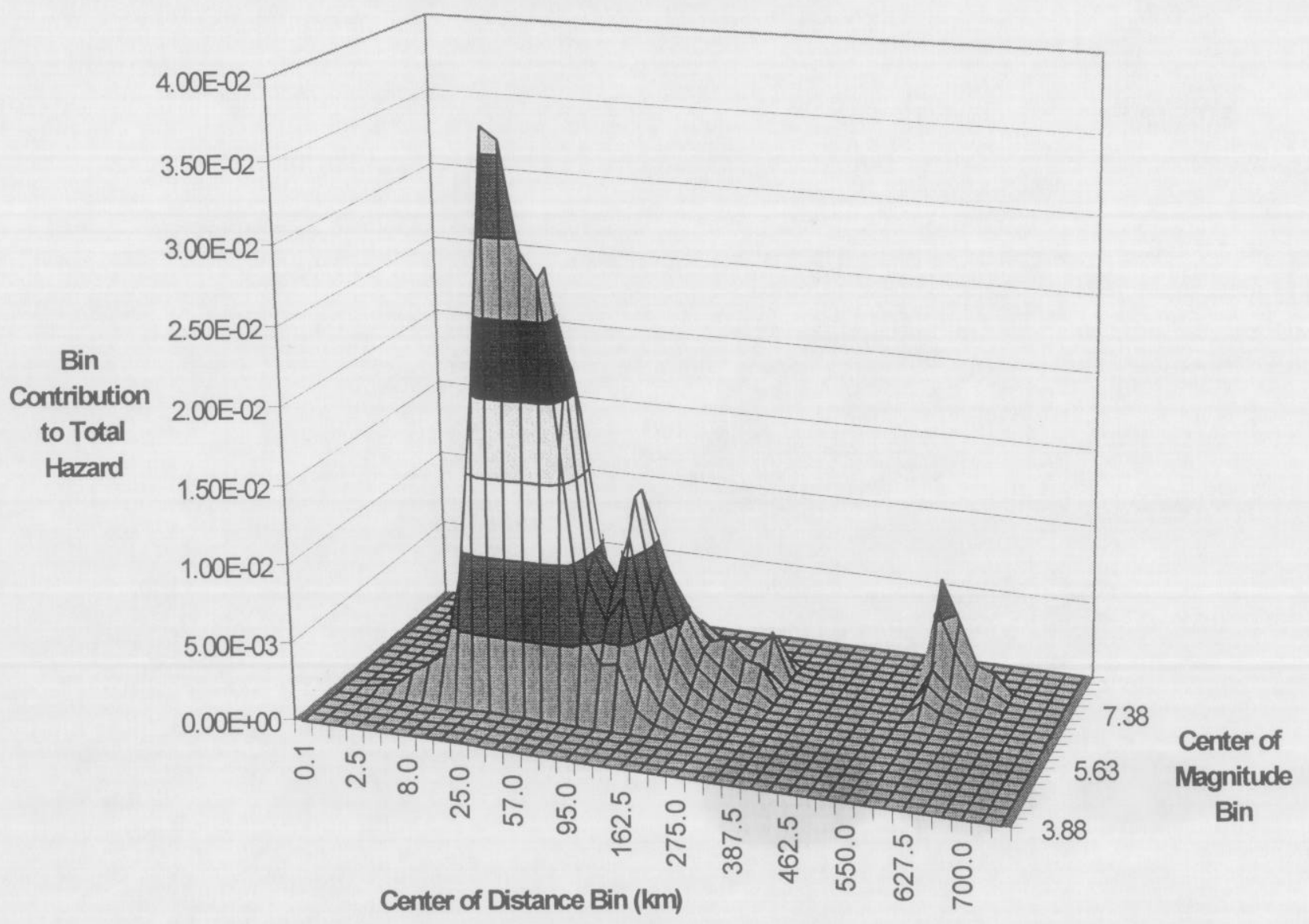

Figure 3.4.3.13: Distance-Magnitude bins contributions to the mean 100-yr return period total hazard at Zaporizhzya, for rock conditions. 


\section{ZAPORYZ-ZYA \\ M-D Bins Contributions \\ 1000 yr Return Period}

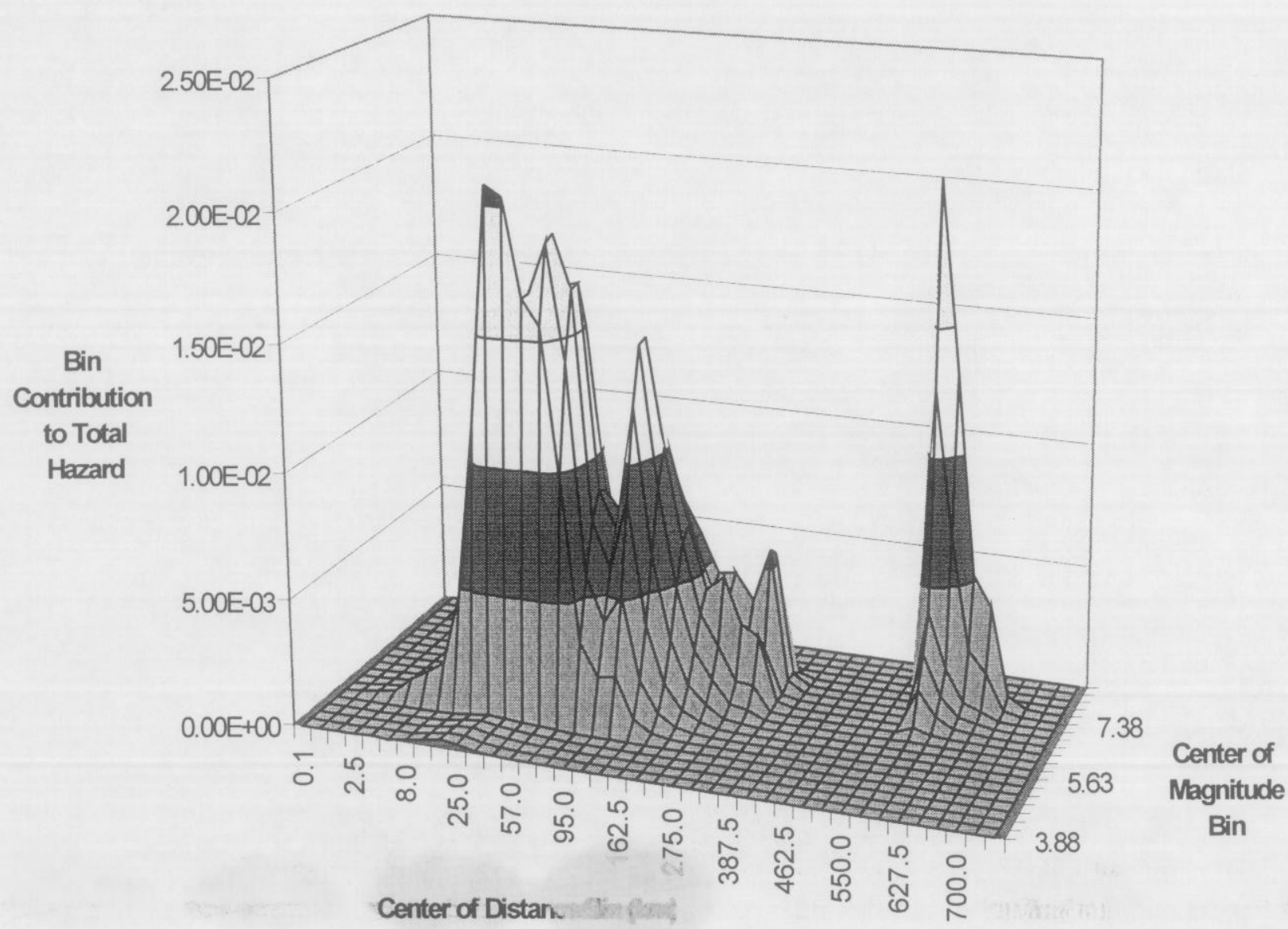

Figure 3.4.3.14: Distance-Magnitude bins contributions to the mean 1000-yr return period total hazard at Zaporizhzya, for rock conditions. 
ZAPORYZ-ZYA

M-D Bins Contributions

10,000 yr Return Period

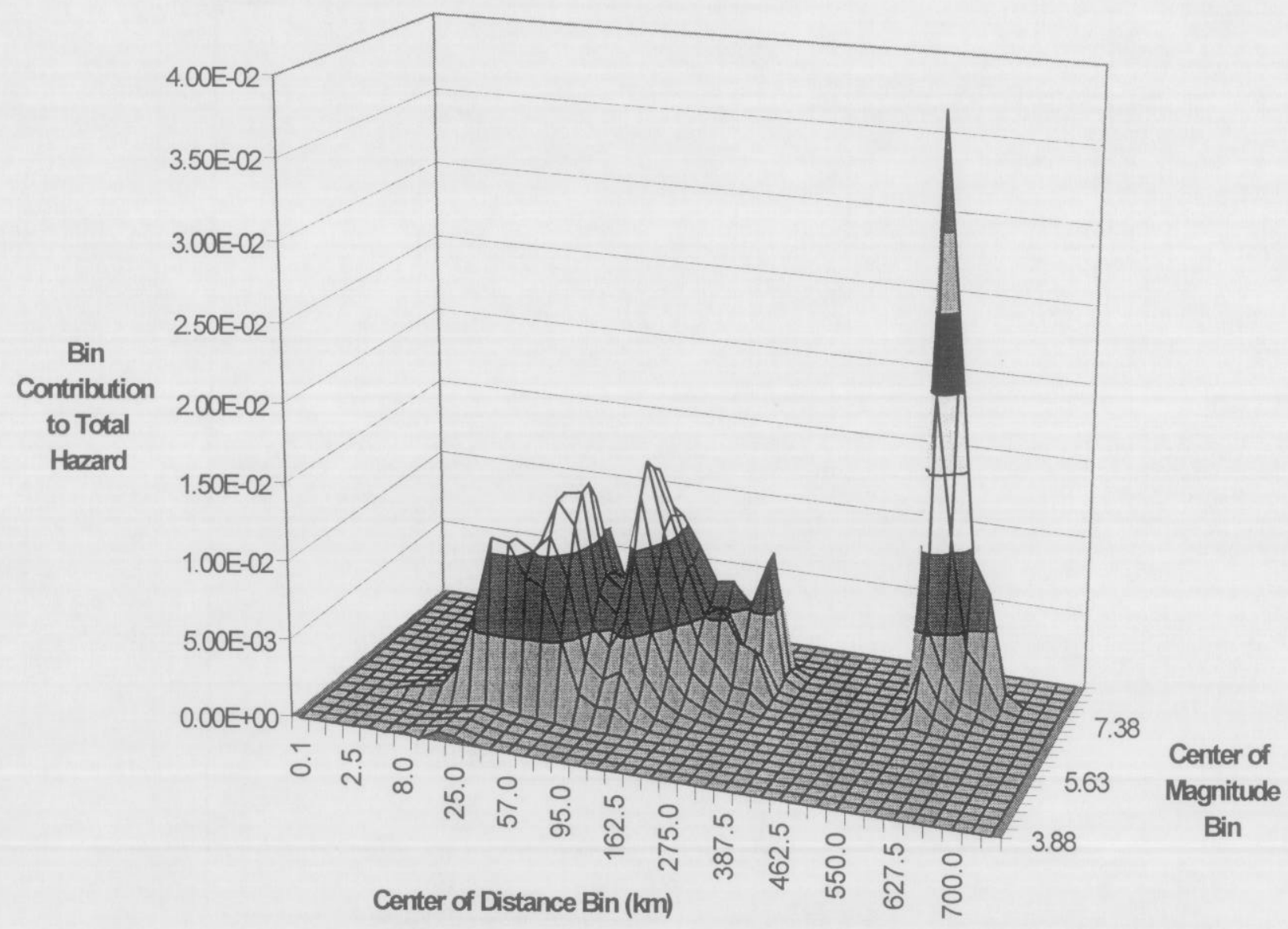

Figure 3.4.3.15: Distance-Magnitude bins contributions to the mean 10,000 -yr return period total hazard at Zaporizhzya, for rock conditions. 


\section{CHERNOBYL}

Magnitude Bins Contributions to TOTAL Hazard

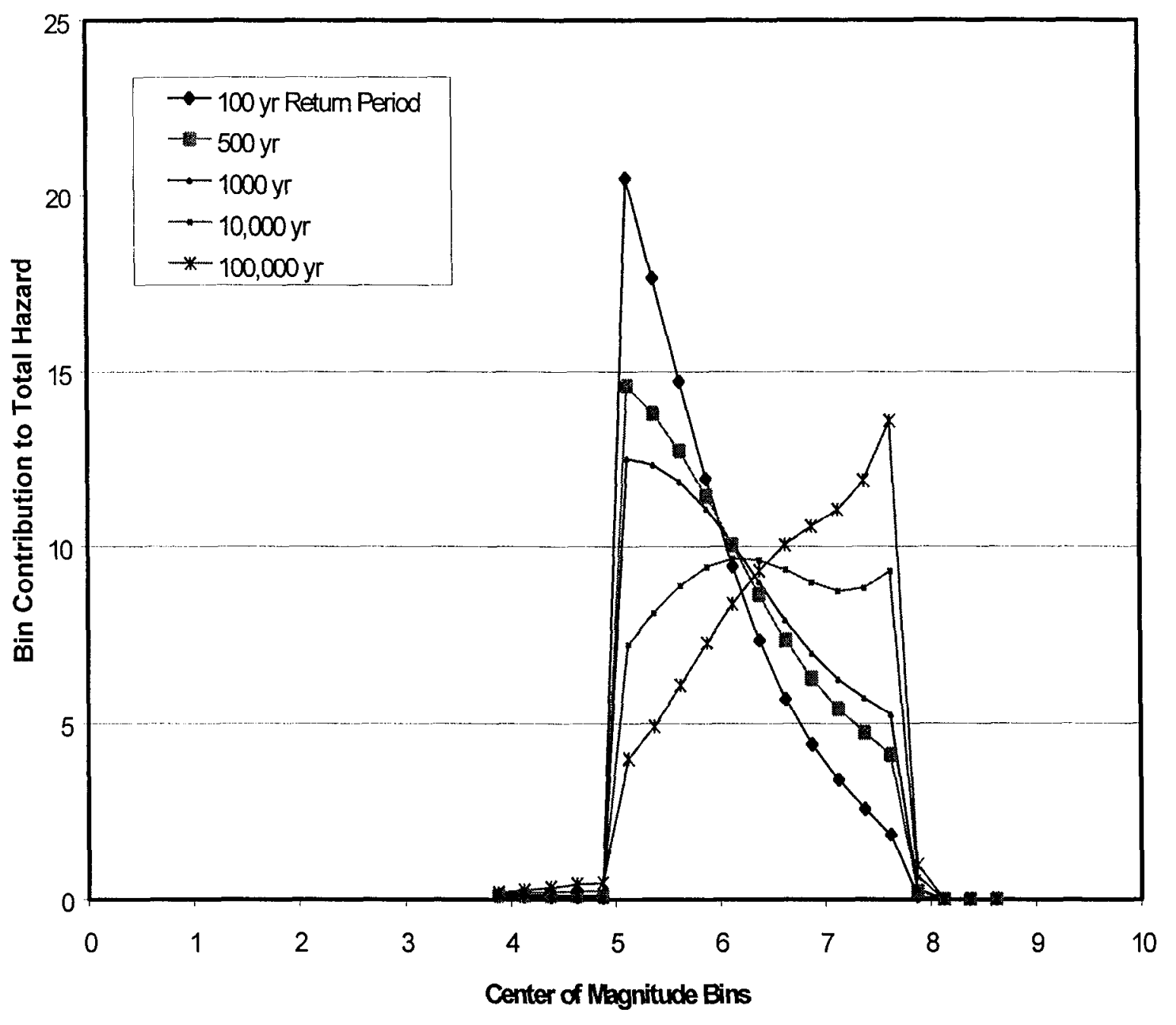

Figure 3.4.3.16: Magnitude bins contributions to the total mean hazard at Chernobyl, for rock site conditions for 100-yr, 500-yr, 1000-yr, $10,000-y r$ and $100,000-y r$ return periods. 
KNENYTSKY

Magnitude Bins Contributions to TOTAL Hazar

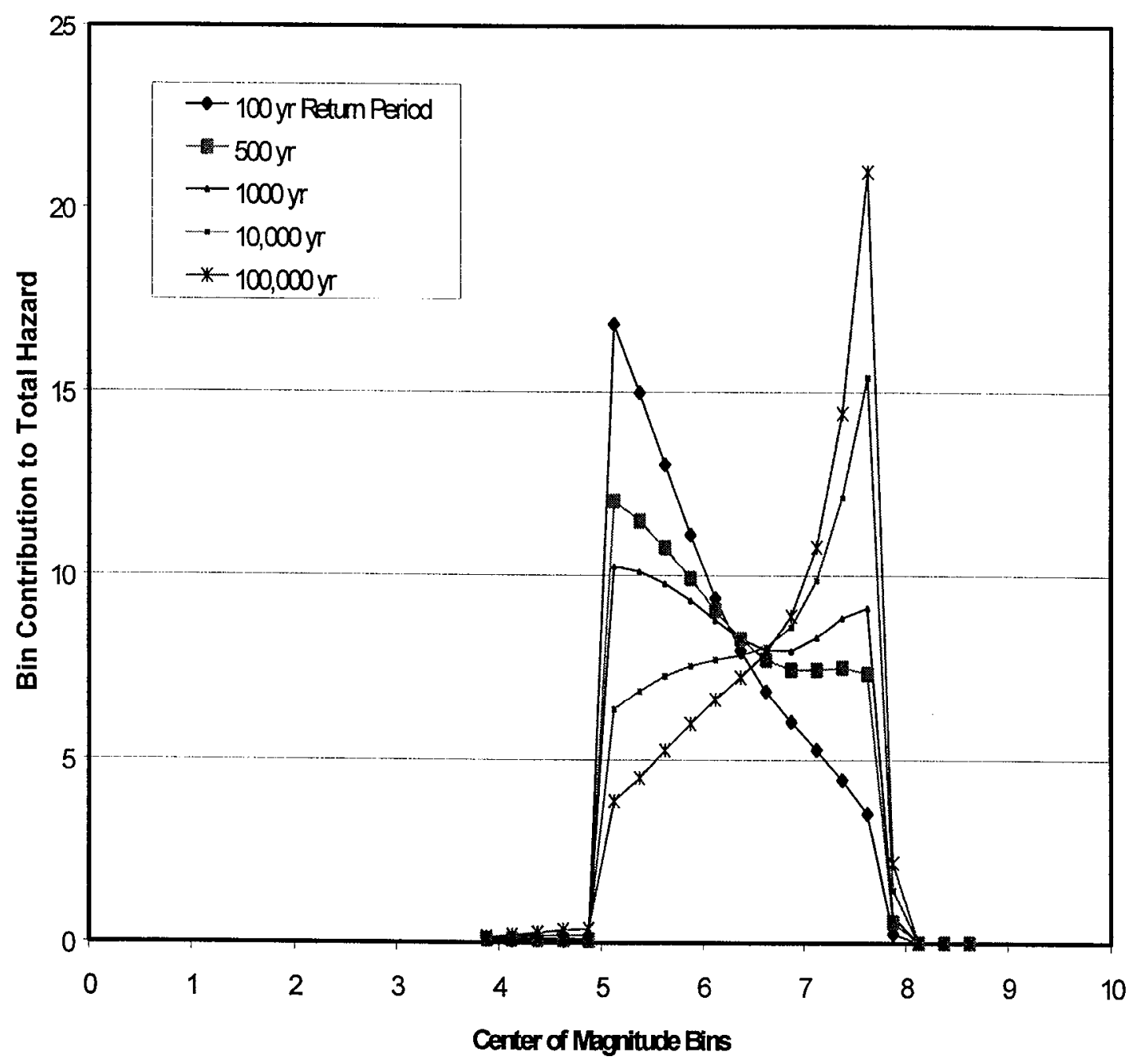

Figure 3.4.3.17: Magnitude bins contributions to the total mean hazard at Khmelnytskyy, for rock site conditions for 100-yr, 500-yr, 1000-yr, $10,000-y r$ and $100,000-y r$ return periods. 
RVNE

Magnitude Bins Contributions to TOTAL Hazar

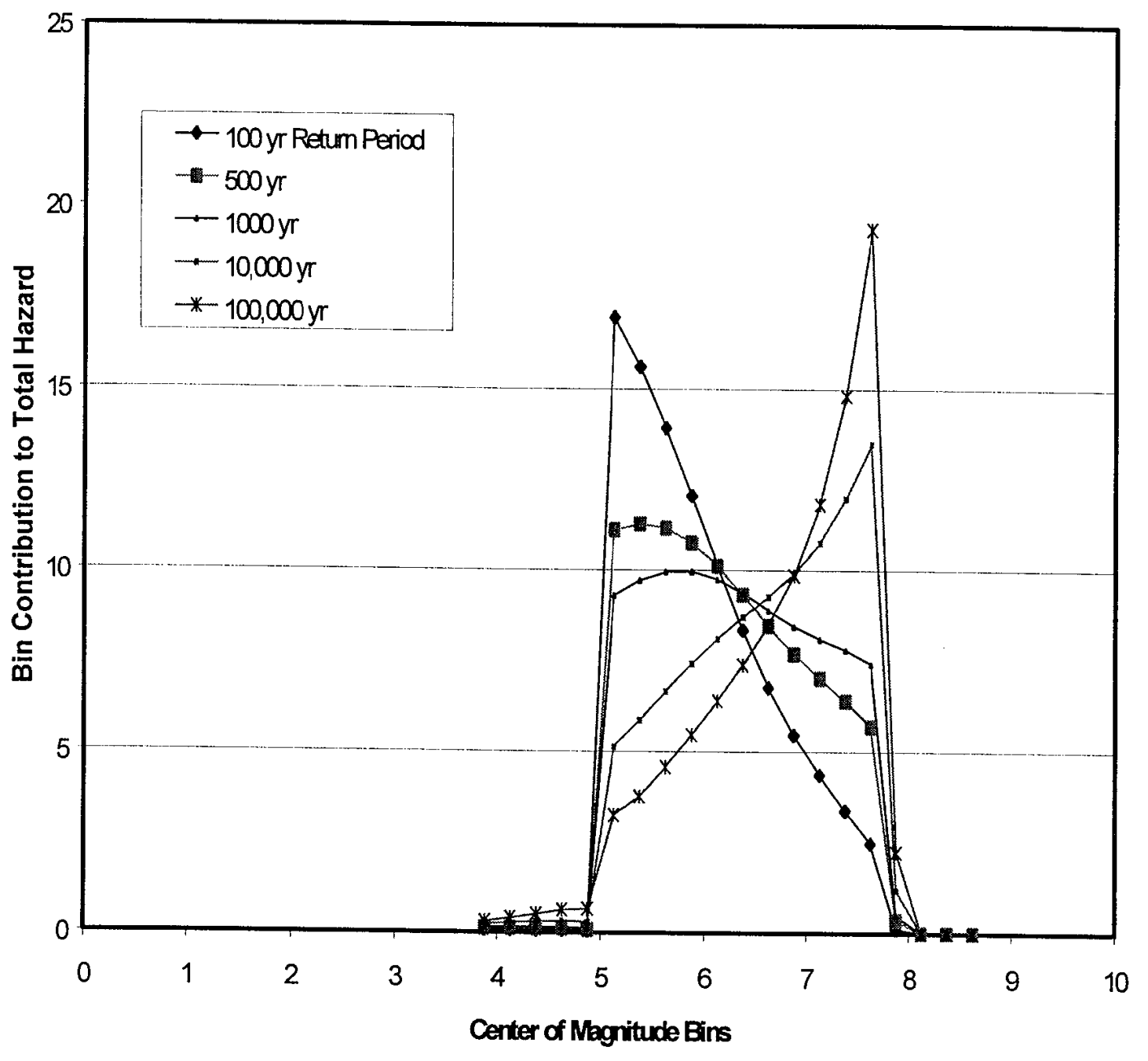

Figure 3.4.3.18: Magnitude bins contributions to the total mean hazard at Rivne, for rock site conditions for 100-yr, 500-yr, 1000-yr, 10,000-yr and 100,000 -yr return periods. 


\section{SOUTHURAINE}

Magnitude Bins Contributions to TOTAL Hazar

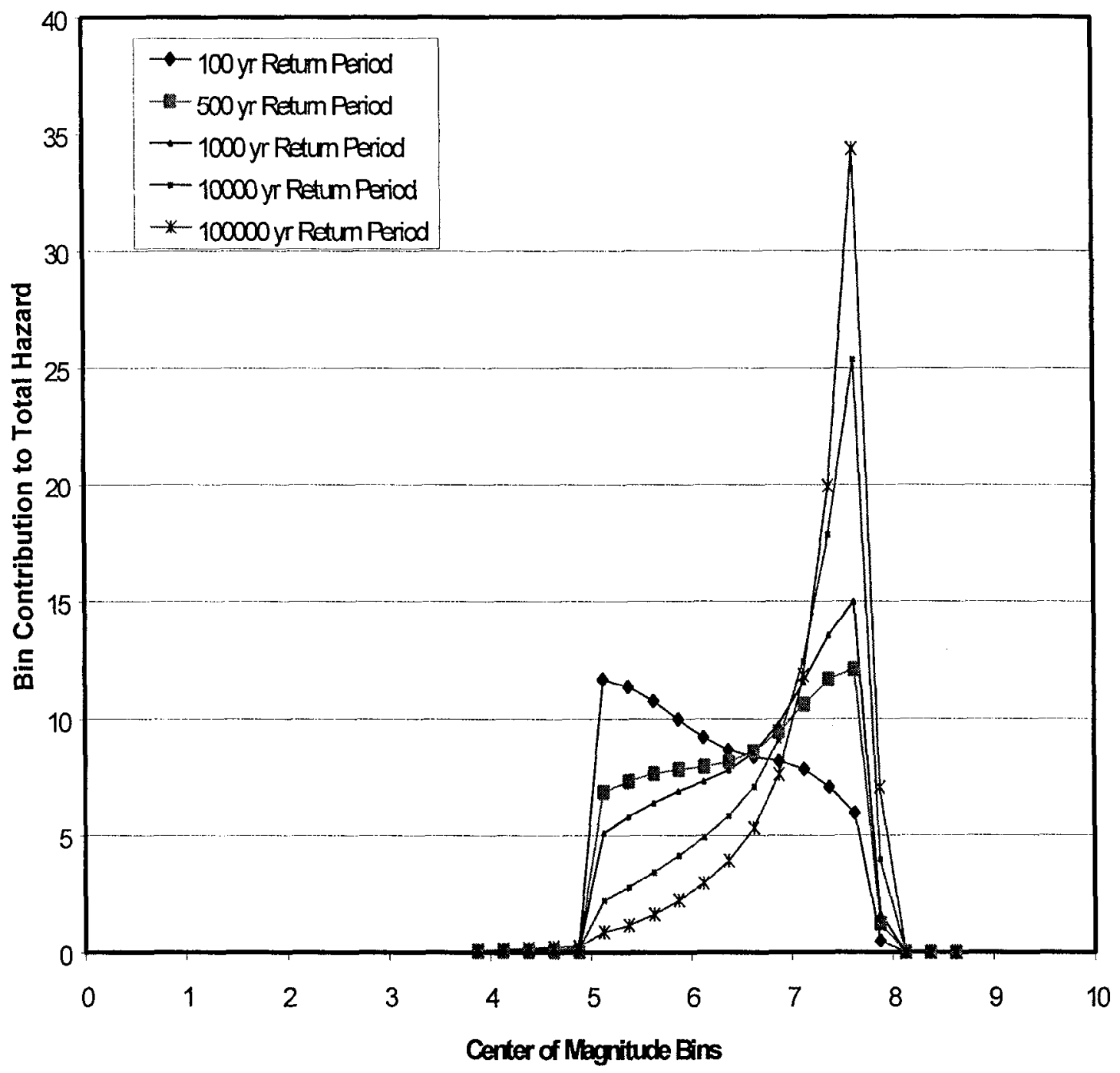

Figure 3.4.3.19: Magnitude bins contributions to the total mean hazard at South-Ukraine, for rock site conditions for 100-yr, 500-yr, 1000-yr, $10,000-y r$ and $100,000-y r$ return periods. 
ZAPORYZ-ZYA

Magnitude Bins Contributions to TOTAL Hazar

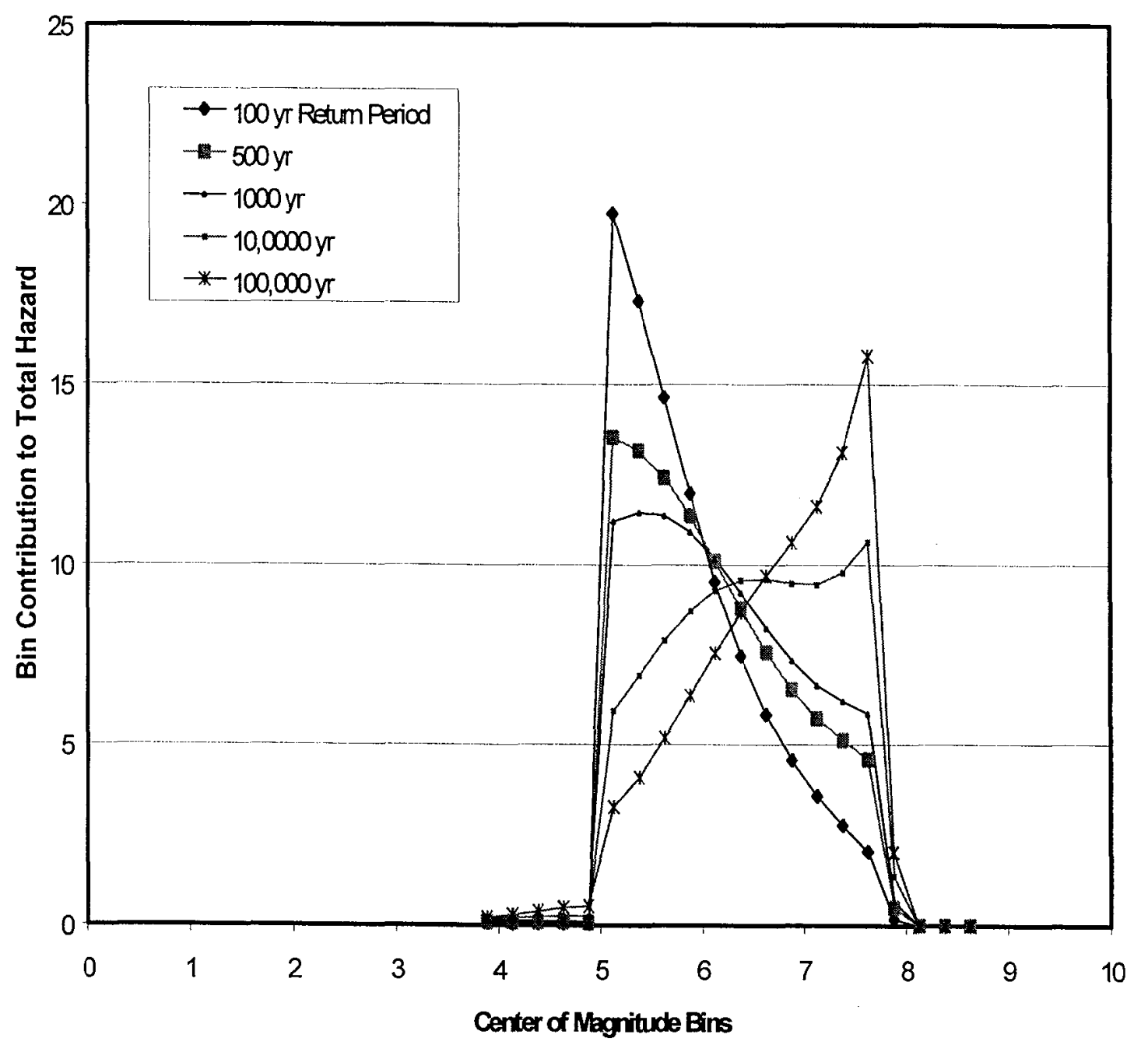

Figure 3.4.3.20: Magnitude bins contributions to the total mean hazard at Zaporizhzya, for rock site conditions for 100-yr, 500-yr, 1000-yr, $10,000-y r$ and $100,000-y r$ return periods. 
CHENOBY

Distance Bins Contribution to TOTAL Hazar

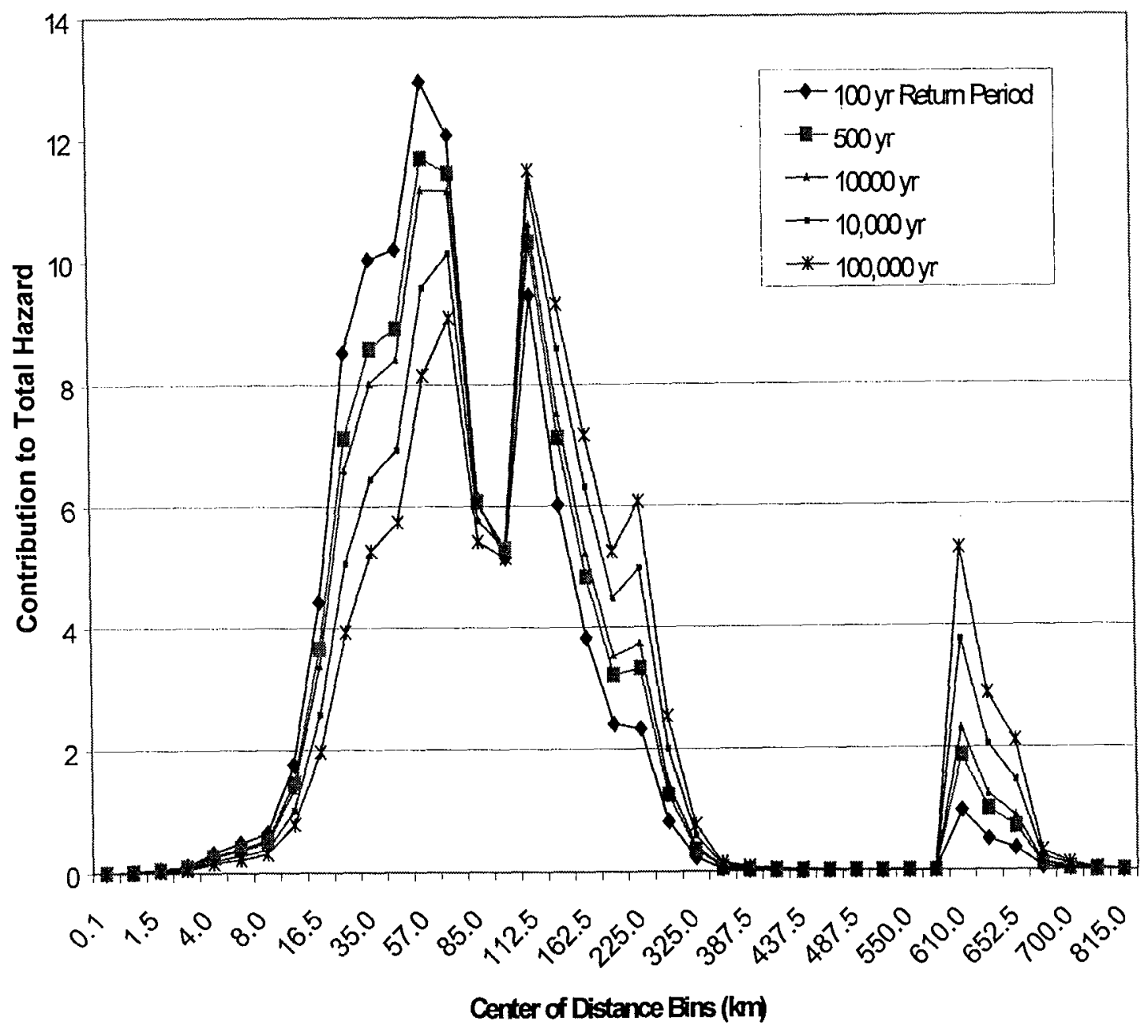

Figure 3.4.3.21: Distance bins contributions to the total mean hazard at Chernobyl, for rock site conditions for 100-yr, 500-yr, 1000-yr, 10,000yr and 100,000-yr return periods. 


\section{KMENYTSKY}

Distance Bins Contribution to TOTAL Hazard for 5 Retum Periods

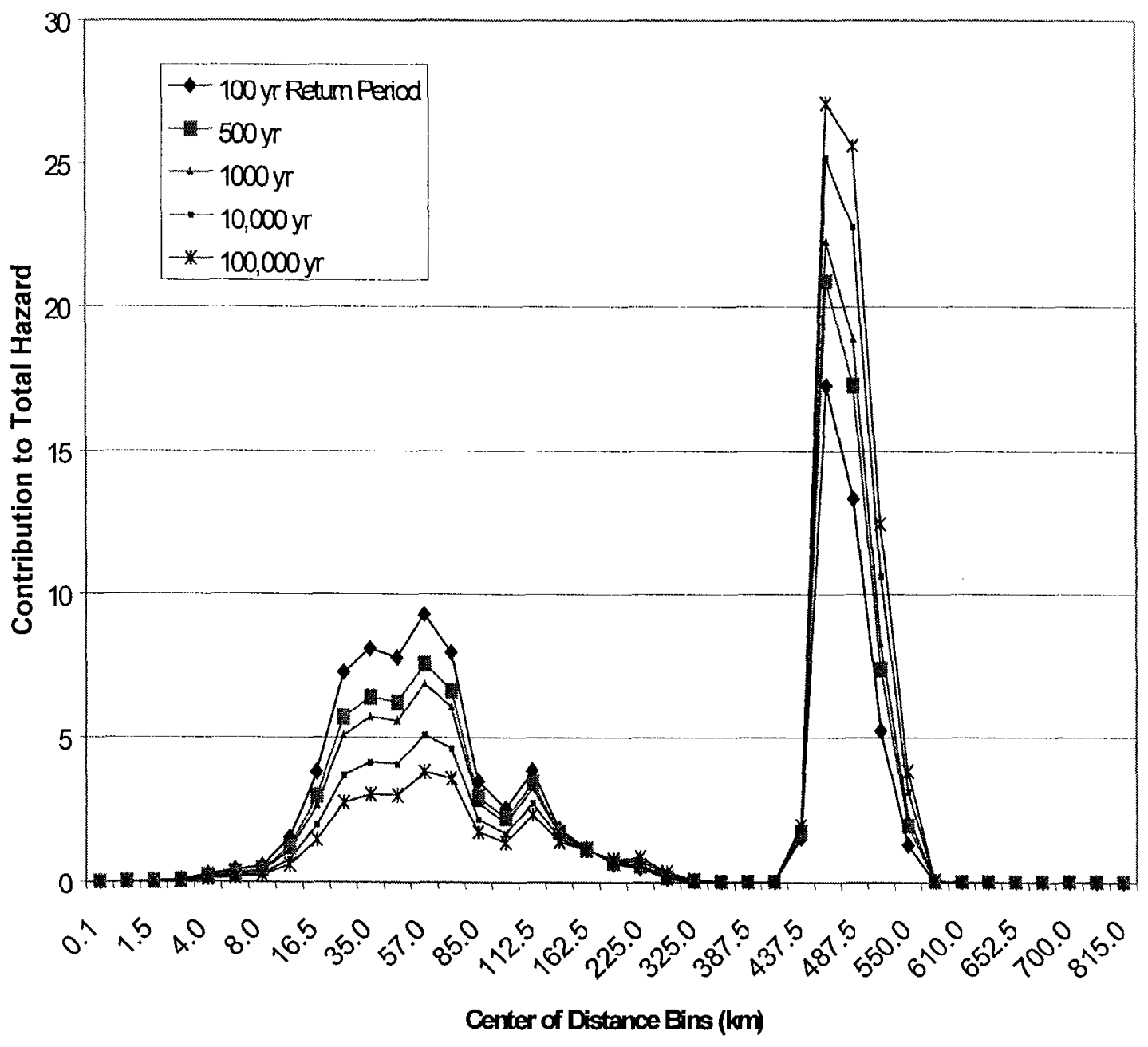

Figure 3.4.3.22: Distance bins contributions to the total mean hazard at Khmelnytskyy, for rock site conditions for 100-yr, 500-yr, 1000-yr, $10,000-y r$ and $100,000-y r$ return periods. 
RVNE

Distance Bins Contribution to TOTAL Hazar

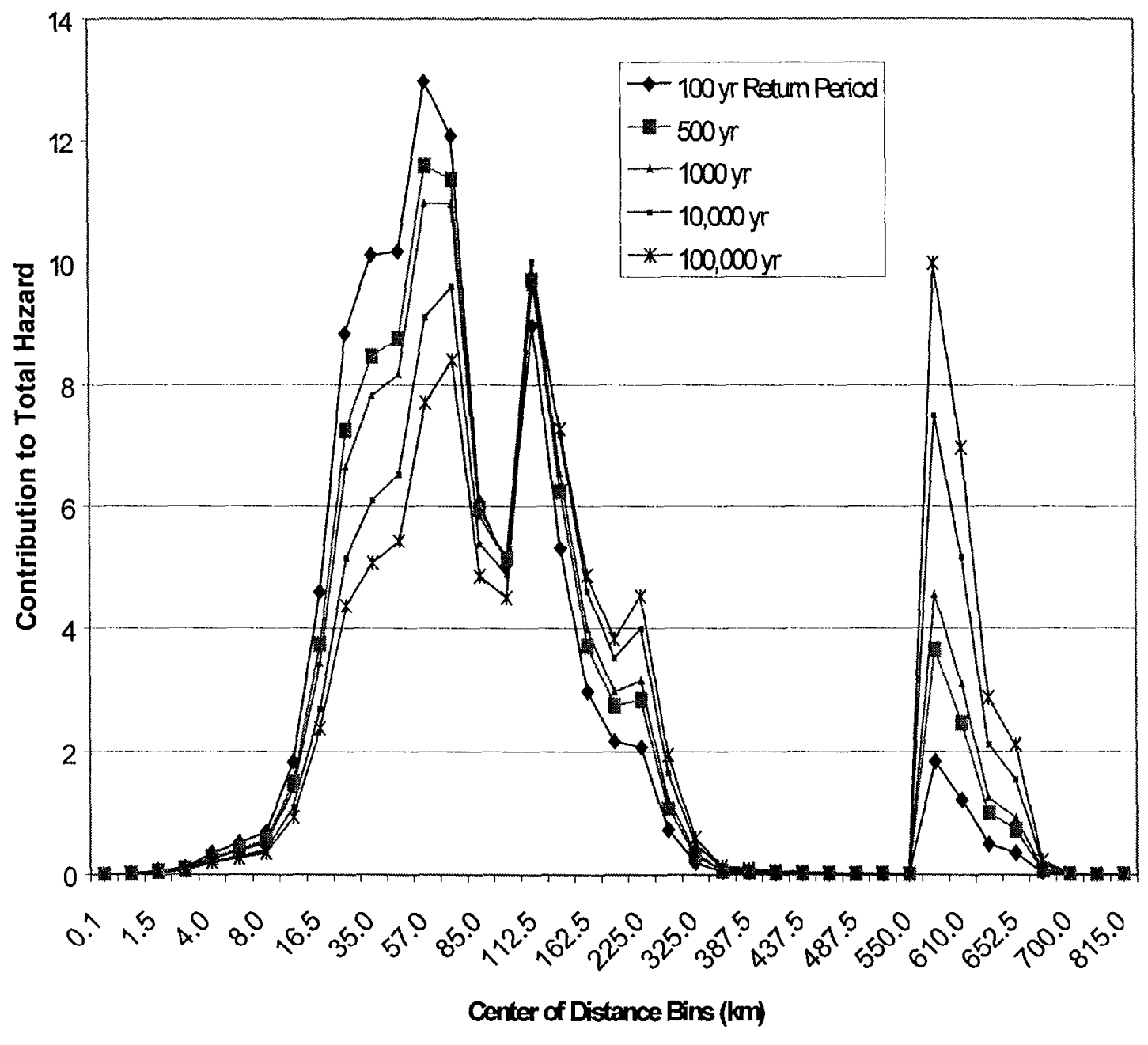

Figure 3.4.3.23: Distance bins contributions to the total mean hazard at Rivne, for rock site conditions for 100-yr, 500-yr, 1000-yr, 10,000-yr and $100,000-y r$ return periods. 
SOUTH UKRAINE

Distance Bins Contribution to TOTAL Hazard

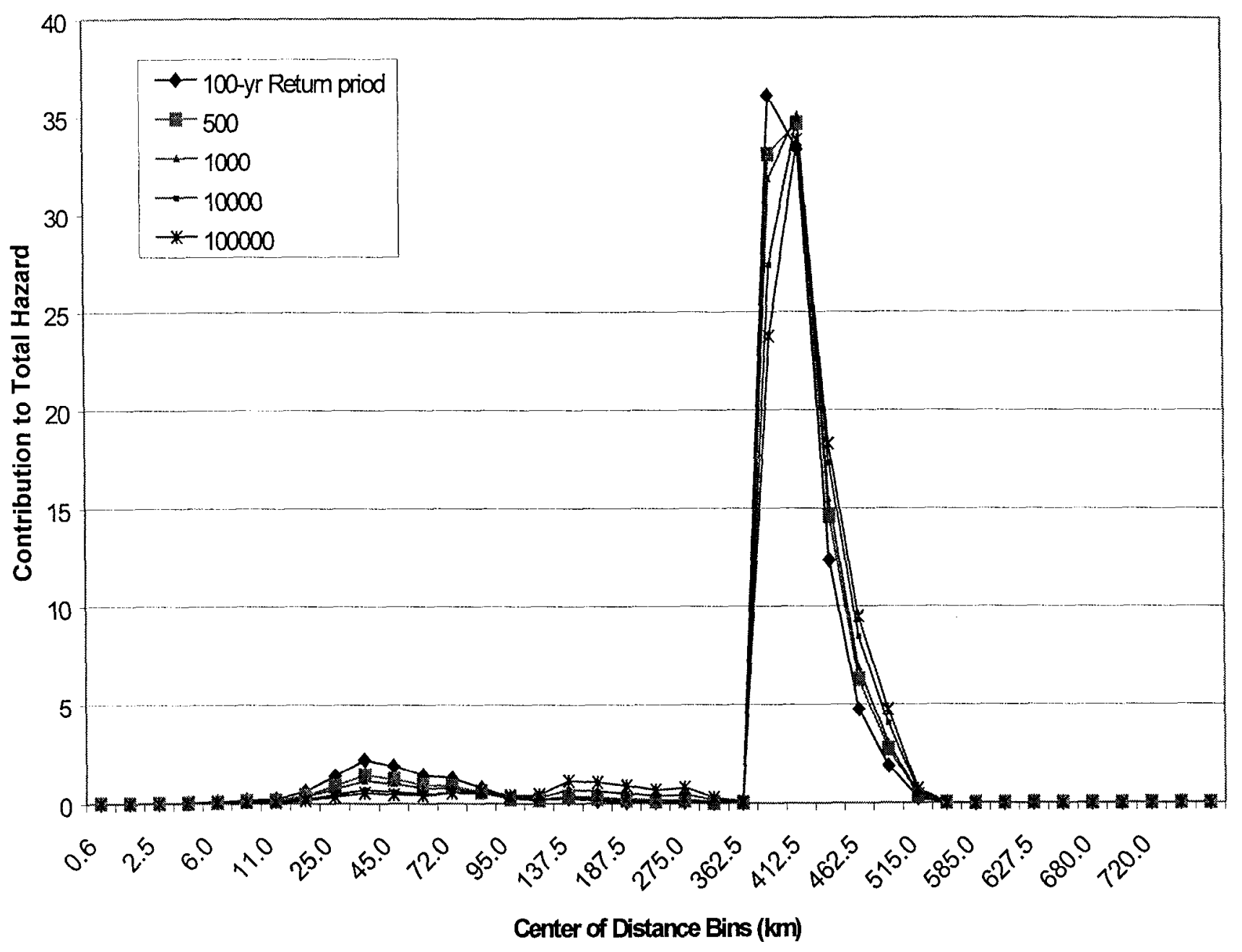

Figure 3.4.3.24: Distance bins contributions to the total mean hazard at South-Ukraine, for rock site conditions for 100-yr, 500-yr, 1000-yr, 10,000 -yr and 100,000-yr return periods. 
ZAPORZZZYYA

Distance Bins Contribution to TOTAL Hazar

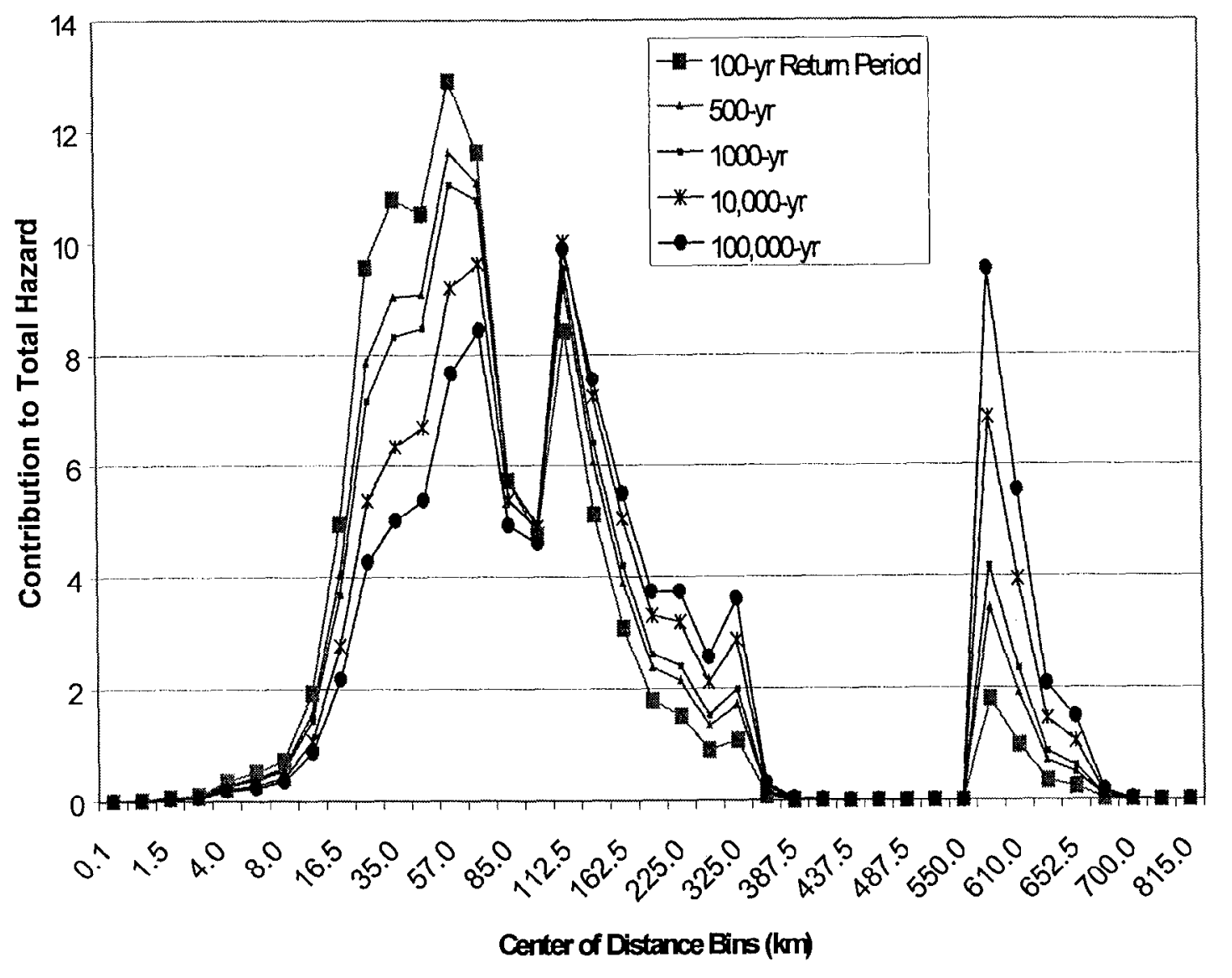

Figure 3.4.3.25: Distance bins contributions to the total mean hazard at Zaporizhzya, for rock site conditions for 100-yr, 500-yr, 1000-yr, $10,000-y r$ and $100,000-y r$ return periods. 


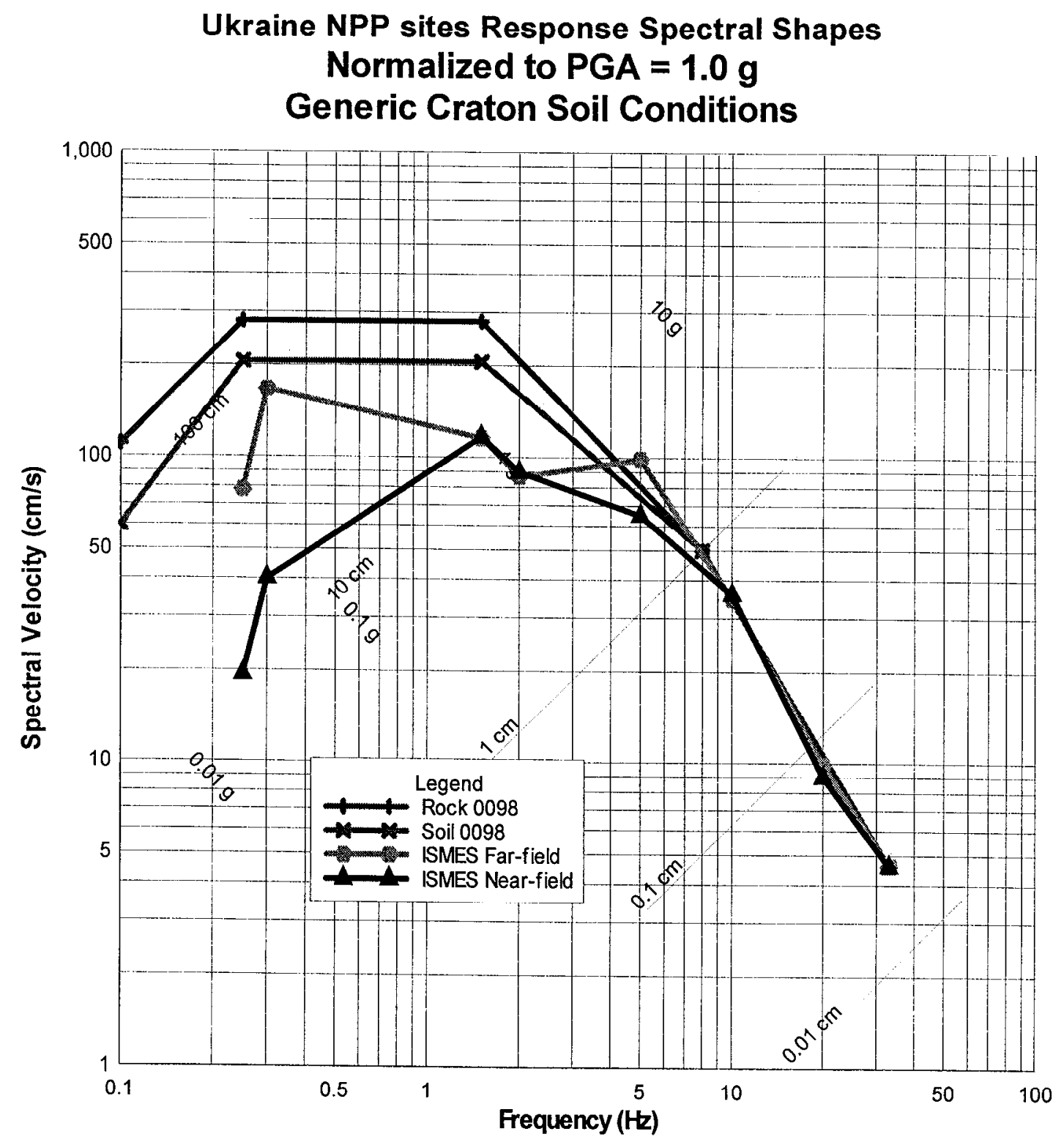

Figure 4.1.1: Comparison of the 5\% Damped Response Spectral Shapes for the Generic Craton Soil Conditions at the Ukraine NPP Sites. 


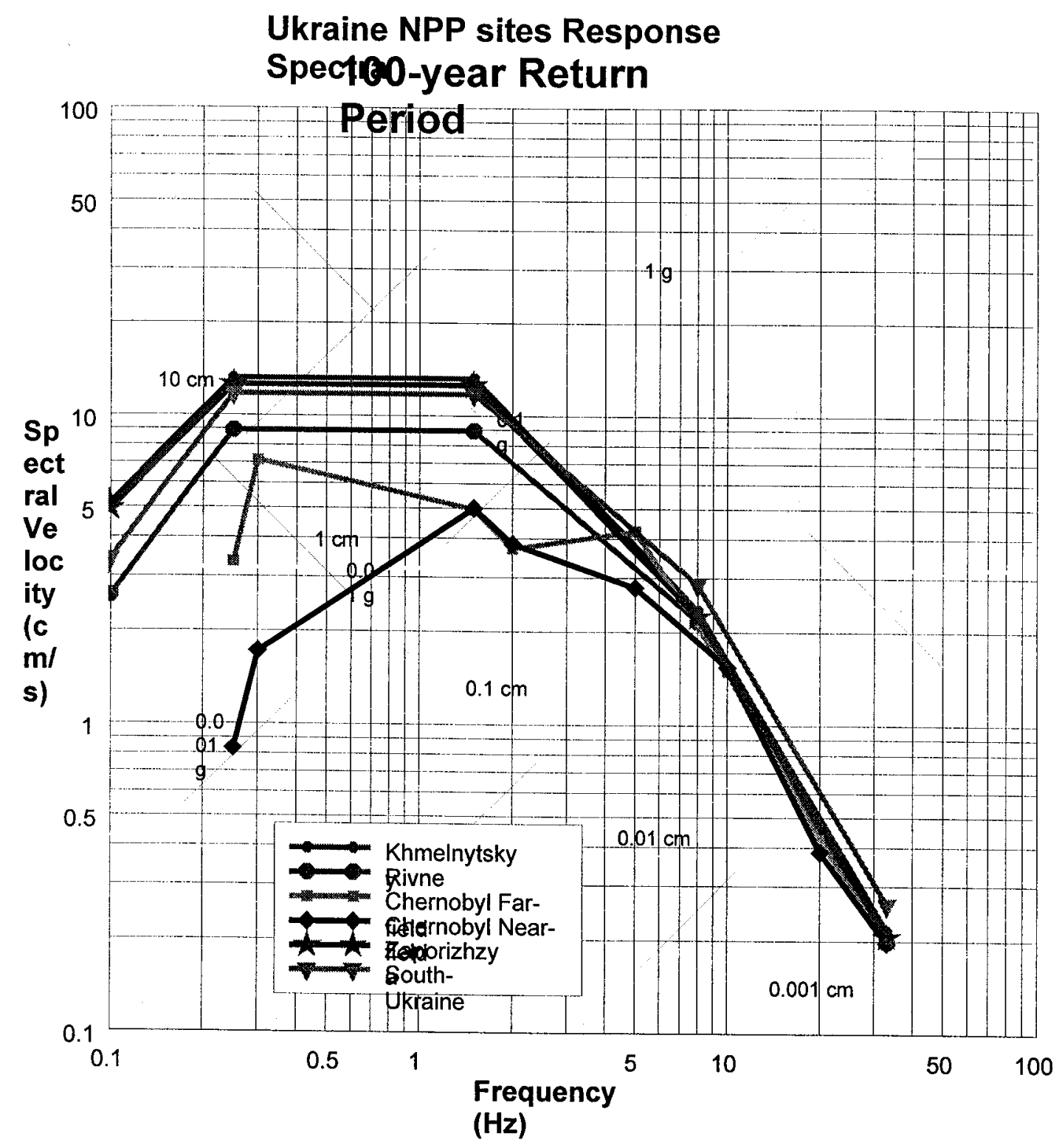

Figure 4.2.1: 100 year Return Period, 5\% Damped Design Response Spectra for the Five Ukraine NPP Sites. 


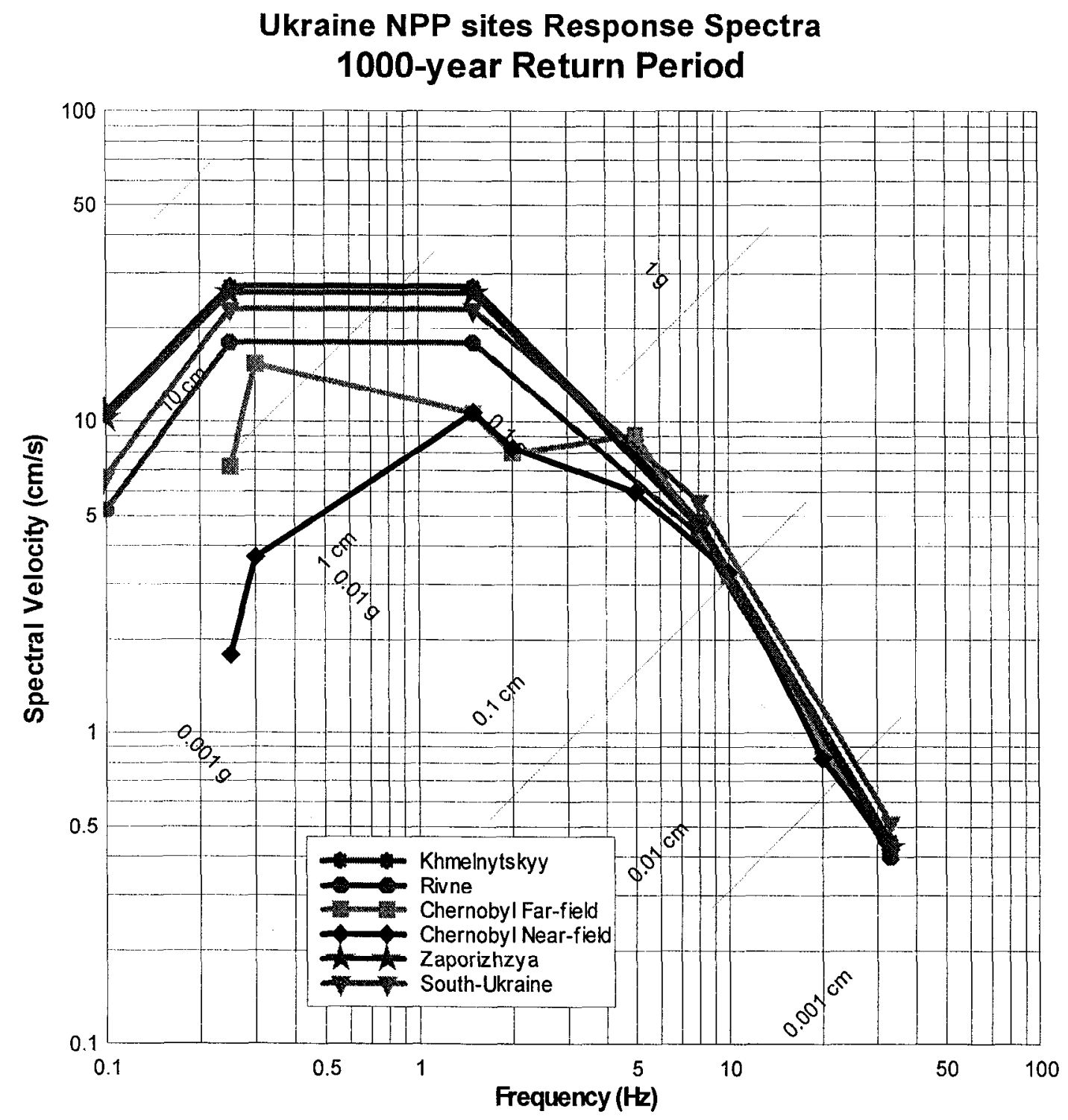

Figure 4.2.2: 1000 year Return Period, 5\% Damped Design Response Spectra for the Five Ukraine NPP Sites. 